Universidade de São Paulo

Instituto de Física

\title{
Estudo das Propriedades Mecânicas da Contração Executada por Células Cardíacas Isoladas Aderidas em Superfície Mimetizada
}

\author{
Andre Luis Brito Querino
}

Orientador: Prof. Dr. Adriano Mesquita Alencar

Tese de doutorado apresentada ao Instituto de Física como requisito parcial para a obtenção do título de Doutor em Ciências.

Banca Examinadora:

Prof. Dr. Adriano Mesquita Alencar (IF - USP)

Prof(a). Dr(a). Ligia Ferreira Gomes (FCF - USP)

Prof. Dr. Leandro Ramos Souza Barbosa (IF - USP)

Prof. Dr. João Medeiros de Araújo (CCEN - UFRN)

Prof. Dr. Alexandre da Costa Pereira (HCFM - USP - FM) 
FICHA CATALOGRÁFICA

Preparada pelo Serviço de Biblioteca e Informação do Instituto de Física da Universidade de São Paulo

Querino, Andre Luis Brito

Estudo das propriedades mecânicas da contração executada por células cardíacas isoladas aderidas em superfície mimetizada. São Paulo, 2019.

Tese (Doutorado) - Universidade de São Paulo. Instituto de Física.

Orientador: Prof. Dr. Adriano Mesquita Alencar

Departamento: Física Geral

Área de Concentração: Biofísica

Unitermos: 1. Biofísica; 2. Mecânica Celular; 3. Microscopia de Força e Tração; 4. Células Cardíacas.

USP/IF/SBI-002/2020 


\title{
University of São Paulo \\ Physics Institute
}

\section{Study of the Mechanical Properties of Contracting Performed by Isolated Cardiac Cells Adhered in a Mimetic Surface}

\author{
Andre Luis Brito Querino
}

Supervisor: Prof. Dr Adriano Mesquita Alencar

Thesis submitted to the Physics Institute of the University of São Paulo in partial fulfillment of the requirements for the degree of Doctor of Science. 
Dedico essa Tese à minha Família e aos meus Amigos. 


\section{Agradecimentos}

Ao meu Deus, por tudo.

Aos meus queridos Avós José Brito de Lima e Iraci Silva Lima, que sempre cuidaram de mim e por terem me dado os ensinamentos mais valiosos, eles sempre serão os meus melhores professores.

A minha querida Mãe Jamile Domingues de Brito, a responsável por todas as minhas conquistas, sempre incentivando-me nos estudos, mesmo com tantas adversidades.

Aos meus Irmãos Kenny Vincent e Juan Rodrigues e aos meus Primos Keilla Cristina, José Brito Neto, Ian, Emily, André e Eduardo, além dos outros não citados, mas não menos importantes e que também fazem parte da minha grande família que tanto gosto.

Ao professor Adriano Mesquita Alencar, meu orientador, pela orientação segura, pela confiança concedida, por sua dedicação e paciência durante todo o desenvolvimento deste trabalho, por ser um exemplo de grande pessoa e profissional.

Aos professores do IFUSP, por suas contribuição para a minha formação acadêmica.

Aos funcionários do IFUSP, que sempre prontamente e com muita gentileza se disponibiliza a ajudar todos os alunos do PPGF.

Aos meus colegas que conviveram com o meu dia a dia no IFUSP: Ligia, Juan, Adriana, Isis, Vinicius, Mariana, Marcel, Arthur, Yan e Antônio. Os meus dias foram mais agradáveis e divertidos com essas pessoas.

Ao CNPQ, CAPES e FAPESP pelo apoio financeiro. 
"Quem pode, pois, calcular o trajecto de uma molécula? Que dados temos para não acreditar que a criação de mundos seja determinada pela queda de grãos de areia? Quem conhece pois os fluxos e refluxos do infinitamente grande e do infinitamente pequeno, o ecoar das causas nos precipícios do ser e as avalanches da criação?."

( Victor Hugo ) 


\section{RESUMO}

Evidencias recentes demonstram que o estudo do comportamento mecânico celular é crucial para a compreensão de vários processos fisiológicos como diferenciação, migração e contração. Tanto as forças de tração celular quanto as propriedades mecânicas da matriz extracelular (ECM) contribuem para a regulação biológica da célula, que foi previamente

compreendida com base em princípios de bioquímica. É evidente a importância das forças mecânicas na sinalização celular em diferentes processos. Nosso trabalho tem por objetivo principal o estudo das propriedades mecânicas da contração cíclica, executada por células cardíacas isoladas, aderidas em superfície mimetizada (imita o tecido). Motivado pela demanda de novos métodos de investigação dos cardiomiócitos in vitro. Onde a abordagem se concentra no estudo das propriedades mecânicas. Analisamos e quantificamos o sinal de resposta mecânico destas células quando aderidas, objetivando a caracterização da resposta mecânica destas para o desenvolvimento de novas metodologias que visa o uso destas células com modelos in vitro, avaliado possíveis efeitos que se manifestam em órgão com base em parâmetros mecânicos. Nesse trabalho utilizamos como amostras, cardiomiócitos neonatais de ratos em estado basal e com estímulo químico usando isoproterenol. Para tanto, utilizamos a técnica experimental Microscopia de Força e Tração (TFM) modificada para quantificar a contração no tempo, e métodos de análise e distribuição dos sinais, que possibilitam a caracterização do sinal mecânico de contração cíclica entre estado basal e estimulado com isoproterenol. Dentre os resultados relatados nesse trabalho esta a caracterização das regiões atividade contráctil, caracterizada por se distribuirem de forma discreta ao longo da borda da célula, apresentando uma campo de tensão multipolar com anisotropia. Além da sua distribuição e orientação sobre a área de adesão celular. Outro resultado encontrando é a forma e as etapas do ciclo contráctil do sinal de tensão e variação de tensão, mostrando sua semelhança com o modelo de oscilação de Van Der Pol invertido. E por ultimo, relatamos as variação do acréscimo de frequência de batimento cardíaco celular em função da frequência basal, além disso, mostramos as condições 
de área de adesão celular e frequência basal para o máximo acréscimo de frequência das células cardíacas. Os resultados apresentados nessa Tese possui aplicações em pesquisa básica e clínica.

Palavras-chave: Mecânica Celular, Microscopia de Força e Tração, Células Cardíacas. 


\section{ABSTRACT}

Recent evidence demonstrates that the study of cellular mechanical behavior is crucial for understanding various physiological processes such as differentiation, migration and contraction. Both the cellular tensile forces and the extracellular matrix (ECM) mechanical properties contribute to the biological regulation of the cell, which was previously understood based on the principles of biochemistry. The importance of mechanical forces in cellular signaling in different processes is evident. Our work has as main objective the study of the mechanical properties of cyclic contraction, performed by isolated cardiac cells, adhered to a mimic surface (mimics the tissue). Motivated by the demand for new methods of investigation of cardiomyocytes in vitro. Where the approach focuses on the study of mechanical properties. We analyzed and quantified the mechanical response signal of these cells when adhered, aiming to characterize the mechanical response of these cells to the development of new methodologies aimed at the use of these cells with in vitro models, evaluating possible effects that manifest on organ based on mechanical parameters. In this work we used as samples, neonatal rats cardiomyocytes in basal state and with chemical stimulation using isoproterenol. For this, we used the modified Force and Traction Microscopy (TFM) technique to quantify the contraction in time, and signal analysis and distribution methods, which allow the characterization of the mechanical signal of cyclic contraction between isoproterenol-stimulated basal state. Among the results reported in this work is the characterization of the contractile activity regions, characterized by their discrete distribution along the cell edge, presenting a multipolar stress field with anisotropy. In addition to its distribution and guidance on the area of adhesion. Another finding finding is the shape and steps of the contractile cycle of the voltage signal and voltage variation, showing their similarity to the inverted Van Der Pol oscillation model. Finally, we report the variation of the increase in the cellular heartbeat frequency as a function of the basal rate. In addition, we show the conditions of cell adhesion area and basal rate for the maximum increase in heart cell frequency. The 
results presented in this Thesis have applications in basic and clinical research.

Keywords: Cell Mechanics, Force and Traction Microscopy, Cardiac Cells. 


\section{Sumário}

1 Introdução 1

2 Objetivos 8

3 Medição de Forças Geradas por Células 10

3.1 Adesão Celular . . . . . . . . . . . . . . . . . . . . . . . . 12

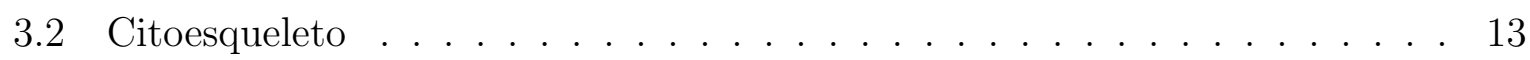

3.3 Mecânica Celular dos Cardiomiócitos . . . . . . . . . . . . . . 15

4 Princípios da Teoria da Elasticidade aplicados em Mecânica Celular 18

4.1 Teoria da Elasticidade Linear . . . . . . . . . . . . . . . . . . . . 19

4.2 Elasticidade em Materiais Continuos . . . . . . . . . . . . . . . 21

4.3 Fourier Transform Traction Cytometry FTTC . . . . . . . . . . . . 24

5 Microscopia de Força e Tração TFM 27

6 Métodos Numéricos para Análise de Dados 34

6.1 Mapeamento Bidimensional do Dados . . . . . . . . . . . . . . . . 34

6.2 Métodos de Análise de Sinais . . . . . . . . . . . . . . . . . . . 39

6.2.1 Transformada de Fourier . . . . . . . . . . . . . . . . 39

6.2 .2 Periodograma de Lomb-Scargle . . . . . . . . . . . . . . . . . 42

6.2.3 Transformada de Wavelet . . . . . . . . . . . . . . . 44

7 Resultados e Discussões $\quad 48$

7.1 Descrição das Amostras . . . . . . . . . . . . . . . . . . . . 48

7.2 Área de Adesão Celular . . . . . . . . . . . . . . . . . . . . 51 
7.3 Tensão Média . . . . . . . . . . . . . . . . . . . . . . . . . . 52

7.4 Amplitude de Contração . . . . . . . . . . . . . . . . . . . . 54

7.5 Distribuição das Amplitudes . . . . . . . . . . . . . . . . . . 56

7.6 Grau de Correlação . . . . . . . . . . . . . . . . . . . . . . . . . 59

7.7 Orientação das Tensões . . . . . . . . . . . . . . . . . . . . . . . 61

7.8 Análise dos Sinais de Contração Cíclica . . . . . . . . . . . . . . . . 66

7.9 Frequência de Contração Basal e Estimulada . . . . . . . . . . . . . . . 77

7.10 Modelo de Oscilador para a Contração Cíclica . . . . . . . . . . . . . . . . 84

8 Conclusões $\quad 90$

Referências Bibliográficas $\quad 93$ 


\section{Lista de Figuras}

1.1 Estrutura molecular da Adenosina trifosfato. . . . . . . . . . . . . . . . . . 1

1.2 Representação esquemática da formação de uma adesão focal imatura. . . . 2

1.3 Representação esquemática da formação de uma adesão focal matura. . . . 3

1.4 Representação esquemática de duas configurações de TFM. . . . . . . . . . . 4

1.5 Estrutura molecular da Poliacrilamida. . . . . . . . . . . . . . . . . 4

1.6 Representação esquemática do TFM. . . . . . . . . . . . . . . . . 5

3.1 Esquema da aplicação de forças ao substrato pela célula . . . . . . . . . . . 10

3.2 Ferramentas experimentais em mecanobiologia. . . . . . . . . . . . . . 11

3.3 Etapas do processo de adesão celular de uma célula em um substrato rígido 13

3.4 Subunidades do citoesqueleto celular. . . . . . . . . . . . . . . . . . . 14

3.5 Microscopia de cardiomiócitos neonatais. . . . . . . . . . . . . . 17

4.1 Conjunto de tensões aplicadas em um elemento de volume elástico. . . . . 20

4.2 TFM em um substrato elástico com marcadores fluorescentes. . . . . . . . 21

4.3 Conjunto de tensões aplicadas em uma superfície elástica. . . . . . . . . . . 23

5.1 Esquema experimental do TFM . . . . . . . . . . . . . . . . . 28

5.2 Concentração de acrilamida e bisacrinamida . . . . . . . . . . . . . . . . 29

5.3 Montagem experimental do TFM modificado para alta velocidade de captura desenvolvido pelo LabM ${ }^{2}$ (Parte 1) . . . . . . . . . . . . . . . 30

5.4 Montagem experimental do TFM modificado para alta velocidade de cap-

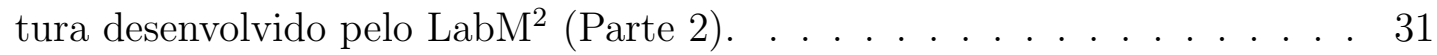

5.5 Imagens de células cardíacas e do substrato elástico com a partículas fluorescentes. . . . . . . . . . . . . . . . . . 32

6.1 Esquema da análise de imagens de TFM. . . . . . . . . . . . . . . 35 
6.2 Mapa de cores obtido com os valores da Tabela 6.1. . . . . . . . . . . . . . 37

6.3 Transformada de Fourier. . . . . . . . . . . . . . . . . . . . . . . 42

6.4 Periodograma de Lomb-Scargle. . . . . . . . . . . . . . . . . . . . . . 44

6.5 Wavelet Molet. . . . . . . . . . . . . . . . . . . . 46

6.6 Transformada de Wavelet e o Periodograma de Lomb aplicados para um sinal. . . . . . . . . . . . . . . . . . 47

7.1 Conjunto de imagens de microscopia de contraste de fase de alguns cardiomiócitos neonatais do grupo de amostra. . . . . . . . . . . . . . . . . 49

7.2 Conjunto de sinais de tensão (em pascal $\mathrm{Pa}$ ) produzido por uma cardiomiócito neonato. . . . . . . . . . . . . . . . . 50

7.3 Densidade de probabilidade dos valores de área de adesão celular. . . . . . 51

7.4 Probabilidade acumulada dos valores de área de adesão celular. . . . . . . . 52

7.5 Gráficos do mapeamento da tensão media em função da posição. . . . . . . 53

7.6 Gráficos do mapeamento da amplitude de contração em função da posição. 55

7.7 Densidade de probabilidade dos valores de amplitude de contração. . . . . 56

7.8 Densidade de probabilidade dos valores de amplitude de contração. . . . . 57

7.9 Probabilidade acumulada dos valores de amplitude de contração. . . . . . . 58

7.10 Probabilidade acumulada dos valores de amplitude de contração. . . . . . . 58

7.11 Gráficos do mapeamento do grau de correlação em função da posição. . . 60

7.12 Gráficos do campo de tensão sobreposto com as curvas de nível de correlação. 63

7.13 Gráficos do campo de tensão sobreposto com as curvas de nível de correlação para varias etapas do ciclo. . . . . . . . . . . . . . . . . . 64

7.14 Gráfico da tensão média em conjunto com as curvas de nível de correlação. 65

7.15 Gráfico do sinal de tensão ao longo do tempo de um cardiomiócito. . . . . 66

7.16 Transformada de Wavelet e Periodograma de Lomb aplicados em conjunto em um sinal de tensão baixa frequência. . . . . . . . . . . . . . . . . 67

7.17 Transformada de Wavelet e Periodograma de Lomb aplicados em conjunto em um sinal de tensão tensão alta frequência. . . . . . . . . . . . . . . 68

7.18 Conjunto de sinais de tensão $\sigma(t)$ para diferentes frequências de células em estado basal. . . . . . . . . . . . . . . . . . . . . . . . 70

7.19 Conjunto de sinais de variação de tensão $\frac{\Delta \sigma(t)}{\Delta t}$ para diferentes frequências de células em estado basal. . . . . . . . . . . . . . . . . . . . . 72 
7.20 Ampliação da forma do sinal de variação de tensão $\frac{\Delta \sigma(t)}{\Delta t}$ de baixa frequência. 73

7.21 Ampliação da forma do sinal de variação de tensão $\frac{\Delta \sigma(t)}{\Delta t}$ de alta frequência. 74

7.22 Estrutura molecular do Isoproterenol. . . . . . . . . . . . . . . 75

7.23 Alteração da frequência do sinal de tensão com aplicação do isoproterenol . 76

7.24 Alteração da frequência do sinal de variação tensão com aplicação do iso-

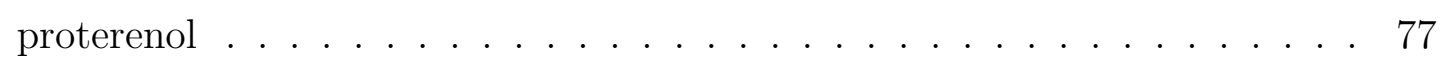

7.25 Gráfico de densidade de probabilidade dos valores de frequência. . . . . . 78

7.26 Gráfico de probabilidade acumulada dos valores de frequência. . . . . . . 79

7.27 Gráfico com os valores de frequência basal em função da área de adesão celular. . . . . . . . . . . . . . . . . . . 81

7.28 Gráfico com os valores de frequência com isoproterenol em função da área de adesão celular. . . . . . . . . . . . . . . . . . . . . . . 81

7.29 Gráfico do valor de percentual de acréscimo de frequência $\mathrm{P}=\frac{f_{\text {iso }}}{f_{\text {bas }}}-1 \mathrm{em}$ função da frequência basal FN, nesse gráfico temos um ajuste gaussiano $P(F N)=1,2 \mathrm{e}^{\left(\frac{0,8-F N}{1,1}\right)}$, onde $R^{2}=0,8 \ldots \ldots \ldots \ldots$. . . . . 82

7.30 Gráfico do mapeamento do percentual de acréscimo de frequência $\mathrm{P}$ em função da frequência basal e da área de adesão celular. . . . . . . . . . . . . 83

7.31 Gráfico da solução do oscilador de Van Der Pol para $\mu=3$. . . . . . . . . 84

7.32 Conjunto de soluções $\sigma(t)$ do oscilador de Van Der Pol inverso para diferentes valores de $\mu \ldots \ldots \ldots \ldots \ldots$. . . . . . . . . . . . . . . . . . . .

7.33 Evolução do ciclo limite no plano de fase do oscilador inverso de Van Der Pol em função de $\mu \ldots \ldots$. . . . . . . . . . . . . . . . . . 86

7.34 Retrato de fase empírico de dos sinais de tensão de frequências basais dife-

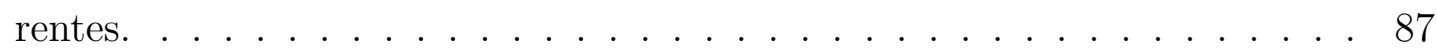

7.35 Retrato de fase empírico do mesmo sinal de tensão com frequência basal e frequência com isoproterenol. 


\section{Lista de Tabelas}

1.1 Tabela com as informações químicas da Adenosina trifosfato (ATP). . . . . 1

4.1 Tabela contendo as relações entre tensão e deformação nos três eixos. . . 19

6.1 Tabela contendo valores para as variáveis $\sigma_{i, j}(l) \ldots \ldots$. . . . . . 36

6.2 Matriz de correlação. . . . . . . . . . . . . . . . . . . . . . 38

7.1 Tabela com as informações químicas do Isoproterenol . . . . . . . . . . . 75

7.2 Conjunto de parâmetros mecânicos de um grupo cardiomiócitos neonatais . 80 


\section{Lista de Abreviaturas}

1. ATP: Adenosina Trifosfato

2. ECM: Matriz Extracelular

3. TFM: Microscopia de Força e Tração

4. PAA: Poliacrilamida

5. PDMS: Polidimetilsiloxano 


\section{Capítulo 1}

\section{Introdução}

A geração de forças mecânicas são umas das habilidades mais impressionantes das células vivas. Elas são geradas em escala molecular através de complexos protéicos [1]. Como exemplo, temos as proteínas motoras, presentes em células eucariontes.

Essas proteínas motoras converte a energia química da adenosina trifosfato (ATP) em energia mecânica, dentre as proteínas motoras conhecidas, temos os motores de miosina que se movem ao longo de um filamento de actina [2] e também os motores de cinesina e dineína que se movem ao longo de microtúbulos [3]. Basicamente, a célula possui estruturas que garantem propriedades mecânicas, onde o estudo dessas propriedades mecânicas é conhecido por Mecânica Celular. [4].

Tabela 1.1: Tabela com as informações químicas da Adenosina trifosfato (ATP).

\begin{tabular}{cc}
\hline \hline Fórmula Molecular & $\mathrm{C}_{10} \mathrm{H}_{16} \mathrm{~N}_{5} \mathrm{O}_{13} \mathrm{P}_{3}$ \\
Massa Molar & $507,11 \mathrm{~g} / \mathrm{mol}$ \\
Entalpia de Combustão & $7 \mathrm{kcal} / \mathrm{mol}$ \\
\hline \hline
\end{tabular}<smiles>Nc1ncnc2c1ncn2[C@@H]1O[C@H](COP(=O)(O)OP(=O)(O)OP(=O)(O)O)[C@@H](O)[C@H]1O</smiles>

Figura 1.1: Estrutura molecular da Adenosina trifosfato. O ser humano consome uma quantidade de ATP equivalente a sua massa corpórea em $24 \mathrm{~h}$, além disso, se o armazenamento de energia não fosse via ATP, calor gerado pela combustão da glicose $\mathrm{C}_{6} \mathrm{H}_{12} \mathrm{O}_{6}$ iria destruir suas próprias células. 
A Física contribuiu significativamente para a compreensão dos processos associados a Mecânica Celular nas ultimas décadas. Trabalhos recentes demostram a importância das forças mecânicas em diferentes processos fisiológicos [5], entre eles: a diferenciação [7], migração e contração [6]. As forças mecânicas são aplicadas durante o processo de adesão celular [8], que consiste em acionamento e acoplamento do citoesqueleto celular a uma matriz extracelular (ECM) in vivo ou ao um substrato mimetizado (imita o ECM) in vitro, modulando processos fisiológicos dentro da célula.

Mensurar forças celulares com precisão espacial e temporal são fundamentais para compreender a influência gerada destas na sinalização celular $[6,7,18]$. Além de detectar forças mecânicas através da mecanossensibilidade [12], células animais são capazes de aplicar forças mecânicas em seu microambiente celular, como no exemplo da Figura 1.2.

Na Figura 1.2 temos uma contração mecânica gerada pelas proteínas actina e miosina e mediadas pela proteína integrina que se fixa ao ECM. A montagem inicial de actina e miosina pode ser reforçada (Figura 1.3), gerando uma fibra de tensão na qual produz forcas de maior magnitude. Basicamente essa estrutura produz um sinal de resposta mecânico ao substrato (ECM). A caracterização e interpretação desses sinais torna-se um foco de pesquisa fundamental [9].

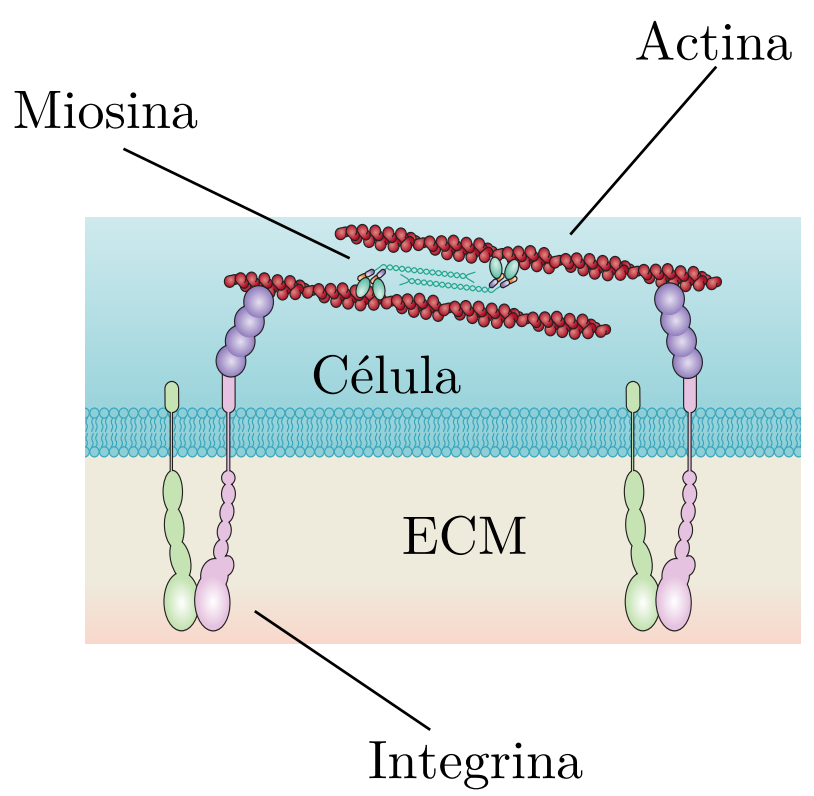

Figura 1.2: Representação esquemática da formação de uma adesão focal imatura, onde temos a atuação do motor celular de actina e miosina, Figura modificada de [14].

Nessa linha de estudo, o nosso grupo do pesquisa do Laboratório de Micro Reologia da USP LabM² fez um questionamento sobre a possibilidade da caracterização desses 


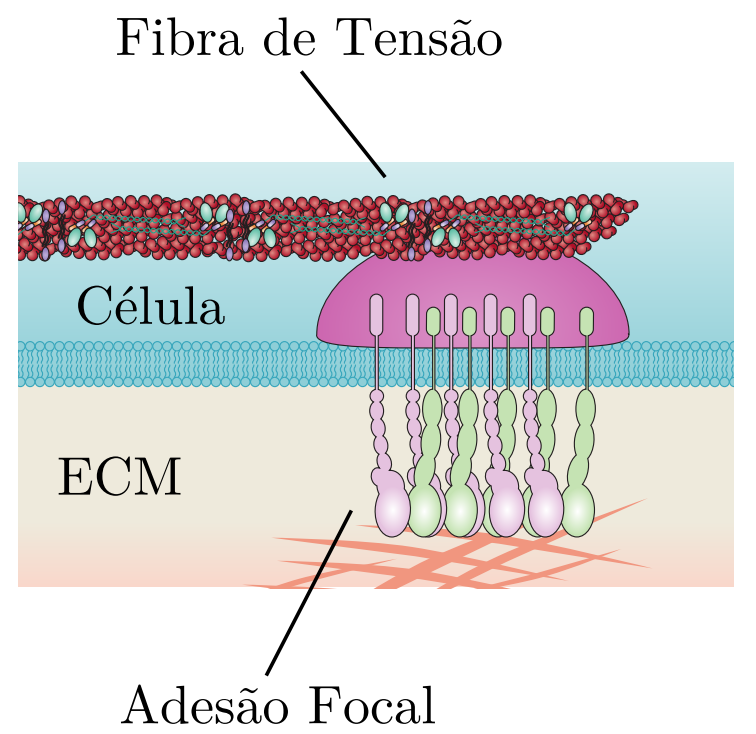

Figura 1.3: Representação esquemática da formação de uma adesão focal matura com a formação da fibra de tensão [14].

sinais mecânicos para um determinado tipo de célula in vitro. Escolhemos em estudar os cardiomiócitos, nossa motivação para o estudo desse tipo de células se baseiam na demanda de novos métodos de investigação dos cardiomiócitos in vitro. Onde a abordagem se concentra no estudo das propriedades mecânicas. A célula cardíaca ou cardiomiócito é um tipo de célula muscular responsável de pulsação do coração, o cardiomiócito é uma das células mais estrutural e funcionalmente especializada nos mamíferos [10].

Insuficiência cardíaca, arritmias ou cardiopatias afetam milhões de pessoas no mundo inteiro. Essas patologias estão associadas as propriedades contrateis ou condutoras dos cardiomiócitos, sendo um foco de investigação fundamental [11]. Nesse aspecto, engenharia de tecidos, testes e descoberta de drogas e desenvolvimento de novos diagnósticos, dependem de modelos de miocárdio in vitro. Propomos o uso dos cardiomiócitos neonatais de ratos como modelo de miocárdio in vitro, concentrando a investigação no sinal de resposta mecânica destas células que possuem uma pulsação cardíaca espontânea quando isolados. Para o uso dessa abordagem que possuem implicações teóricas e clinicas, é necessário quantificar e caracterizar o sinal de resposta mecânico dessas células in vitro.

Dentre os procedimentos adotados para a medição de forças em escala celular. A medição de forças na interface célula e matriz extracelular (ECM) [12] é o mais usado. Isso permite a medição de forças com uma célula aderida a um substrato. O conjunto de técnicas desenvolvidas a partir dessa abordagem se chama Microscopia de Força de Tração (TFM). Nesse trabalho em particular, discutiremos a Microscopia de Força de 
Tração em substratos elásticos que imitam as condições de tecido dos cardiomiócitos na qual modificamos para altas velocidades de captura.

De forma resumida, o TFM baseia-se na dedução das forças aplicadas com base nos movimentos observados. Esses movimentos podem apresentar diferentes relações físicas, dependendo do sistema observado, mas deduzir forças requer essencialmente acompanhar algum tipo de dinâmica. Por exemplo, em uma mola elástica, a força uniaxial aplicada sobre ela é igual $\mathbf{F}=-\mathbf{k x}, \mathbf{F}$ é a força elástica, $\mathbf{x}$ é a deformação e $\mathrm{k}$ a constante elástica, para pequenos movimentos e conhecendo a constante elástica $\mathrm{k}$ é possível determinar o valor de $\mathbf{F}$ com base na deformação $\mathbf{x}$.

No TFM é usado um material cuja relação deformação e força seja conhecida onde a célula vai aderir, entretanto é necessário um material elástico que possa se desformar quando aplicadas forças celulares ou trações celulares.

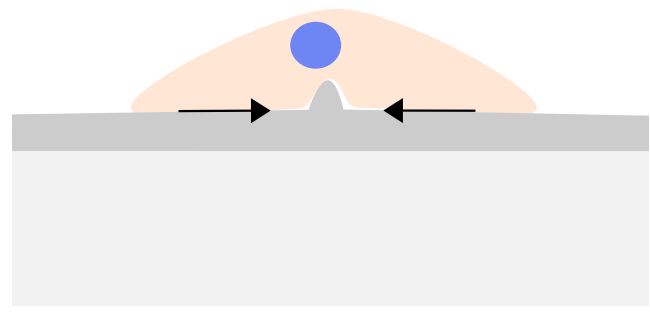

(a)

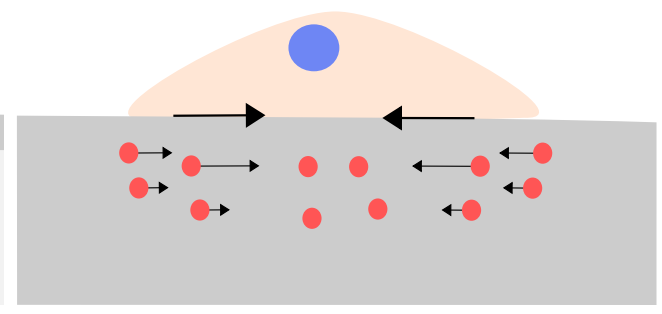

(b)

Figura 1.4: Representação esquemática de duas configurações de TFM. (a) Célula aderida ao um filme elástico com resposta não linear, (b) Configuração com filme elástico linear com marcadores fluorescentes. Figura modificada de [15].

Nas primeiras tentativas de fazer TFM em cultura celular sobre substrato elástico (Figura 1.6), usaram filmes finos de silicone [5] e depois com filmes de poliacrilamida (PAA), substância cuja rigidez (modulo de Young) pode ser controlada alterando a concentração de bisacrilamida [13].

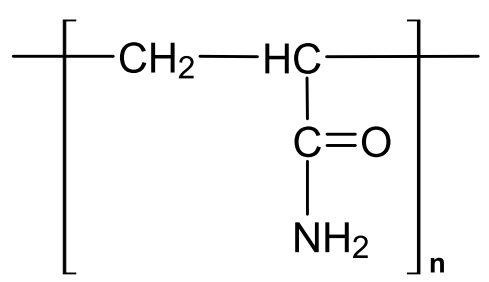

Figura 1.5: Estrutura molecular da Poliacrilamida, material que se comporta com um elástico linear cuja rigidez pode ser controlada.

Atualmente é possível incorporar marcadores fluorescentes aos substratos, nesse traba- 
lho são usadas nanopartículas $(0,2 \mu \mathrm{m})$ fluorescentes [15]. Registrado toda a movimentação desses marcadores, temos um campo de deformação. Nesse ponto, o problema se resume em constituir o campo de tração com base no campo de deformação.

Na Figura 1.6 temos uma configuração esquemática do TFM, a célula aderida está tracionando o gel elástico de poliacrilamida, a movimentação é acompanhada pelas partículas fluorescentes. Através de múltiplas capturas de imagens, é reconstruído a trajetória dessas partículas em um elástico linear devido as forças aplicadas pela célula no elástico linear. O diferencial do TFM aplicado no LabM² está na alta velocidade de captura, garantido sinal com maior resolução espacial, necessário para o estudo de células com alta velocidade de contração dinâmica como os cardiomiócitos.

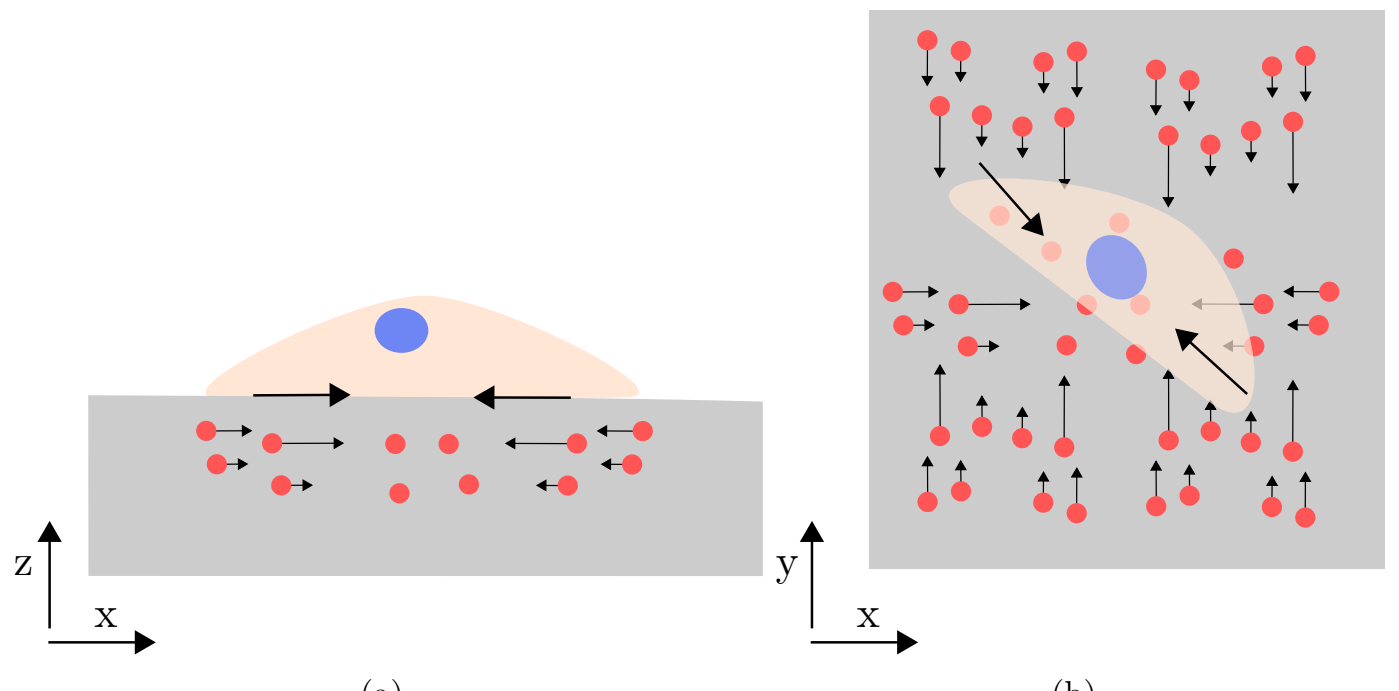

(a)

(b)

Figura 1.6: Representação esquemática do TFM. (a) Visão no plano zx (b) Visão no plano yx [18].

Esse problema é resolvido utilizando a Teoria da Elasticidade Linear, no caso da célula em um substrato elástico, o problema é necessariamente deduzir as trações tangencias [16] sobre o substrato com base nas deformações provocadas. Para pequenas deformações $(x<<1)$ esse problema é resolvido no formalismo das funções de Green [17]. A vantagem desse método e a implementação de algoritmos rápidos para a solução.

Esse método tem como solução, o campo de tração aplicado ao substrato, ele mostra a distribuição das trações tangenciais aplicadas na superfície do substrato durante a adesão celular. O método garantiu resultados importantes, um deles é que para a maioria dos tipos de célula uma alta rigidez do substrato (módulo de Young) se correlaciona com grandes forças de tração, não só para a estabilidade mecânica, mas para uma sinalização 
celular, durante a disseminação e migração de células [18] ou para a diferenciação de células tronco [19].

É evidente a importância do TFM em pesquisas sobre Mecânica Celular, nesse aspecto, nosso trabalho faz uso dessa técnica para o estudo da dinâmica de contração desempenhada por células cardíacas isoladas.

No trabalho, desenvolvemos uma tipo de TFM com alta velocidade de captura junto com análise de dados para elucidar as suas propriedades mecânicas de células in vitro, onde o objeto de estudo são células cardíacas isoladas, aderidas em uma superfície mimetizada feita com filme de gel poliacrilamida e revestida com colágeno. Dessa forma, obtendo o sinal de resposta mecânico dessas células.

Surgiram alguns questionamentos sobre as propriedades dos sinais mecânicos produzidos pelas células cardíacas. Inicialmente devemos entender que essas células possuem restrições quando comparadas a situação em tecido, elas tem uma restrição dimensional pois estão aderidas em uma superfície bidimensional e não tridimensional como no tecido, a outra restrição é dinâmica, o material é um filme de poliacrilamida que possui um coeficiente de Poisson igual a 0,45, ou seja, a célula não consegui produzir deformações elásticas no eixo z da mesma forma que nos eixos x e y.

Nosso questionamento se trata da aplicabilidade das propriedades mecânicas dessas células, como um possível modelo in vitro sobre essas condições experimentais. A reprodutividade da pulsação (forma do sinal de contração) in vitro, a estabilidade estatística das amostras, onde parâmetro possui a mesma distribuição de probabilidade para varias amostras, reprodução dos efeitos do órgão (coração) ou tecido em escala celular in vitro e a modelagem dos sinais resposta são evidencias que corroboram para o uso de células cardíacas neonatais isoladas como modelo de miocárdio in vitro.

Dessa forma além de quantificar e caracterizar o sinal de resposta mecânico, buscamos investigar a aplicabilidade clínica dessas células, em nosso estudo utilizamos uma substância teste chamada isoproterenol que é conhecida por aumentar a frequência cardíaca, para comparamos entre o sinal mecânico de um grupo de amostras no estado basal, com um grupo de amostra com a aplicação do isoproterenol.

Esse texto está estruturado da seguinte forma: introdução, objetivos, fundamentação teórica, resultado e discussões e resultados.

A fundamentação teórica, correspondentes aos capítulos 3, 4, 5, 6. Mostra todo o 
desenvolvimento teórico e experimental utilizados para a obtenção dos resultados nesse trabalho. O capítulo 7 mostra todos os resultados obtidos e discussões a respeito destes. E finalizando com o capítulo 8 que trás as conclusões e possíveis extensões e perspectivas deste trabalho. 


\section{Capítulo 2}

\section{Objetivos}

O trabalho tem por objetivo principal o estudo das propriedades mecânicas da contração cíclica, executada por células cardíacas isoladas, aderidas em superfície mimetizada (imita o tecido). Quantificado e analisado o sinal de resposta mecânico destas células quando aderidas, objetivando sua caracterização para o desenvolvimento de novas metodologias que visa o uso destas células com modelos in vitro, avaliado possíveis efeitos que se manifestam em órgão com base em parâmetros mecânicos. Nesse trabalho utilizamos como amostras, cardiomiócitos neonatais de rato em estado basal e com estímulo químico usando isoproterenol.

Para tanto, utilizamos a técnica experimental Microscopia de Força e Tração (TFM) para quantificar a contração no tempo, e métodos de análise de correlação, além de análise da distribuição dos sinais, que possibilitam a caracterização do sinal mecânico de contração cíclica e diferenciação entre estado basal e estimulado com isoproterenol.

Microscopia de força e tração de cardiomiócitos neonatais: obter o sinal de reposta mecânico produzido por cardiomiócitos neonatais de rato em estado basal e com estímulo químico usando isoproterenol, aderidos em superfície mimetizada.

1) Mapea os valores de tensão gerados pelos cardiomiócitos ao substrato.

2) Quantificar os parâmetros referentes a contração cíclica, como frequência e amplitude.

3) Quantificar os valores de área de adesão celular dos cardiomiócitos.

4) Analisar a direção das forças geradas pelos cardiomiócitos. 
Estudo dos sinais contração cíclica no tempo: analisar o sinal de contração no tempo gerado pela microscopia de força e tração com alta frequência de imagens.

1) Obter o sinal de contração no tempo e da velocidade de contração no tempo.

2) Fazer análise por correlação do conjunto de sinais gerados pelas células.

3) Caracterizar o sinal de contração no tempo e da velocidade de contração no tempo.

4) Verificar modelos que possibilitam a modelagem desses sinais.

Estudo das distribuições dos parâmetros mecânicos: analisar como se distribuem os valores dos parâmetros mecânicos das amostras de cardiomiócitos.

1) Obter a distribuição de área de adesão, frequência e amplitude.

2) Verificar distribuições teóricas que se ajustam ao dados empíricos encontrados. 


\section{Capítulo 3}

\section{Medição de Forças Geradas por Células}

Células animais podem gerar e manter forças mecânicas em seu microambiente e são capazes detectar e responder uma estimulação mecânica, essas funções fazem parte da sua fisiologia [6]. Basicamente a célula possui complexos proteicos que funcionam como via de sinalização mecanossensíveis, resultando na resposta mecânica ao um estímulo com a reorganização do citoesqueleto e geração de força. Porque apesar da estrutura dos animais sejam determinadas pelo genoma, o processo de desenvolvimento em nível celular, envolve uma interação entre forças mecânicas, crescimento e mortalidade celular [14].

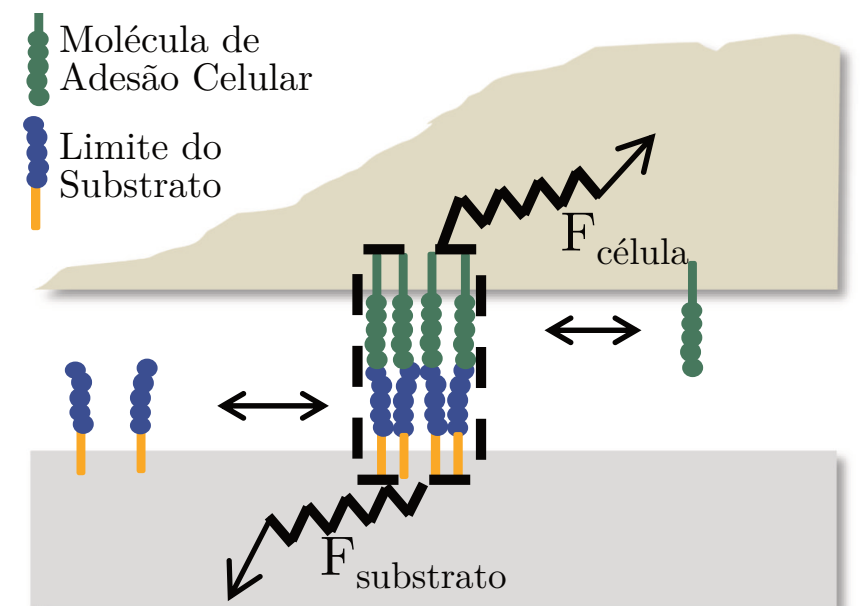

Figura 3.1: Esquema da aplicação de forças ao substrato pela célula, nesta configuração existe uma restrição, sendo que a célula tem um contato bidimensional com o substrato. Figura modificada de [20].

A Mecanobiologia é uma disciplina dedicada ao estudo das forças mecânicas geradas por células animais e os seu efeitos na sua fisiologia. Dispõem para o estudo em Mecanobiologia, o uso de ferramentas experimentais que visam mensurar forças mecânicas aplicadas por uma célula in vitro.

Na Figura 3.2, temos as seguintes ferramentas experimentais em mecanobiologia: a 
varredura da matriz de pilares, que consiste em micropilares de PDMS (Dimetil polissiloxano), dos quais se deformam elasticamente devido a tração da célula, a microscopia de força de tração TFM que mapeia o deslocamento de partículas incorporadas em um substrato elástico, as pinças magnéticas que usam partículas ferromagnéticas que se difunde no citoesqueleto celular e as armadilhas ópticas que consiste na captura e aplicação de forças em partículas incorporadas ao citoesqueleto utilizando um feixe laser.

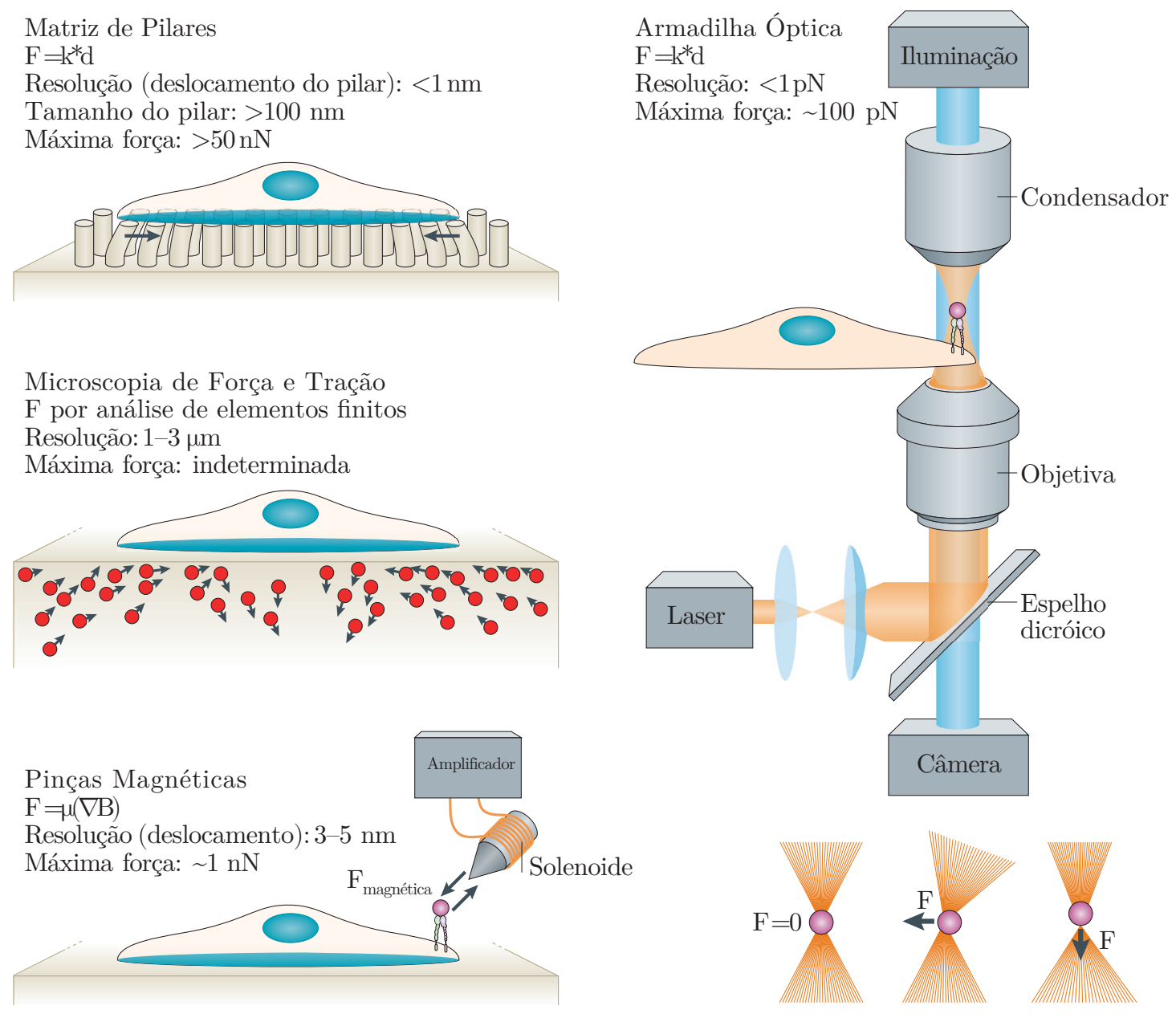

Figura 3.2: Ferramentas experimentais em mecanobiologia: A varredura da matriz de pilares pode ser realizada em dimensões variadas, permitindo assim a determinação da rigidez do substrato e a resolução da força; A microscopia de força de tração utiliza esferas fluorescentes incorporadas e análise de elementos finitos para medir as deformações do substrato pela célula; As pinças magnéticas criam campos magnéticos que fazem com que as esferas magnéticas apliquem forças a moléculas in vitro ou in vivo (por exemplo, a integrinas com esferas revestidas com fibronectina); As armadilhas ópticas usam um feixe de laser focalizado para fornecer forças laterais ou axiais nas esferas de diâmetro de micrômetro e, assim, aplicar forças às moléculas; objetos dielétricos. Figura modificada de [14].

Em nosso trabalho, usamos a técnica microscopia de força e tração (TFM). Essa técnica utiliza partículas fluorescentes incorporadas em um substrato linearmente deformável, em conjunto com análise de elementos finitos para medir as forças aplicadas pela célula 
(Figura 3.2). Nesse aspecto, a região da célula onde as forças são mensuradas é na interface célula matriz extracelular onde ocorre a adesão celular.

\subsection{Adesão Celular}

A adesão celular é uma ligação de células com outras células ou uma ligação de células a uma matriz extracelular (ECM). Importante para a formação de tecidos e para o comportamento fisiológico [20].

Por exemplo, a maioria das células de mamíferos entra em apoptose ou morte celular, quando seus receptores de adesão (proteína transmembranar) não reconhecem os ligantes e a rigidez do substrato [8]. Outro exemplo é que rigidez do substrato determina que tipo de célula uma célula tronco irá se especializa.

Existem vários tipos de adesão celular, dentre eles: junção comunicante, junção apertada, junção célula-célula e junção célula-matriz. Cada uma possui uma função especifica, junções comunicantes são utilizadas para troca de pequenas moléculas para sinalização celular, junções apertadas são usadas por células epiteliais para produzir barreiras a prova de água e as junções célula-célula e junção célula-matriz são importantes para manter a estrutura dos tecidos [21]. O Trabalho da ênfase a junção célula-matriz, pois se trata do processo envolvido no objeto de estudo.

As adesões de célula com a matriz extracelular requer varias proteínas e moléculas mediadoras entre elas: proteínas adaptadoras, moléculas de adesão celular e um conjunto de filamentos do citoesqueleto que se liga ao ECM.

Na Figura 3.3, temos as etapas do processo de adesão celular de uma célula em um substrato rígido [14], inicialmente ocorre a formação de aglomerados de integrina, sendo a proteína responsável pela ancoragem do citoesqueleto ao substrato (ECM), a integrina se liga ao colágeno presente no substrato. A próxima etapa é a polimerização da actina, proteína responsável pela contração celular, onde ocorre a montagem do motor de actina e miosina. Com a conformação da célula na superfície, criam-se tensões na membrana e estas tensões ativam a contração através dos sensores de rigidez. Isso provoca a ativação do reforço da adesão com a formação das fibras de tensão.

As fibras de tensão se formam nas adesões forcais e nelas produzem o sinal de resposta mecânico no substrato rígido. Depois de aproximadamente $24 \mathrm{~h}$ desde da formação inicial 
a) Formação inicial de aglomerados

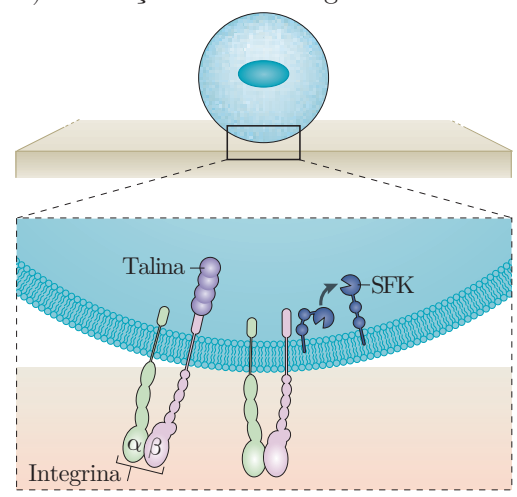

d) Força ativam fatores da montagem da actina
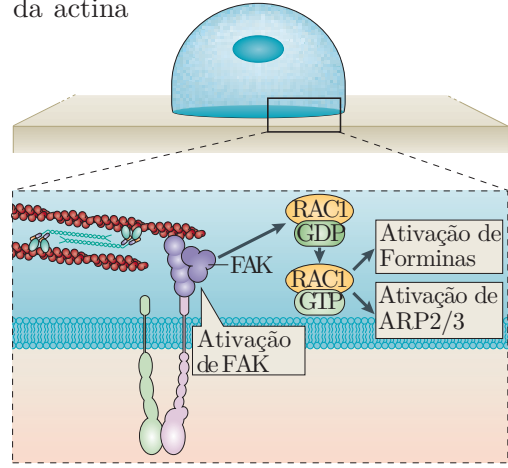

g) Sensor de rigidez

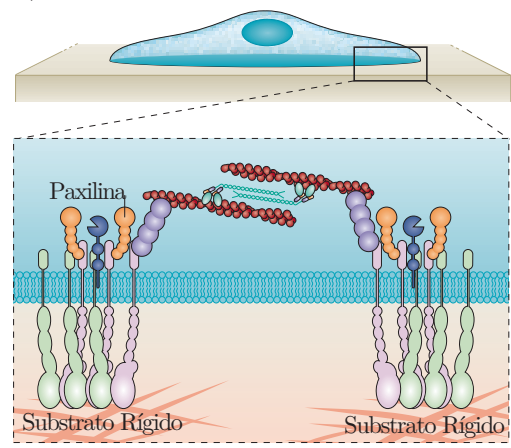

b) Polimerização inicial da actina

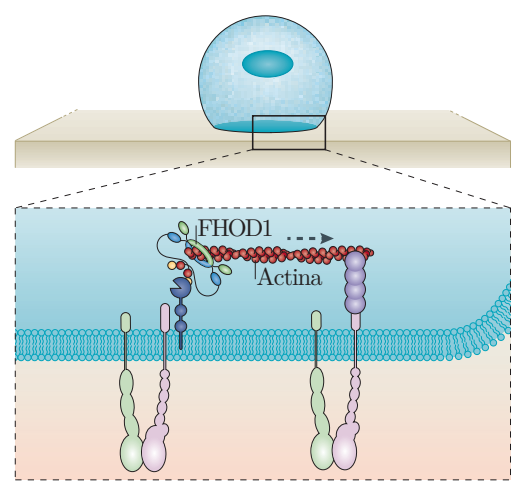

e) Montagem da actina

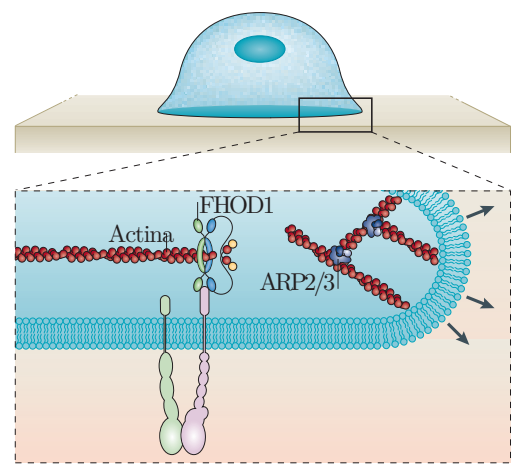

h) Reforço da adesão

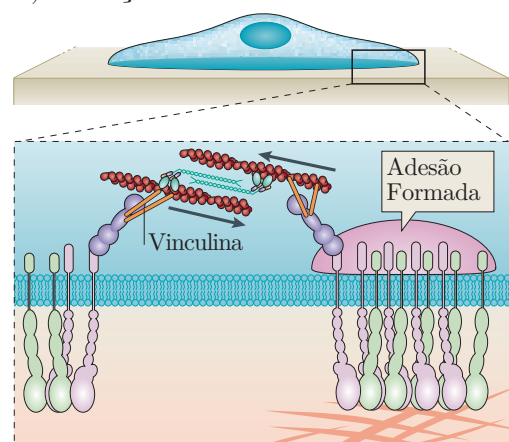

c) Contração

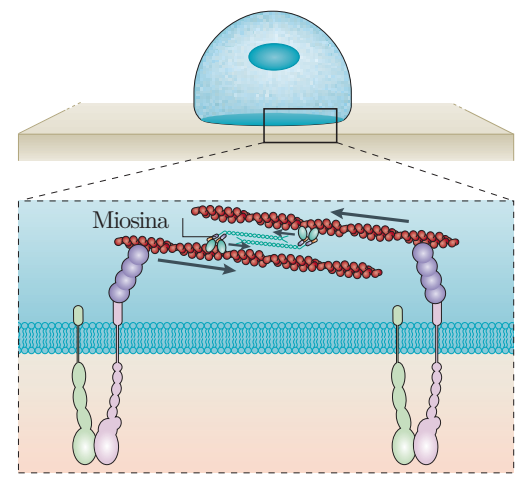

f) A tensão da membrana ativa a contração

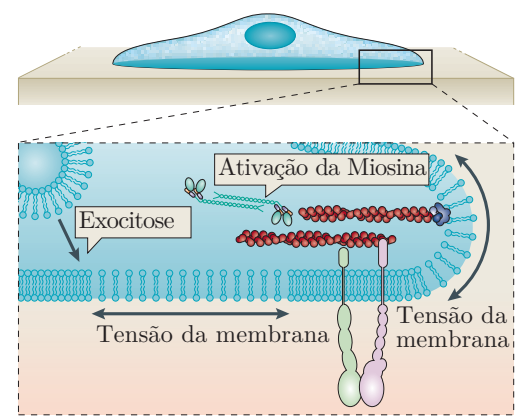

i) Maturação da adesão

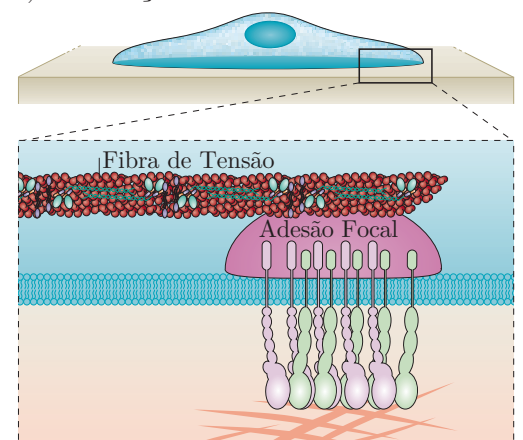

Figura 3.3: Etapas do processo de adesão celular de uma célula em um substrato rígido. Figura modificada de [14].

dos aglomerados de integrina até a maturação das adesões focais. No TFM, as forças mesuradas originam justamente das adesões forcais com as fibras de tensão, da quais compõem o citoesqueleto celular.

\subsection{Citoesqueleto}

O citoesquelo é o complexo de proteínas filamentosas que se extende por todo o volume celular, sua função é crucial para a geração de força e para estruturação da célula [23, 24]. É responsável por diversos processos fisiológico, como migração, transporte de organelas 
e divisão celular.

No citoesquelo encontramos três subunidade protéicas: filamentos intermediários, microtúbulos e filamentos de actina. Os filamentos intermediários são estruturas proteicas constituídos por mais de 50 tipo de proteínas [22, 23], possuindo basicamente uma função estrutural para a célula, sendo muito resistes quando comparados com as outras subunidade do citoesqueleto, por ser estável e com função estrutural, os filamentos intermediários não gastam energia.

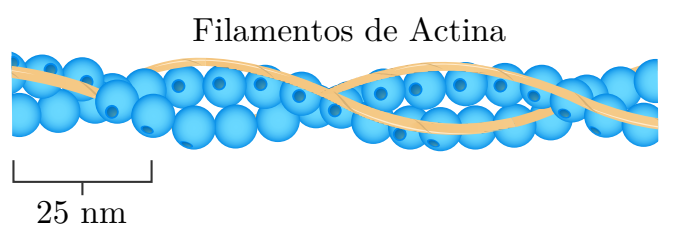

- Polímero de monômeros de actina, $7 \mathrm{~nm}$ de diâmetro

- Proteína globular disposta em hélice

- Componente contrátil principal das células musculares

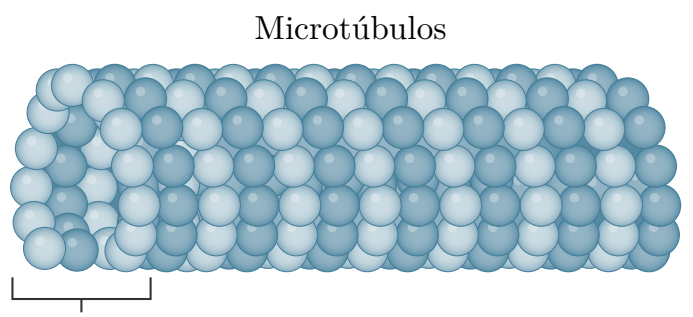

- Filamento de monômeros de tubulina, 25 nm de diâmetro

- Desempenha um papel na estrutura celular, organização, mitose e movimentação

$25 \mathrm{~nm}$

Filamentos Intermediários

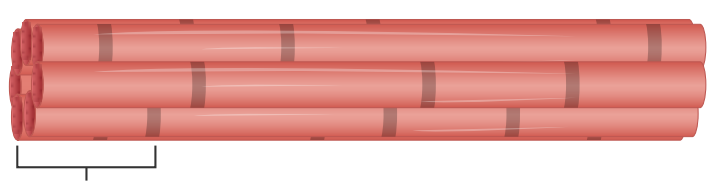

- Filamento citoesquelético, 8 - 12 nm de diâmetro

- Proteína Estrutural em células eucarióticas

$25 \mathrm{~nm}$

Figura 3.4: Subunidades do citoesqueleto celular, filamentos de actina, microtúbulos, e filamentos intermediarios

Os microtúbulos são formados por monômeros de tubulina, possuem um arranjo helicoidal com um diâmetro de aproximadamente 25nm [22, 24]. É a subunidade mais dinâmica do citoesqueleto, polimerizando e despolimerizando para executar funções como transporte intracelular e migração.

Já os filamentos de actina são responsáveis pela atividade contráctil da célula $[22,23$, 24]. Quando a célula adere a um substrato, ela ativa os filamentos de actina que forma as fibras de tensão para aplicar forças no substrato (ECM). 


\subsection{Mecânica Celular dos Cardiomiócitos}

Células animais produzem forças de tração para regular os processos fisiológicos [14]. Dentre eles temos a contração muscular, despenhada por células especializadas na geração de força através das fibras de tensão.

As forças são transmitidas via ECM, onde a interação célula e ECM é mediada pelas adesões focais [25]. Elas criam uma ponte estrutural entre o citoesqueleto celular e a ECM, a proteína integrina é uma das mais relevantes nesse processo.

De forma simplificada, no processo de formação das fibras de tensão, vários filamentos de actina e miosina se polimerizam em torno da adesão focal formando a fibra de tensão, ela exerce a força mecânica sobre o ECM. Por conta disso, no TFM é necessário que a superfície do substrato mimetize uma ECM através do uso de substâncias presentes na ECM, em nossos experimentos utilizamos o colágeno.

Em células cardíacas ou cardiomiócitos, o processo de formação das adesões focais ocorre da mesma forma do que uma célula muscular, a tração mecânica é exercida por uma estrutura chamada sarcômero [26]. O sarcômero consiste em um conjunto de fibras de actina e miosina alinhadas, convertendo energia química da adenosina trifosfato ATP em energia mecânica, gerando um ciclo contrátil. Em cardiomiócitos neonatais o arranjo das fibras de actina e miosina é desordenado [27]. Além disso, eles possuem contração cíclica e espontânea. Por conta disso, ele são modelos em potencial para replicar um estado de contração in vitro.

A geração de força mecânica depende potencial de ação ao longo do sarcolema que induz o influxo iônico de cálcio para a célula através de canais de íons dependentes de voltagem, desencadeando uma maior liberação de cálcio através do retículo sarcoplasmático [22, 23, 24]. O cálcio liberado induz a função motora nos complexos de fibras de tensão localizados em cada sarcômero, iniciando uma contração. O processo de contração ocorre após a formação das adesões focais e consequentemente a formação das fibras de tensão.

Os cardiomiócitos neonatais na sua forma isolada são amplamente utilizados em estudos de fisiologia ou engenharia dos tecidos. Geralmente, proveniente de animais como camundongos ou ratos, devido a sua relativa robustez em cultura e custo [10]. Além da existência de vários protocolos consolidados para o isolamento desse tipo de célula [28], [29]. Quando isolados, os cardiomiócitos neonatais podem durar varias semanas em cultura. Entretanto, com aproximadamente uma semana eles já apresentam sinais de 
maturação física e demostram contractibilidade cíclica e espontânea. Apresentando essa propriedade quando cultivada em ambiente que mimetiza a rigidez característica dessa célula. Por exemplo, os filmes de gel de poliacrilamida utilizados nesse trabalho.

Esse tipo de células são adequadas em experimentos que necessitam de grandes intervalos de tempo, porque são mais resistentes a privação de oxigênio quando comparado com cardiomiócitos já maduros, devido a sua maior capacidade glicolítica [10]. Entretanto, cardiomiócitos neonatais possuem uma desvantagem, a sua estrutura morfológica em cultura é imatura, apesar de possuir contractibilidade, suas fibras de tensão estão supostamente desalinhadas o que torna a sua dinâmica complexa. Além disso, essas células não possuem o túbulo T (túbulo transversal).

Devido a essas propriedades apresentadas pelos cardiomiócitos neonatais, eles se tornam um modelo de teste bastante versátil, com potencial de modelagem da suas propriedades mecânicas in vitro. Por esse motivo, utilizamos esse tipo de célula com modelo in vitro para o estudo das suas propriedades mecânica e teste com fármaco.

O tipo de cardiomiócitos neonatais utilizados em especifico no trabalho, são derivados de ratos (Rattus norvegicus) da linhagem Wistar. São extraídos do coração de recémnascidos após 1 dia de vida, utilizado o método pre-plating [28]. 


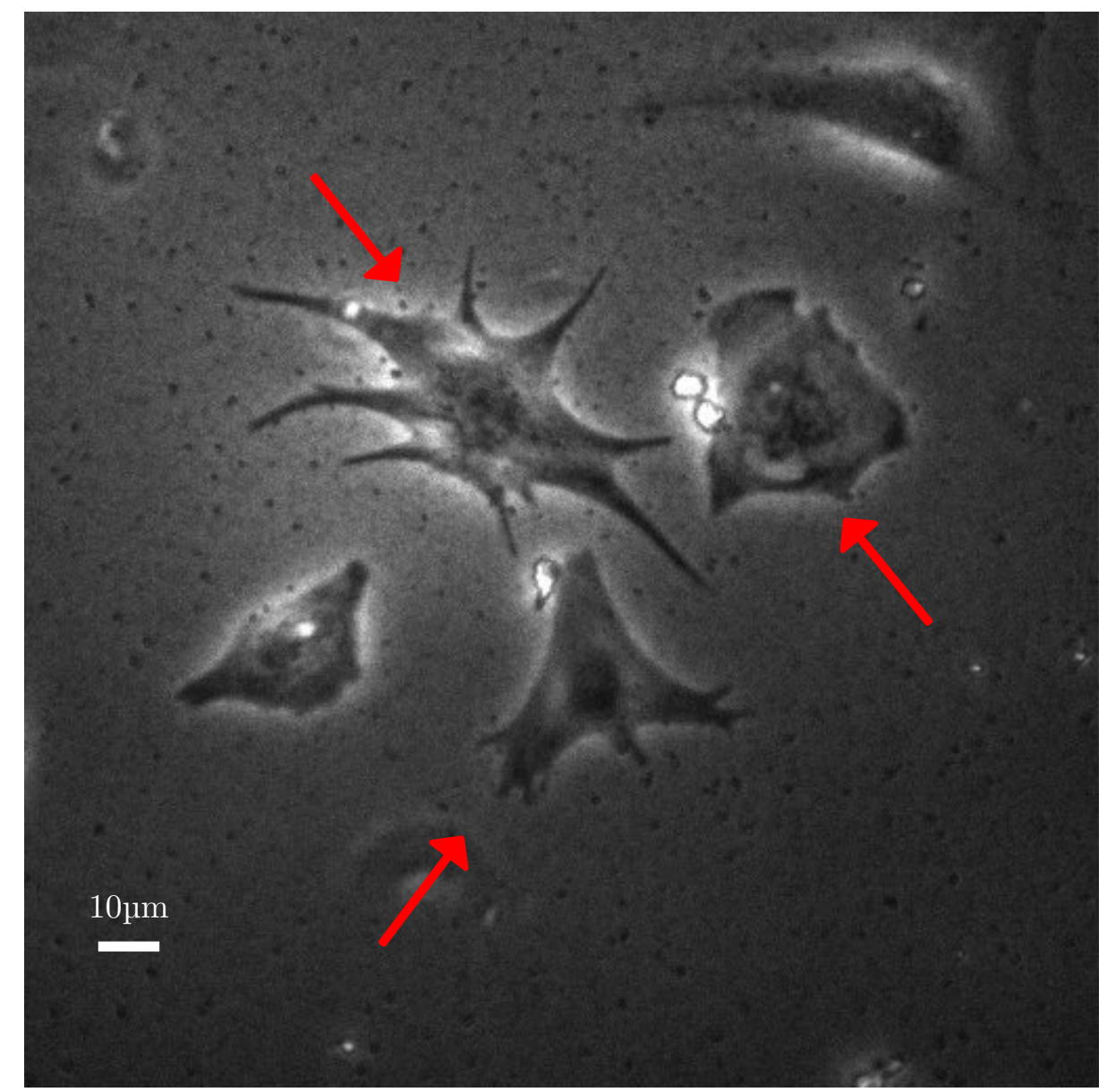

Figura 3.5: Microscopia de cardiomiócitos neonatais. Indicados pelas setas, temos a microscopia de contraste de fase de três cardiomiócitos neonatais de ratos. 


\section{Capítulo 4}

\section{Princípios da Teoria da Elasticidade aplicados em Mecânica Celular}

Para a reconstrução das trações aplicadas em substrato elástico com base nas deformações observadas, é necessário ter o conhecimento dos princípios da Teoria da Elasticidade, especificamente nesse trabalho, a Teoria da Elasticidade Linear. Em resumo, a Teoria da Elasticidade Linear estuda o comportamento das deformações e tensões de um corpo quando sujeito a forças externas, considerando-o elástico [30].

Tensão $\sigma$ é uma grandeza física que significa força por unidade de área $\left(\frac{N}{m^{2}}\right)$ aplicada a um ponto material da superfície de um corpo, ela é escrita na unidade pascal Pa. A tensão é utilizada para descrever como as forças externas aplicas a um corpo são distribuídas. Outra quantidade importante na Teoria da Elasticidade é a deformação $\epsilon$, ela é a mudança nas dimensões do corpo devido a forças externas aplicadas [30].

Um corpo elástico retorna as suas dimensões de forma reversível, cessando as forças externas aplicadas, entretanto as deformações provocadas devem ser pequenas em comparação as dimensões do corpo. Para um material ser linearmente elástico, são consideradas duas hipóteses básicas sobre o material. A primeira hipótese é que a quantidade de matéria no corpo se distribui continuamente e que suas partes são unidas, desconsiderando rachaduras ou falhas. A segunda hipótese é que o corpo é homogêneo e isotrópico, homogêneo significa que qualquer parte do corpo possui todas as propriedades físicas do todo e isotrópico significa que as propriedades elásticas são iguais em todas as direções.

Um conceito essencial nesse estudo são as relações constitutivas. As relações constitutivas são expressões que mostram a dependência entre as tensões e deformações, por exemplo, a Lei de Hooke para o caso unidimensional: $\epsilon_{x}=\frac{\sigma_{x}}{E}$, onde $\epsilon_{x}$ é a deformação, 
$\sigma_{x}$ a tensão e $E$ o módulo de Young. A importância da Lei de Hooke é a possibilidade de calcular a tensão, conhecendo a deformação do material. Com isso é possível em algumas situações determinar as tensões ou parte delas, apenas observando as deformações produzidas em um corpo.

\subsection{Teoria da Elasticidade Linear}

A Lei de Hooke $\epsilon_{x}=\frac{\sigma_{x}}{E}$ estabelece uma relação linear entre tensão e a deformação. Isso para o caso unidimensional, quando estudamos um material homogêneo e isotrópico em três dimensões, devemos considerar as deformações provocadas nos três eixos $(x y z)$. A deformação em cada um dos eixos é: $\epsilon_{x}=\frac{\Delta x}{x}, \epsilon_{y}=\frac{\Delta y}{y}$ e $\epsilon_{z}=\frac{\Delta z}{z}$. Para materiais em fase elástica linear, as relações de Poisson são:

$$
-\frac{\epsilon_{x}}{\epsilon_{z}}=-\frac{\epsilon_{y}}{\epsilon_{z}}=\nu
$$

onde $\nu$ é o coeficiente de Poisson do material, com base nessa relação, podemos construir a seguinte tabela com as informações de deformação e tensão em cada um dos eixos [31].

Tabela 4.1: Tabela contendo as relações entre tensão e deformação nos três eixos.

\begin{tabular}{cccc}
\hline \hline \multirow{2}{*}{ Tensão } & \multicolumn{3}{c}{ Deformação } \\
& $\epsilon_{x}$ & $\epsilon_{y}$ & $\epsilon_{z}$ \\
\hline \hline$\sigma_{x}$ & $\frac{\sigma_{x}}{E}$ & $-\nu \frac{\sigma_{x}}{E}$ & $-\nu \frac{\sigma_{x}}{E}$ \\
$\sigma_{y}$ & $-\nu \frac{\sigma_{y}}{E}$ & $\frac{\sigma_{y}}{E}$ & $-\nu \frac{\sigma_{y}}{E}$ \\
$\sigma_{z}$ & $-\nu \frac{\sigma_{z}}{E}$ & $-\nu \frac{\sigma_{z}}{E}$ & $\frac{\sigma_{x}}{E}$ \\
\hline \hline
\end{tabular}

Podemos calcular a deformação resultante em cada um dos eixos usando o princípio da sobreposição dos efeitos [30], somando os termos das colunas Tabela 4.1 temos:

$$
\begin{aligned}
& \epsilon_{x}=\frac{\sigma_{x}}{E}-\frac{\nu}{E}\left(\sigma_{y}+\sigma_{z}\right) \\
& \epsilon_{y}=\frac{\sigma_{y}}{E}-\frac{\nu}{E}\left(\sigma_{x}+\sigma_{z}\right)
\end{aligned}
$$




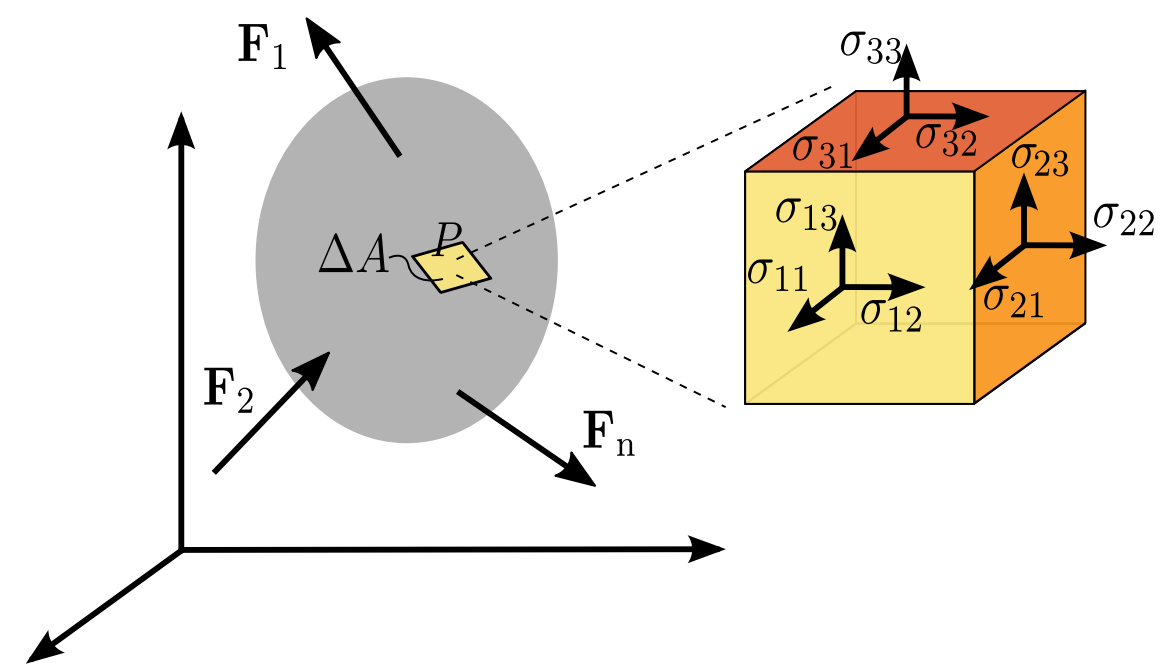

Figura 4.1: Conjunto de tensões aplicadas em um elemento de volume elástico.

$$
\epsilon_{z}=\frac{\sigma_{z}}{E}-\frac{\nu}{E}\left(\sigma_{x}+\sigma_{y}\right)
$$

Essas são as deformações normais conhecidas como $\epsilon_{x x}, \epsilon_{y y}$ e $\epsilon_{z z}$, além delas, existem as deformações por cisalhamento [31], conhecidas por:

$$
\epsilon_{x y}=\frac{\sigma_{x y}}{\frac{E}{2(1+\nu)}}, \epsilon_{x z}=\frac{\sigma_{x z}}{\frac{E}{2(1+\nu)}}, \epsilon_{y z}=\frac{\sigma_{y z}}{\frac{E}{2(1+\nu)}}
$$

onde $\epsilon_{x y}, \epsilon_{x z}$ e $\epsilon_{y z}$ são as deformações por cisalhamento, $\sigma_{x y}, \sigma_{x z}$ e $\sigma_{y z}$ são as tensões por cisalhamento. Os termos $\left(\epsilon_{x x}, \epsilon_{y y}, \epsilon_{z z}, \epsilon_{x y}, \epsilon_{x z}, \epsilon_{y z}\right)$ definem o estado de deformação, com ele é possível definir o estado de tensão, conhecido como a Lei de Hooke Generalizada.

$$
\left(\begin{array}{c}
\epsilon_{x x} \\
\epsilon_{y y} \\
\epsilon_{z z} \\
\epsilon_{x y} \\
\epsilon_{x z} \\
\epsilon_{y z}
\end{array}\right)=\frac{1}{E}\left[\begin{array}{cccccc}
1 & -\nu & -\nu & 0 & 0 & 0 \\
-\nu & 1 & -\nu & 0 & 0 & 0 \\
-\nu & -\nu & 1 & 0 & 0 & 0 \\
0 & 0 & 0 & 2(1+\nu) & 0 & 0 \\
0 & 0 & 0 & 0 & 2(1+\nu) & 0 \\
0 & 0 & 0 & 0 & 0 & 2(1+\nu)
\end{array}\right]\left(\begin{array}{c}
\sigma_{x x} \\
\sigma_{y y} \\
\sigma_{z z} \\
\sigma_{x y} \\
\sigma_{x z} \\
\sigma_{y z}
\end{array}\right)
$$

No caso específico do TFM, as tensões são aplicadas em uma superfície elástica sendo uma simplificação da Lei de Hooke Generalizada [31]. 


\subsection{Elasticidade em Materiais Continuos}

O campo de tração é definido pela força local aplicada por unidade de área. Se uma superfície elástica é tracionada por uma célula aderente, a deformação aplicada pela célula aderente determina o campo de tração na superfície. Nesse sentido é interessante que a superfície tenha propriedades e condições previsíveis com algum modelo teórico conhecido. Se a superfície de gel for aproximada para um solido elástico semi-infinito, utilizamos a teoria da elasticidade linear para calcular o campo de deformação com base no campo de tração, onde o campo de deformação é definido pela deformação local do gel.

O TFM é uma técnica que possibilita mensurar força de tração em um substrato elástico, na Figura 4.8 temos a representação esquemática do TFM. A amostra é uma célula biológica viva, ela está aderida ao substrato elástico, nele encontra-se marcadores fluorescentes incorporados. As forças exercidas pela célula deformam o substrato e movimenta os marcadores, com um microscópio é observado o campo de deformação com base no movimento dos marcadores.

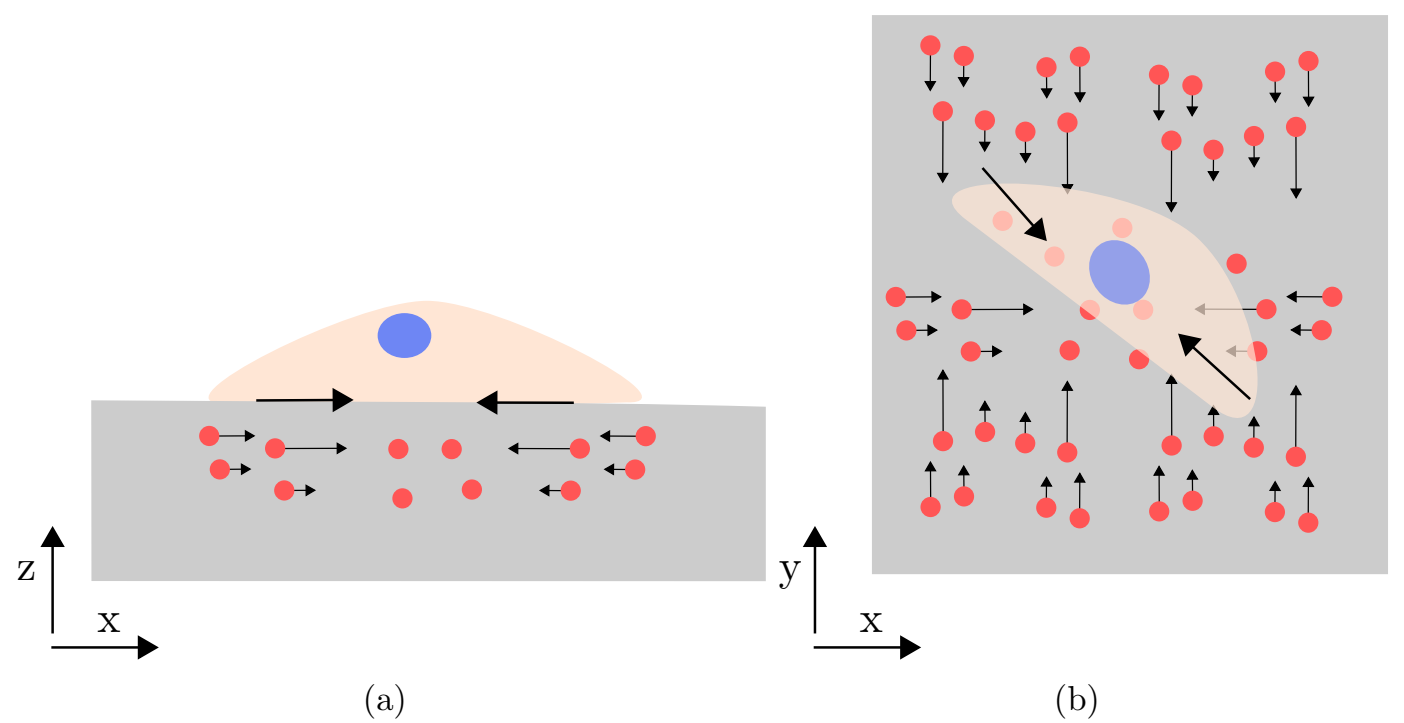

Figura 4.2: Representação esquemática da configuração do TFM em um substrato elástico com marcadores fluorescentes. (a) Visão no plano $z x$ (b) Visão no plano $y x$.

Para mensurar forças de tração com base na deformação de um substrato elástico é necessário aplicar a teoria da elasticidade continua [17], inicialmente para definir o tensor de deformação, usamos o gradiente de deformação $\mathbf{D}$, escrito da seguinte forma: 


$$
\mathbf{D}=\left(\begin{array}{ccc}
\frac{\partial x^{\prime}}{\partial x} & \frac{\partial x^{\prime}}{\partial y} & \frac{\partial x^{\prime}}{\partial z} \\
\frac{\partial y^{\prime}}{\partial x} & \frac{\partial y^{\prime}}{\partial y} & \frac{\partial y^{\prime}}{\partial z} \\
\frac{\partial z^{\prime}}{\partial x} & \frac{\partial z^{\prime}}{\partial y} & \frac{\partial z^{\prime}}{\partial z}
\end{array}\right)
$$

O significado de $\mathbf{D}$ é de um jacobiano da coordenada, por exemplo, ele transforma $\mathbf{x}$ para o estado deslocado $\mathbf{x}^{\prime}$. Agora vamos atribuir $\mathbf{u}=\mathbf{x}^{\prime}-\mathbf{x}$, ele será chamando de vetor de deslocamento, rescrevendo o nosso gradiente de deformação $\mathbf{D}$, o resultado será:

$$
\mathbf{D}=\mathbf{1}+(\nabla \otimes \mathbf{u})^{T}
$$

Nessa forma, temos o gradiente de deformação D escrito em termos do operador nabla $\nabla$ e do produto diádico $\otimes,(\nabla \otimes \mathbf{u})^{T}$ é a matriz transposta de $(\nabla \otimes \mathbf{u})$. A partir das imagens de TFM, são obtidos os campos espaciais $\mathbf{D}$ e $\mathbf{u}$, usados para as medidas de deslocamentos e ângulos durante a deformação. Agora vamos reescrever D utilizando o tensor de Green-Lagrange [15]:

$$
\mathbf{E}=\frac{1}{2}\left(\mathbf{D}^{T} \cdot \mathbf{D}-\mathbf{1}\right)
$$

O tensor de Green-Lagrange $\mathbf{E}$ em termos do operador nabla $\nabla$ é do produto diádico $\otimes$, fazendo a substituição de $\mathbf{D}$ pela expressão (4.9), temos a seguinte expressão

$$
\mathbf{E}=\frac{1}{2}\left((\nabla \otimes \mathbf{u})+(\nabla \otimes \mathbf{u})^{T}+(\nabla \otimes \mathbf{u})(\nabla \otimes \mathbf{u})^{T}\right)
$$

O termo $(\nabla \otimes \mathbf{u})(\nabla \otimes \mathbf{u})^{T}$ é a contribuição não linear do tensor $\mathbf{E}$ [31], para pequenas tensões, o tensor $\mathbf{E}$ tornar-se no tensor de deformação linear, escrito da seguinte forma:

$$
\epsilon=\frac{1}{2}\left((\nabla \otimes \mathbf{u})+(\nabla \otimes \mathbf{u})^{T}\right)
$$




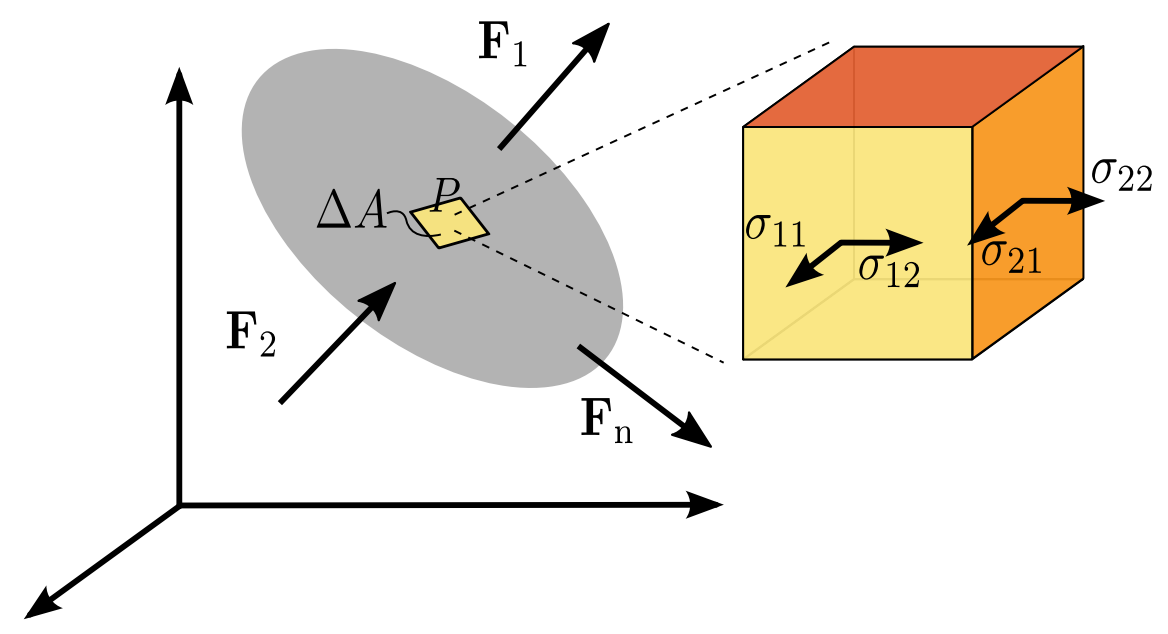

Figura 4.3: Conjunto de tensões aplicadas em uma superfície elástica.

onde as componentes do tensor $\epsilon$ são $\epsilon_{i j}=\frac{1}{2}\left(\frac{\partial u_{i}}{\partial x_{j}}+\frac{\partial u_{j}}{\partial x_{i}}\right)$.

Para manter a linearidade, as deformações devem ser pequenas $\epsilon<<1$, além disso, o material do substrato deve ser isotrópico. Com isso as relações constitutivas do material serão lineares [17].

No TFM, o substrato é uma superfície, assim a tensão $\sigma$ sobre superfícies internas em função da deformação $\epsilon$ pode ser escrita nessa forma [15]

$$
\sigma_{i j}=\frac{E}{1+\nu}\left(\epsilon_{i j}+\frac{\nu}{1-2 \nu} \delta_{i j}\left(\epsilon_{i i}+\epsilon_{j j}+\epsilon_{k k}\right)\right)
$$

onde $\delta_{i j}$ é um delta de Kronecker, $E$ é o módulo de Young e $\nu$ é o raio de Poisson, eles dependem do tipo de material do substrato isotrópico. Podemos calcular as forças internas no substrato usando $\nabla \sigma=\mathbf{f}$.

Nesse sentido as forças internas no substrato elástico podem ser calculadas utilizando uma equação diferencial parcial chamada de equação de Lamé [17].

$$
\frac{E}{2(1+\nu)} \Delta \mathbf{u}+\frac{E}{2(1+\nu)(1-2 \nu)} \nabla(\nabla \cdot \mathbf{u})=\mathbf{f}
$$

Células aderidas no substrato aplicam forças apenas na superfície $z=0$ (ver Figura 4.3). Com isso as forças internas são $\nabla \sigma=0$ para $z<0$ (dentro do substrato). Na superfície $z=0$, as forças aplicadas pela célula são tangencias (plano $x y$ ) equilibradas 
pelas trações tangencias do substrato, as forças verticais (plano $z x$ ) são desprezíveis [17] para $z=0$. Dessa forma podemos considerar o substrato infinitamente estendido no plano $x y$ e $(-\infty<z \leq 0)$. Satisfazendo essas condições, podemos utilizar o formalismo das funções de Green $\mathbf{G}\left(\mathbf{x}, \mathbf{x}^{\prime}\right)$ [33] para calcular as trações exercidas no substrato $\mathbf{t}\left(\mathbf{x}^{\prime}\right)$, utilizando a seguinte integral de convolução

$$
\mathbf{u}(\mathbf{x})=\int \mathbf{G}\left(\mathbf{x}, \mathbf{x}^{\prime}\right) \mathbf{t}\left(\mathbf{x}^{\prime}\right) d \mathbf{x}^{\prime}
$$

Considerando que a força aplicada no substrato como uma força pontual, o substrato elástico no TFM sobre as condições previamente descritas se comporta com um semiespaço elástico isotrópico. Uma solução conhecida para esse tipo de problema é a solução de Boussinesq $[32,33]$. Cuja solução está na forma da seguinte função de Green:

$$
\mathbf{G}(\mathbf{x})=\frac{(1+\nu)}{\pi E r^{3}}\left(\begin{array}{cc}
(1-\nu)+\nu x^{2} & \nu x y \\
\nu x y & (1-\nu)+\nu y^{2}
\end{array}\right)
$$

onde $r=\sqrt{x^{2}+y^{2}}$.

Nas experiencias de TFM com células, usamos uma espessura típica do substrato em torno de $50 \mu \mathrm{m}$, entretanto por simplicidade [15] podemos desprezar as tensões verticais, mantendo a condição de contorno para $-\infty<z \leq 0$. Uma das formas para obter o tensor de tração $\mathbf{t}\left(\mathbf{x}^{\prime}\right)$ na superfície de um material elástico isotrópico semi-infinito é resolvendo a integral de convolução (4.14).

\subsection{Fourier Transform Traction Cytometry FTTC}

A função de Green é uma matriz $3 \times 3$ que descreve os deslocamentos do material em três dimensões. No TFM é muito mais simples tratar com deformações em duas dimensões. Para tornar a função de Green aplicável apenas em duas dimensões, é necessário o material elástico ser incompreensível, ou seja, o raio de Poisson deve ser $\nu \approx 0,5[15]$. Nos experimentos de TFM, são utilizados filmes de poliacrilamida PAA $(\nu \approx 0,45)$.

Umas das formas de resolver a integral de convolução (4.14) é trabalhando no espaço 
de Fourier [17], método conhecido por Fourier Transform Traction Cytometry FTTC [15]. O nosso objetivo é encontra as funções de Green para todos os pontos definidos em uma superfície elástica de estudo. Por exemplo se essa superfície possuem um tamanho $4 \times 4$, as funções de Green será uma matriz $4 \times 4$ da seguinte forma:

$$
G=\left(\begin{array}{llll}
G_{11}\left(r_{1}-r_{1}^{\prime}\right) & G_{12}\left(r_{1}-r_{1}^{\prime}\right) & G_{11}\left(r_{1}-r_{2}^{\prime}\right) & G_{12}\left(r_{1}-r_{2}^{\prime}\right) \\
G_{21}\left(r_{1}-r_{1}^{\prime}\right) & G_{22}\left(r_{1}-r_{1}^{\prime}\right) & G_{21}\left(r_{1}-r_{2}^{\prime}\right) & G_{22}\left(r_{1}-r_{2}^{\prime}\right) \\
G_{11}\left(r_{2}-r_{1}^{\prime}\right) & G_{12}\left(r_{2}-r_{1}^{\prime}\right) & G_{11}\left(r_{2}-r_{2}^{\prime}\right) & G_{12}\left(r_{2}-r_{2}^{\prime}\right) \\
G_{21}\left(r_{2}-r_{1}^{\prime}\right) & G_{22}\left(r_{2}-r_{1}^{\prime}\right) & G_{21}\left(r_{2}-r_{2}^{\prime}\right) & G_{22}\left(r_{2}-r_{2}^{\prime}\right)
\end{array}\right)
$$

Cada elemento da matriz pode ser escrito como uma função de Green da solução de Boussinesq no espaço real:

$$
\mathbf{G}(\mathbf{r})=\frac{(1+\nu)}{\pi E r^{3}}\left(\begin{array}{cc}
(1-\nu)+\nu x^{2} & \nu x y \\
\nu x y & (1-\nu)+\nu y^{2}
\end{array}\right)
$$

onde $r=\sqrt{x^{2}+y^{2}}$.

Encontrando a função de Green para um elástico isotrópico semi-infinito, aplicamos a transformada de fourier na integral de convolução (4.14), dessa forma podemos aplicar o teorema da convolução.

Definição 4.3.1 (Teorema da Convolução) Sendo $f(x)$ e $g(x)$ duas funções convoluídas no domínio do espaço, a transformada de Fourier da convolução é igual ao produto das funções no domínio de Fourier:

$$
(f * g)(x)=h(x)=\int_{-\infty}^{\infty} f(u) \cdot g(x-u)
$$

a transformada de Fourier $\mathcal{F}$ da convolução $(f * g)(x)$ será

$$
\mathcal{F}\{f * g\}=\mathcal{F}\{f\} \cdot \mathcal{F}\{g\}
$$

onde $\mathcal{F}\{f\} \cdot \mathcal{F}\{g\}$ significa produto de ponto a ponto das respectivas transformadas de 


\section{Fourier.}

A vantagem de trabalhar no espaço de Fourier é que as convoluções de funções se transformam no produto das transformadas de Fourier de cada função [19]. Assim podemos reescrever a integral (4.14) da seguinte forma:

$$
\tilde{\mathbf{t}}(\kappa)=\tilde{\mathbf{G}}(\kappa)^{-1} \tilde{\mathbf{u}}(\kappa),
$$

onde $\tilde{\mathbf{t}}(\kappa), \tilde{\mathbf{G}}(\kappa)$ e $\tilde{\mathbf{u}}(\kappa)$ são as transformadas de fourier do campo de tração, da função de Green e do campo de deformação respectivamente, a função de Green em duas dimensões no espaço de Fourier é:

$$
\tilde{\mathbf{G}}(\kappa)=\frac{(1+\nu)}{\pi E \kappa^{3}}\left(\begin{array}{cc}
(1-\nu)+\nu \kappa_{x}^{2} & \nu \kappa_{x} \kappa_{y} \\
\nu \kappa_{x} \kappa_{y} & (1-\nu)+\nu \kappa_{y}^{2}
\end{array}\right) .
$$

Assim é possível fazer a reconstrução do tensor tração $\mathbf{t}(\mathbf{x})$ voltando ao espaço real.

$$
\mathbf{t}\left(\mathbf{r}^{\prime}\right)=\mathcal{F}^{-1}\left(\mathcal{F}\left\{\mathbf{G}\left(\mathbf{r}-\mathbf{r}^{\prime}\right)\right\}^{-1} \mathcal{F}\{\mathbf{u}(\mathbf{r})\}\right)
$$

onde $\mathcal{F}^{-1}$ é a transformada inversa de fourier o e $\mathbf{t}\left(\mathbf{r}^{\prime}\right)$ é o valor de tração para um único ponto na superfície elástica.

A técnica FTTC garante um rápido processamento computacional utilizando apenas o campo de deslocamento do substrato, sendo uma técnica amplamente utilizada para o processamento de imagens de TFM [17], os valores de tensão $\sigma$ são obtidos dividindo o valor de tração $\mathbf{t}\left(\mathbf{r}^{\prime}\right)$ pela área unitária, por exemplo, a área unitária utilizada nesse trabalho é de $14,08 \mu \mathrm{m}^{2}$.

No Laboratório de Micro Reologia da USP, desenvolvemos uma versão do método FTTC que calcula os valores de tensão ao longo do tempo $\sigma(t)$ para intervalos de tempo menores que $10 \mathrm{~ms}$. Justamente para avaliar a atividade contráctil de cardiomiócitos individuais in vitro. 


\section{Capítulo 5}

\section{Microscopia de Força e Tração TFM}

A técnica experimental utilizada nesse trabalho é a Microscopia de Força de Tração (TFM) mostrada na Figura 5.1, para obter o campo de tensão das células. Primeiro forma obtidas 2900 imagens, correspondente a 20 segundos (velocidade da câmera é 145 fps) de filmagem da célula aderida ao um substrato de poliacrilamida (PAA).

A rigidez da poliacrilamida deve ser controla a partir da proporção entre os monômeros de acrilamida e bisacrilamida. Isso é necessário para mimetizar as condições de tecido onde a célula integra. Cada tipo de célula requer uma rigidez específica, para células cardíacas usamos a seguinte rigidez: $E=9.6 \mathrm{kPa}$. A célula se fixa através dos receptores de integrina ao colágeno, que funciona como ECM. O colágeno que por sua vez está fixo ao substrato de PAA.

O substrato de poliacrilamida está marcado com partículas fluorescentes com $0.2 \mu \mathrm{m}$ de diâmetro. E registrado a fluorescência emitida pelas partículas em movimento devido a interação das células com o substrato.

O método computacional utilizado para reconstruir o campo de tração com base nas imagens é o Fourier Transform Traction Cytometry (FTTC), finalizando com o processamento numérico do campo de tração.

Para realizar o experimento, inicialmente é preparado um substrato elástico com poliacrilamida. A poliacrilamida é um gel cuja rigidez pode ser controlada a partir da proporção entre monômeros de acrilamida e o crosslinker na solução a polimerizar.

Após ativar quimicamente a placa de Petri com fundo de vidro onde o gel será formado, um volume determinado de solução a polimerizar é depositado sobre ele. Em seguida, uma lamínula é colocada em cima para dar forma ao gel por capilaridade, depois de 20 minutos, o gel estará polimerizado, bastando retirar a lamínula usada para dar forma. 


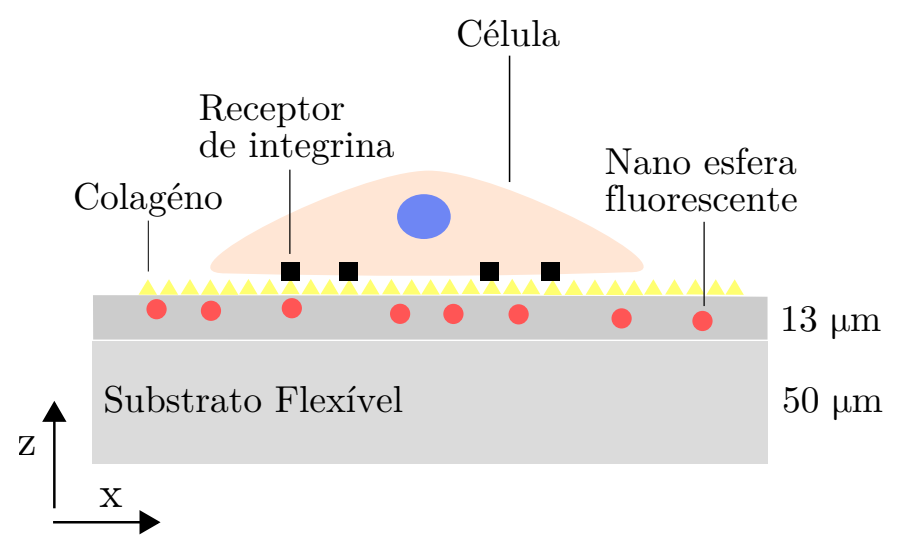

(a)

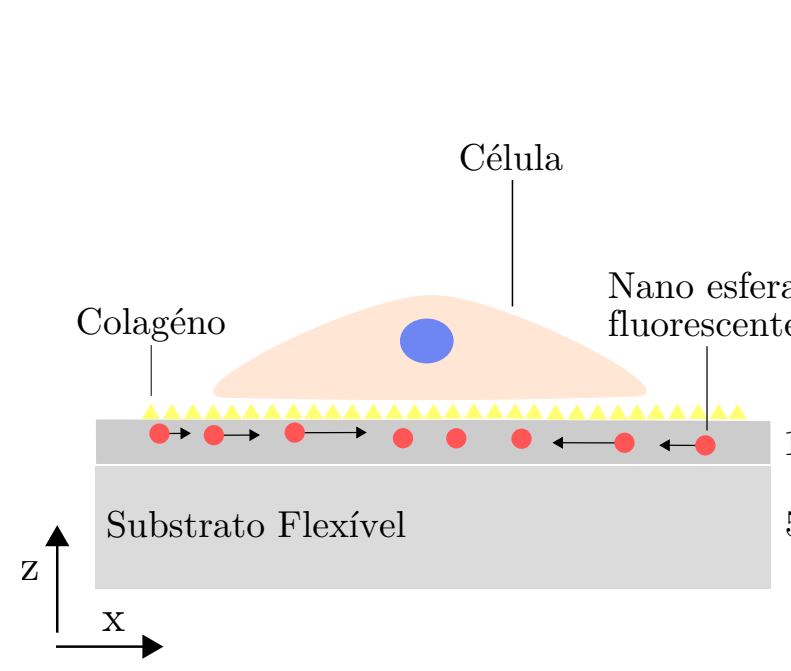

(b)

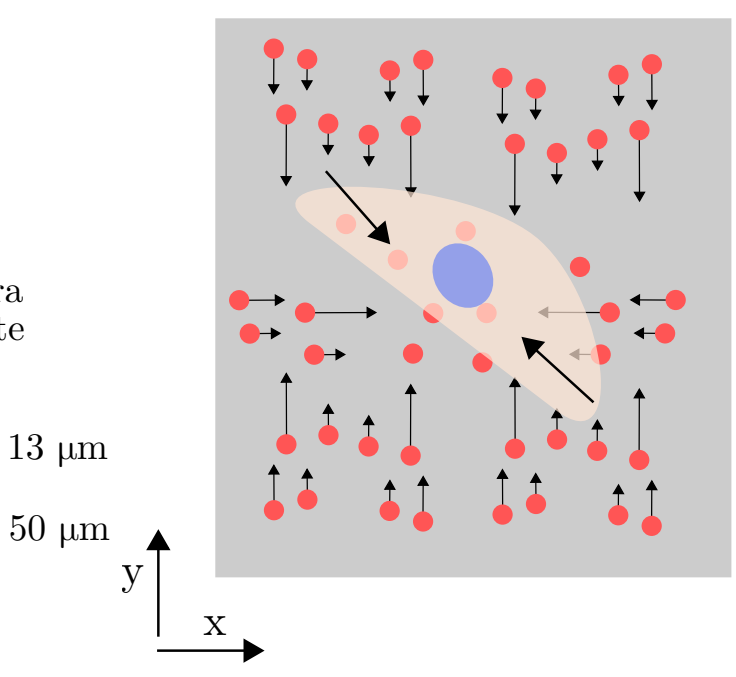

(c)

Figura 5.1: Experimento de TFM. (a) Primeiro as células são depositadas no substrato marcado com nano partículas fluorescentes. (b) Depois da adesão, a tensão produzida pelas células movimentam as nano partículas, resultando em um campo de deslocamento (c) Vista no plano $x y$ do campo de deslocamento.

A próxima etapa é ativar a superfície com o crosslinker Sulfo-SANPAH. Assim, é possível marcar o gel com as partículas fluorescentes e também depositar a matriz extracelular desejada, no caso, colágeno. Feito esse preparo, depositam as células de estudo e espera-se em torno de $72 \mathrm{~h}$ para o inicio do experimento. O tipo de célula utilizada é o cardiomiócito neonatal. Em seguida obtêm imagens de fluorescência, primeiro com as células no substrato, depois aplica a substância tripsina para retirar as células observadas e em seguida, tire-se imagens sem as células no substrato (substrato não deformado).

A montagem do experimento de TFM foi desenvolvida no Laboratório de Micro Reologia LabM² ${ }^{2}$ As células de análise são mantidas em ambiente controlado feito por um invólucro de acrílico anexo ao microscópio (Figura 5.3), sua função é recriar adequadamente as condições de uma incubadora: $5 \%$ de $\mathrm{CO}_{2}$ e temperatura de $37^{\circ} \mathrm{C}$. 


\begin{tabular}{|c|c|c|c|c|c|c|}
\hline & \multicolumn{6}{|c|}{ Polyacrylamide gel stiffness (G) } \\
\hline & $2.3 \mathrm{kPa}$ & $4.1 \mathrm{kPa}$ & $8.6 \mathrm{kPa}$ & $16.3 \mathrm{kPa}$ & $30 \mathrm{kPa}$ & $55 \mathrm{kPa}$ \\
\hline \multicolumn{7}{|c|}{ Stock solution (can be stored up to a year at $+4^{\circ} \mathrm{C}$ ) } \\
\hline $\begin{array}{l}\text { 40\% Acrylamide } \\
(\mathrm{mL})\end{array}$ & 3.75 & 2.34 & 2.34 & 3.00 & 3.00 & 2.25 \\
\hline $\begin{array}{l}\text { 2\% Bisacrylamide } \\
(\mathrm{mL})\end{array}$ & 0.75 & 0.94 & 1.88 & 0.75 & 1.40 & 2.25 \\
\hline$d \mathrm{H}_{2} \mathrm{O}(\mathrm{mL})$ & 0.5 & 1.72 & 0.78 & 1.25 & 0.60 & 0.50 \\
\hline Total volume $(\mathrm{mL})$ & 5 & 5 & 5 & 5 & 5 & 5 \\
\hline \multicolumn{7}{|c|}{ Working solution (use immediately) } \\
\hline Stock solution $(\mu \mathrm{L})$ & 125 & 200 & 200 & 250 & 250 & 333 \\
\hline $\begin{array}{l}\text { Red fluorescent } \\
\text { beads }(\mu \mathrm{L})\end{array}$ & 7.5 & 7.5 & 7.5 & 7.5 & 7.5 & 7.5 \\
\hline $\begin{array}{l}\text { Far-red fluorescent } \\
\text { beads }(\mu \mathrm{L})\end{array}$ & 7.5 & 7.5 & 7.5 & 7.5 & 7.5 & 7.5 \\
\hline $\begin{array}{l}10 \% \text { Ammonium } \\
\text { persulfate }(\mu \mathrm{L})\end{array}$ & 2.5 & 2.5 & 2.5 & 2.5 & 2.5 & 2.5 \\
\hline TEMED $(\mu \mathrm{L})$ & 0.75 & 0.75 & 0.75 & 0.75 & 0.75 & 0.75 \\
\hline $\mathrm{dd} \mathrm{H}_{2} \mathrm{O}(\mathrm{mL})$ & 357 & 282 & 282 & 232 & 232 & 163 \\
\hline
\end{tabular}

Use indicated volumes of stock solution (upper half of table) to make the working solution (lower half of table) for preparing TFM substrates of the desired stiffness. Note that working solutions should be used immediately after adding ammonium persulfate and $\mathrm{N}, \mathrm{N}, \mathrm{N}^{\prime}, \mathrm{N}^{\prime}$-tetramethylethylenediamine (TEMED) as these chemicals induce rapid polymerization of acrylamide. In contrast, after preparation, the stock solutions can be kept for at least a year as long as maintained at $+4{ }^{\circ} \mathrm{C}$.

Note that shear modulus (G) is shown in the table as a measure of gel stiffness. The conversion between the shear modulus (G) and Young's modulus (E) is given by the following formula:

$$
G=\frac{E}{2(1+s)}
$$

Figura 5.2: Concentração de acrilamida e bisacrinamida e soluções de trabalho utilizadas para a preparação dos substratos de poliacrilamida com rigidez controlada utilizados no TFM [34]. 
A estrutura de acrílico é conectada (por um tubo flexível e resistente ao calor) ao aquecedor de ar controlado por um microcontrolador. O microcontrolador (Figura 5.3) monitora a temperatura interna da caixa de acrílico mantendo o sistema estável nas proximidades de $(36 \pm 1)^{\circ} \mathrm{C}$. Próximo à objetiva (dentro do invólucro de acrílico), um segundo sistema de incubação (Warner Instrument Corporation, TC-324B) mantém as células aquecidas a $(37 \pm 0.1)^{\circ} \mathrm{C}$, em uma atmosfera de $5 \%$ de $\mathrm{CO}_{2}$.

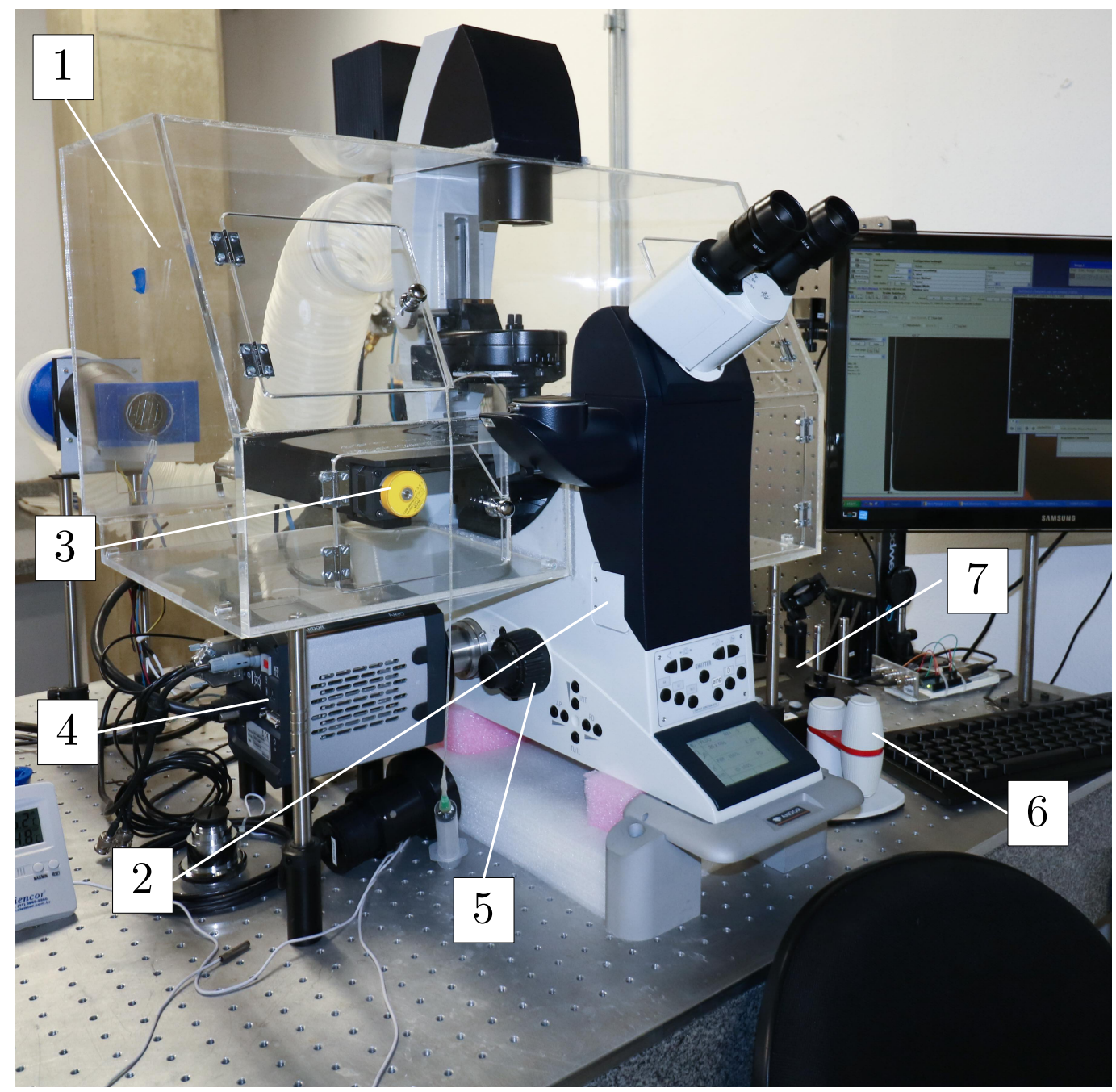

Figura 5.3: Montagem experimental do TFM modificado para alta velocidade de captura desenvolvido pelo LabM $^{2}$. 1) incubador de acrilico, 2) microscópio (Leica DMI 4000B), 3) base motorizada para o controle dos eixos x e y, 4) câmera (Andro Neo sCMOS) utilizada no TFM, 5) moto de ajuste do eixo z, 6) controlador dos eixos x e y, 7) controlador do eixo z.

Desta forma, as amostras podem ficar no microscópio como se estivessem na incubadora, permitindo experimentos com longos períodos e a utilização da mesma amostra para diversas aquisições de imagens. A câmera utilizada para o TFM é a Andor Neo sCMOS. Esta câmera é de alta velocidade podendo chegar a 1000 fps. 


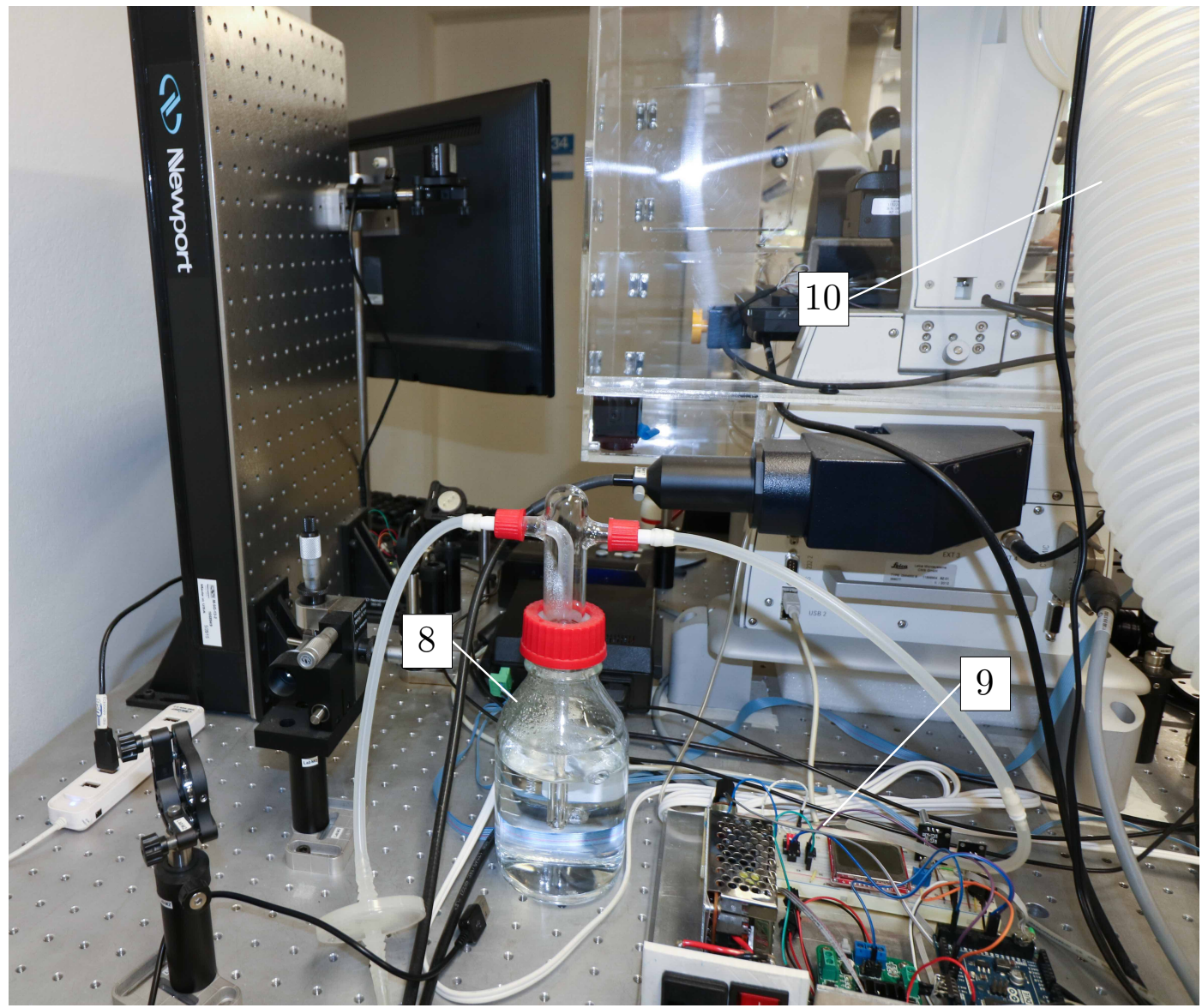

Figura 5.4: Montagem experimental do TFM modificado para alta velocidade de captura desenvolvido pelo LabM ${ }^{2}$. 8) humidificador, 9) controle externo da velocidade de captura da câmera, 10) aquecedor. 

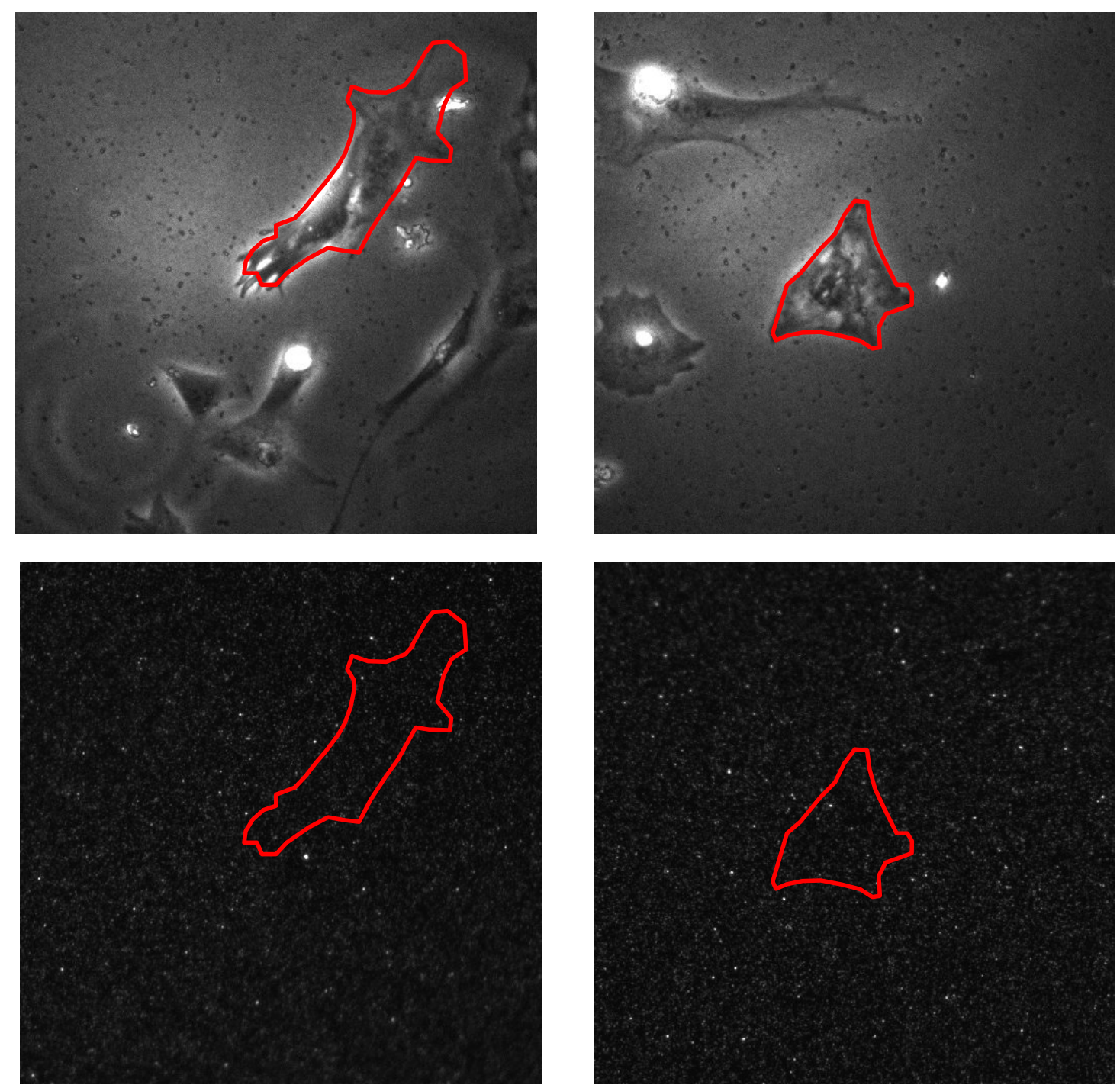

Figura 5.5: Imagens de células cardíacas com a sua área de adesão delimitada para o calculo das tensões usando o FFTC, no software do TFM, delimitamos a área que corresponde a área da célula na imagem do substrato elástico com as partículas fluorescentes. 
Dessa forma, obtemos os valores de tensão para cada célula em função da posição e do tempo, entretanto é necessário fazer o processamento e analise desses resultados. 


\section{Capítulo 6}

\section{Métodos Numéricos para Análise de Dados}

Nesse capítulo mostramos os métodos numéricos utilizados para o análise dos dados provenientes do software do TFM. Utilizamos como hipótese que o sinal de tensão ao longo do tempo teria uma característica oscilatória, onde os métodos apresentados são adequados para sinais periódicos.

\subsection{Mapeamento Bidimensional do Dados}

As imagens obtidas no TFM consistem em matrizes $i \times j$ onde cada elemento da matriz corresponde a um pixel da imagem. Um número de imagens com o mesmo tamanho são obtidas de forma sequencial ao longo do tempo, registrado o movimento das nanopartículas fluorescentes anexas ao substrato elástico. Pelo fato das partículas estarem fixas ao substrato, este movimento corresponde a própria deformação do substrato, provocado por uma célula, por exemplo.

Conhecendo a rigidez do substrato elástico, além dos valores de deformação e tempo é possível estimar os valores de tensão por pixel aplicados sobre o substrato ao longo do tempo, usando o método numérico Fourier Transform Traction Cytometry (FTTC).

O resultado desse método é um conjunto de $n$ matrizes, cada matriz mostra as componentes de tensão tangencial $\sigma_{x}, \sigma_{y}$ por elemento (pixel), como mostrado na Figura 6.1.

A forma geral do resultado é uma matriz multidimensional de índices $i, j, l, \sigma_{x}$ e $\sigma_{y}$, onde $i$ e $j$ correspondem a posição do pixel na imagem, $l$ é o índice da imagem na sequência temporal $1,2, \ldots n$ e $\sigma_{x}$ e $\sigma_{y}$ são as componentes da tensão tangencial como mostrado na Figura 6.1. Note que o tempo $t$ em que cada imagem foi fotografada é dado por $t(l)=\frac{1}{f}$ onde $f$ é a frequência de amostragem (no caso $145 \mathrm{fps}$ ), $n$ é o número 

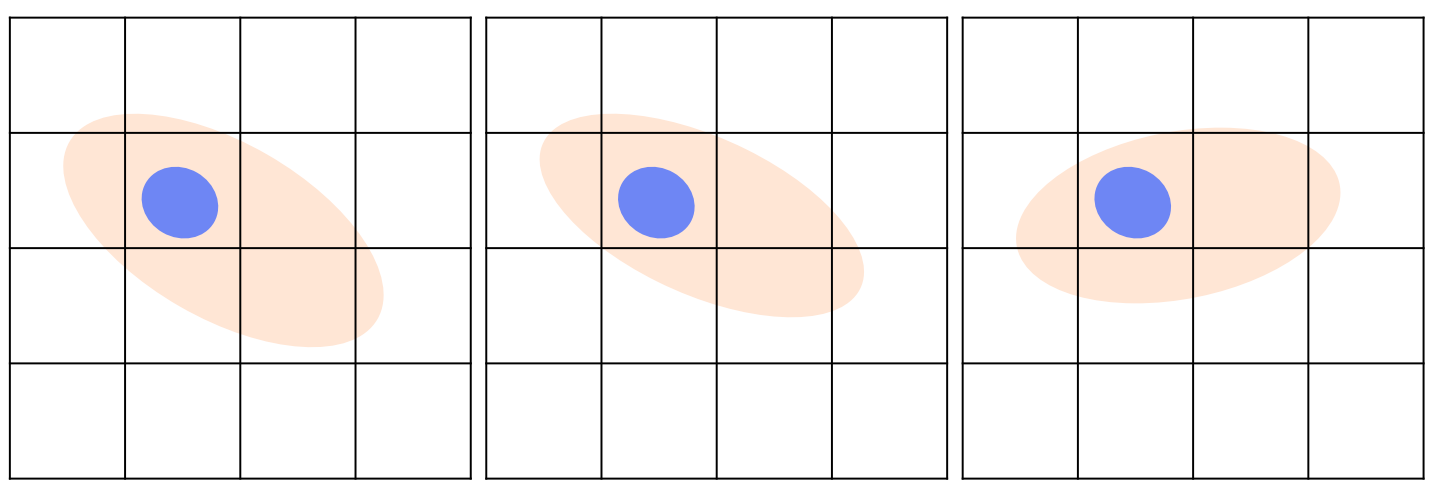

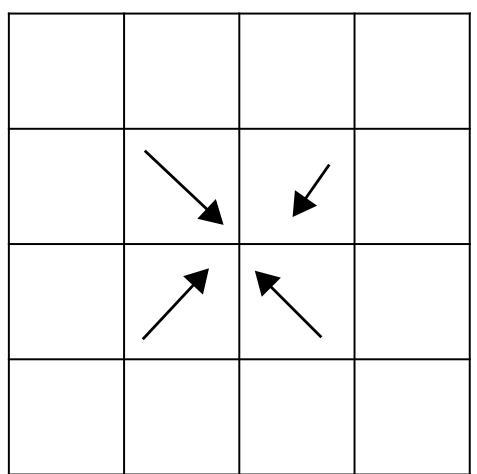

(a)

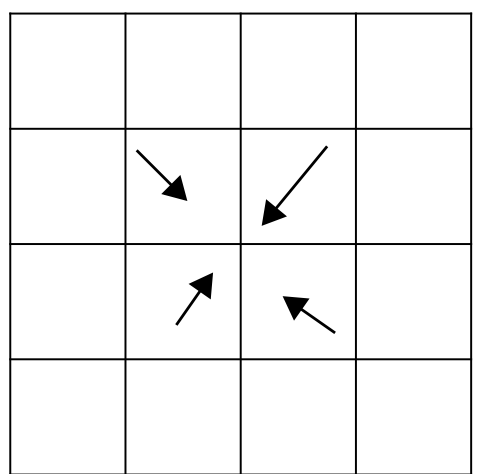

(b)

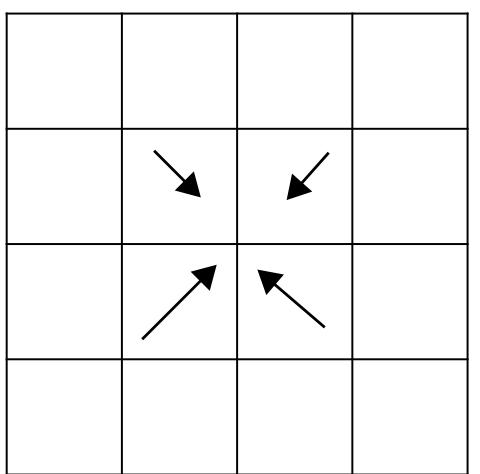

(c)

Figura 6.1: Esquema da análise de imagens de TFM, as Figuras (a), (b) e (c) correspondem a três imagens sequenciais da mesma célula com suas respectivas matrizes onde cada elemento possui os valores de tensão tangencial $\left(\sigma_{x}, \sigma_{y}\right)$ aplicadas ao substrato elástico.

de imagens. O campo de tensão pode ser simplificado para uma matriz tridimensional colocado apenas a resultante tangencial da tensão aplicada ao substrato flexível, ou seja: $\sigma_{i, j}(l)=\sqrt{\sigma_{i, j}(l)_{x}^{2}+\sigma_{i, j}(l)_{y}^{2}}$. No exemplo Eq.(6.1) abaixo, cada elemento da matriz é atribuído a um valor de tensão $\sigma_{i, j}(l)$

$$
\left(\begin{array}{ccc}
\sigma_{1,1}(l) & \sigma_{1,2}(l) & \sigma_{1,3}(l) \\
\sigma_{2,1}(l) & \sigma_{2,2}(l) & \sigma_{2,3}(l) \\
\sigma_{3,1}(l) & \sigma_{3,2}(l) & \sigma_{3,3}(l)
\end{array}\right)
$$

Cada elemento $(i, j)$ da Matriz Eq.(6.1) possui uma variável $\sigma_{i, j}(l)$, que significa a tensão tangencial resultante ao longo de $l=1,2, \ldots n$ para o elemento $(i, j)$. Uma forma simplificada de analisamos essas variáveis é o obtendo o valor médio $\frac{1}{n} \sum_{l=1}^{n} \sigma_{i, j}(l)$ de cada 
elemento da matriz. Utilizando a Eq.(6.1), o resultado é a Matriz Eq.(6.2)

$$
\left(\begin{array}{lll}
\frac{1}{n} \sum_{l=1}^{n} \sigma_{1,1}(l) & \frac{1}{n} \sum_{l=1}^{n} \sigma_{1,2}(l) & \frac{1}{n} \sum_{l=1}^{n} \sigma_{1,3}(l) \\
\frac{1}{n} \sum_{l=1}^{n} \sigma_{2,1}(l) & \frac{1}{n} \sum_{l=1}^{n} \sigma_{2,2}(l) & \frac{1}{n} \sum_{l=1}^{n} \sigma_{2,3}(l) \\
\frac{1}{n} \sum_{l=1}^{n} \sigma_{3,1}(l) & \frac{1}{n} \sum_{l=1}^{n} \sigma_{3,2}(l) & \frac{1}{n} \sum_{l=1}^{n} \sigma_{3,3}(l)
\end{array}\right) .
$$

onde estão localizados os valores médios das variáveis $\sigma_{i, j}(l)$. Esta medida tem o significado da tensão média por elemento ao longo de todas as $n$ imagens. Entretanto, pelo fato da quantidade de pixeis ser grande, utilizamos mapas de cores para representar a magnitude do valor médio. Para exemplificar, vamos usar os valores de uma região aleatória de 6 imagens consecutiva da Tabela 6.1 e aplicar o método.

Tabela 6.1: Tabela contendo valores para as variáveis $\sigma_{i, j}(l)$ do exemplo $(6.1)$ e $l=1,2, \ldots 6$.

\begin{tabular}{ccccccc}
\hline \hline Variável & & \multicolumn{9}{c}{$l$} & & & \\
& $l=1$ & $l=2$ & $l=3$ & $l=4$ & $l=5$ & $l=6$ \\
\hline \hline$\sigma_{0,0}(l)$ & 0 & 0 & 0 & 0 & 0 & 0 \\
$\sigma_{0,1}(l)$ & 1 & 2 & 0 & 1 & 0 & 2 \\
$\sigma_{0,2}(l)$ & 2 & 4 & 1 & 4 & 2 & 0 \\
$\sigma_{1,0}(l)$ & 0 & 6 & 4 & 2 & 4 & 2 \\
$\sigma_{1,1}(l)$ & 6 & 4 & 6 & 4 & 2 & 2 \\
$\sigma_{1,2}(l)$ & 6 & 0 & 6 & 6 & 6 & 6 \\
$\sigma_{2,0}(l)$ & 8 & 4 & 8 & 4 & 8 & 4 \\
$\sigma_{2,1}(l)$ & 8 & 6 & 8 & 6 & 8 & 6 \\
$\sigma_{2,2}(l)$ & 10 & 6 & 10 & 4 & 12 & 6 \\
\hline \hline
\end{tabular}

Com os valores médios de cada variável da Tabela 6.1 é gerado o mapa de cores da Figura 6.2 abaixo, os valores dos eixos vertical $i$ e horizontal $j$ indicam a variável $\sigma_{i, j}$, o valor dentro do quadrado correspondente o valor médio dessa variável, dependendo do valor médio é atribuído uma cor do gradiente de cores. Os mapas de cores serão utilizados para representar uma matrizes com grande número de elementos.

A próxima análise consiste em avaliar o grau de correlação entre os diferentes sinais de tensão produzidos pela célula. Para quantificar é utilizado uma matriz de correlação dos sinais de tensão $\sigma_{i, j}(l)$ associados a cada elemento $(i, j)$ das imagens de TFM.

A matriz de correlação é uma matriz bidimensional composta pelos coeficientes de correlação das diversas variáveis entre si. A utilidade desta na visualização esta na observação de prováveis correlações entre duas ou mais variáveis. Basicamente, o coeficiente de correlação $\rho$ entre duas variáveis indica o comportamento linear entre elas, ou seja, caso 


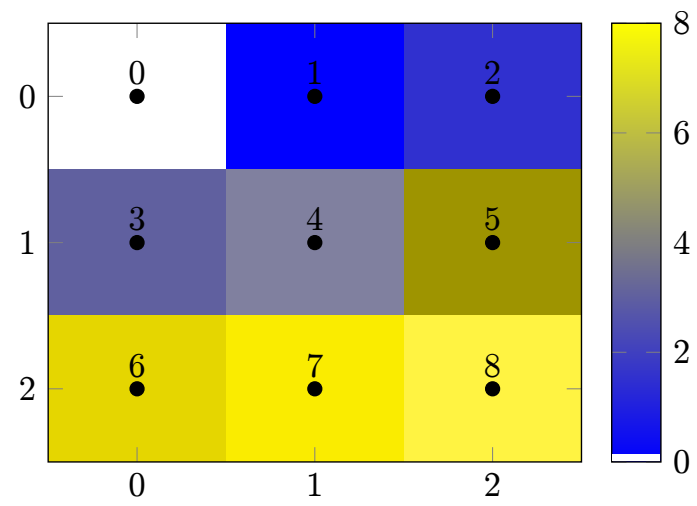

Figura 6.2: Mapa de cores obtido com os valores da Tabela 6.1, os valores dos eixos vertical $i$ e horizontal $j$ indicam a variável $\sigma_{i, j}$, o valor dentro do quadrado correspondente a certa variável é o seu valor médio $\frac{1}{6} \sum_{l=1}^{6} \sigma_{i, j}(l)$, associado a uma cor da barra de cores.

uma variável aumenta com o aumento da outra, temos uma correlação positiva $(\rho>0)$, se uma variável diminui com o aumento da outra, temos uma correlação negativa $(\rho<0)$. O coeficiente de correlação usando para calcular a correlação entre as variáveis foi o coeficiente de Pearson, ele varia de -1 a +1 , expresso por:

$$
\rho\left(\sigma, \sigma^{\prime}\right)=\frac{\sum_{l=1}^{n}\left(\sigma_{l}-\bar{\sigma}\right)\left(\sigma_{l}^{\prime}-\bar{\sigma}^{\prime}\right)}{\sqrt{\sum_{l=1}^{n}\left(\sigma_{l}-\bar{\sigma}\right)^{2}} \sqrt{\sum_{l=1}^{n}\left(\sigma_{l}^{\prime}-\bar{\sigma}^{\prime}\right)^{2}}}, \quad \bar{\sigma}=\frac{1}{n} \sum_{l=1}^{n} \sigma_{l}, \quad \bar{\sigma}^{\prime}=\frac{1}{n} \sum_{l=1}^{n} \sigma_{l}^{\prime} .
$$

Para exemplificar, será usada uma matriz de correlação com valores mostrados na Tabela 6.2. Esses valores correspondem aos coeficientes de correlação entre duas variáveis (exemplo: $\left.\rho\left(\sigma_{2,2}(l), \sigma_{1,1}(l)\right)=0.4\right)$.

Note que apenas os elementos abaixo da diagonal estão preenchidos. Isso porque na Tabela 6.2, o grupo de variáveis nas colunas é o mesmo grupo de variáveis nas linhas, tornando os elementos de acima da diagonal idênticos aos elementos abaixo da diagonal (exemplo: $\left.\rho\left(\sigma_{1,1}(l), \sigma_{2,2}(l)\right)=\rho\left(\sigma_{2,2}(l), \sigma_{1,1}(l)\right)\right)$.

O próximo passo é contabilizar para cada variável da Matriz 6.1, um valor que indique o quão esta correlacionada com ao resto do grupo de variáveis. Para isso podemos contar o número de vezes em que a correlação dessa satisfaz um limiar. Nesse exemplo usamos como limiar $\rho \geq 0.5$. Portanto, esse valor significa o número de variáveis $\sigma_{i, j}(l)$ onde a correlação é $\rho \geq 0.5$. Entretanto, deve ser desconsiderado dessa análise a correlação de uma determinada variável com ela mesma, porque não acrescenta informação á medida visto que essa correlação é sempre igual a 1. Por exemplo, usando os dados da Tabela 6.2 , o elemento $\sigma_{1,1}$ tem nota 4 . 
Tabela 6.2: Matriz de correlação, matriz composta pelos coeficientes de correlação de um grupo de variáveis $\sigma$. Arbitrariamente, foi estimado apenas os elementos abaixo da diagonal $\left(\sigma_{i, j}\right.$ onde $\left.i=j\right)$, não contabilizando correlações repetidas, por exemplo $\rho\left(\sigma_{1,1}(l), \sigma_{2,2}(l)\right)=\rho\left(\sigma_{2,2}(l), \sigma_{1,1}(l)\right)$.

\begin{tabular}{cccccccccc}
\hline \hline \multirow{2}{*}{ Variável } & \multicolumn{10}{c}{ Variável } \\
& $\sigma_{1,1}(l)$ & $\sigma_{1,2}(l)$ & $\sigma_{1,3}(l)$ & $\sigma_{2,1}(l)$ & $\sigma_{2,2}(l)$ & $\sigma_{2,3}(l)$ & $\sigma_{3,1}(l)$ & $\sigma_{3,2}(l)$ & $\sigma_{3,3}(l)$ \\
\hline \hline$\sigma_{1,1}(l)$ & 1.0 & & & & & & & & \\
$\sigma_{1,2}(l)$ & 0.6 & 1.0 & & & & & & & \\
$\sigma_{1,3}(l)$ & 0.5 & 0.7 & 1.0 & & & & & \\
$\sigma_{2,1}(l)$ & 0.3 & 0.1 & 0.8 & 1.0 & & & & \\
$\sigma_{2,2}(l)$ & 0.4 & 0.3 & 0.9 & 0.5 & 1.0 & & & \\
$\sigma_{2,3}(l)$ & 0.1 & 0.6 & 0.7 & 0.9 & 0.8 & 1.0 & & \\
$\sigma_{3,1}(l)$ & 0.9 & 0.1 & 0.5 & 0.6 & 0.5 & 0.3 & 1.0 & & \\
$\sigma_{3,2}(l)$ & 0.2 & 0.9 & 0.8 & 0.6 & 0.4 & 0.2 & 0.1 & 1.0 & \\
$\sigma_{3,3}(l)$ & 1.0 & 0.2 & 0.2 & 0.4 & 0.5 & 0.7 & 0.1 & 0.8 & 1.0 \\
\hline \hline
\end{tabular}

Chamando essa nota de $C$ e dividindo por $10^{-2} N$, onde $N$ é o número total de variáveis. Quantifica-se a porcentagem $C_{\rho}=\frac{C}{10^{-2} N}$ das variáveis onde determinada variável possui correlação $\rho$ que satisfaz o limiar. Aplicando esse método para o exemplo da Matriz (6.2) os valores de cada elemento são:

$$
\begin{gathered}
\left(\begin{array}{rrr}
\frac{4}{9 \cdot 10^{-2}}=44 \% & \frac{4}{9 \cdot 10^{-2}}=44 \% & \frac{7}{9 \cdot 10^{-2}}=78 \% \\
\frac{5}{9 \cdot 10^{-2}}=56 \% & \frac{5}{9 \cdot 10^{-2}}=56 \% & \frac{5}{9 \cdot 10^{-2}}=56 \% \\
\frac{4}{9 \cdot 10^{-2}}=44 \% & \frac{3}{9 \cdot 10^{-2}}=33 \% & \frac{4}{9 \cdot 10^{-2}}=44 \%
\end{array}\right)= \\
\left(\begin{array}{rrr}
44 \% & 44 \% & 78 \% \\
56 \% & 56 \% & 56 \% \\
44 \% & 33 \% & 44 \%
\end{array}\right) .
\end{gathered}
$$

O elementos $(i, j)$ da Matriz (6.5) são os valores $C_{\rho}$ das variáveis $\sigma_{i, j}(l)$ da Tabela 6.2. Por exemplo, o elemento $(1,1)$ é igual a $44 \%$, isso significa que a variável $\sigma_{1,1}(l)$ da Tabela 6.2 tem correlação $\rho \geq 0.5$ com $44 \%$ do grupo de variáveis analisadas. Avaliando estatisticamente a formação de agregados (grupos de elementos) com diferentes faixas de correlação, podemos implementar o mapas de cores da Figura 6.2 para simplificar a visualização dos agregados.

As células cardíacas neonatais podem se contrair de forma espontânea e periódica, 
a tensão tangencial resultante $\sigma_{i, j}(l)=\sqrt{\sigma_{i, j}(l)_{x}^{2}+\sigma_{i, j}(l)_{y}^{2}}$ no substrato varia de forma periódica ao longo do tempo. Além disso nos diferente pontos da célula a frequência de contração é a mesma. Portanto, um outro tipo de análise realizada em conjunto com o método citado é o uso de transformadas integrais para avaliar o sinal de tensão tangencial resultante. Chamamos esse sinal de contração celular $\sigma(l)$.

\subsection{Métodos de Análise de Sinais}

\subsubsection{Transformada de Fourier}

A Transformada de Fourier (FT) é uma ferramenta amplamente utilizada para analise de dados (funções matemáticas, medidas experimentais e etc), de forma simplificada, a FT decompõem um sinal $x(t)$ em termos elementares de seno e cosseno.

Definição 6.2.1 (Transformada de Fourier) Sendo $x(t)$ um sinal, sua Transformada de Fourier é definida como a distribuição complexa $X(\omega)$ tal que:

$$
x(t)=\frac{1}{2 \pi} \int_{-\infty}^{\infty} X(\omega) e^{i \omega t} d \omega
$$

Inicialmente é necessário definir os tipos de sinais que podem se aplicar a Transformada de Fourier. Os sinais devem corresponder hipoteticamente, à medição de uma grandeza física num sistema fisicamente realizável.

Portanto é possível fazer uma considerável simplificação, todos os sinais irão satisfazer as condições de convergência da Transformada de Fourier (condições de Dirichilet). Sinais físicos necessariamente atendem a tais condições, sendo que sinais que não o fazem não podem ser empiricamente produzidos.

Definição 6.2.2 (Condições de Dirichilet) Um sinal $x(t) \in \mathbb{D}$ é definido como uma distribuição que satisfaz às condições de Dirichilet:

1. $\int_{T}|x(t)| d t<\infty \quad \forall T$;

2. $x(t)$ possui um número finito de mínimos e máximos em todo intervalo $T$;

3. $x(t)$ possui um número finito de descontinuidades em todo intervalo $T$, 
sendo $T$ um intervalo finito de $\mathbb{R}$.

De acordo com esta definição, os sinais podem ser, por exemplo, descontínuos, o que se aproxima do comportamento de muitos sinais físicos. Esta é uma das razões para definir sinais no conjunto das distribuições, e não no conjunto das funções continuas.

Para compreender o significado da distribuição complexa $X(\omega)$, ela será decomposta em sua representação polar, na forma:

$$
X(\omega)=\rho(\omega) e^{i \theta(\omega)}
$$

Substituindo na integral em (6.6):

$$
\begin{aligned}
x(t) & =\frac{1}{2 \pi} \int_{-\infty}^{\infty} \rho(\omega) e^{i \theta(\omega)} e^{i \omega t} d \omega \\
= & \frac{1}{2 \pi} \int_{-\infty}^{\infty} \rho(\omega) e^{i(\omega t+\theta(\omega))} d \omega .
\end{aligned}
$$

Um das propriedades da distribuição $X(\omega)$ na forma (6.7), é que $\rho(\omega)$ deve ser uma distribuição real par, enquanto $\theta(\omega)$ deve ser uma distribuição real impar. Essas condições garantem que $x(t)$ seja uma distribuição real. Então:

$$
\begin{array}{r}
x(t)=\frac{1}{2 \pi} \int_{-\infty}^{0} \rho(\omega) e^{i(\omega t+\theta(\omega))} d \omega+\frac{1}{2 \pi} \int_{0}^{\infty} \rho(\omega) e^{i(\omega t+\theta(\omega))} d \omega \\
=\frac{1}{2 \pi} \int_{0}^{\infty} \rho(\omega)\left(e^{i(\omega t+\theta(\omega))}+e^{-i(\omega t+\theta(\omega))}\right) d \omega .
\end{array}
$$

Usando a fórmula de Euler, é possível mostrar que:

$$
\cos (\omega t+\theta)=\frac{1}{2}\left(e^{i(\omega t+\theta)}+e^{-i(\omega t+\theta)}\right) .
$$

Substituído esta relação em (6.11), leva a:

$$
x(t)=\frac{1}{\pi} \int_{0}^{\infty} \rho(\omega) \cos (\omega t+\theta(\omega)) d \omega
$$

Da relação (6.13), as funções $\rho(\omega)$ e $\theta(\omega)$ podem ser interpretadas da seguinte maneira. A distribuição $\rho(\omega)$ traz a informação sobre quais cossenoides existem no sinal $x(t)$, e quais as suas amplitudes. A distribuição $\theta(\omega)$ informa qual é o defasamento entre as diversas cossenoides do sinal $x(t)$. Geralmente $X(\omega)$ é chamando de espectro de frequência, devido 
a sua conotação de informar as frequências de um determinado sinal $x(t)$. Porém, para analise de sinais empíricos, é necessário obter uma aproximação da Transformada de Fourier através de calculo numérico. O calculo pode ser realizado considerando o sinal $x(t)$ constituído por valores discretos e igualmente espaçados no tempo, esta operação denomina-se Transformada Discreta de Fourier (DFT).

Definição 6.2.3 (Transformada Discreta de Fourier) Sendo $x(t)$ um sinal constituído por valores discretos e igualmente espaçados no tempo, sua Transformada Discreta de Fourier é definida como a distribuição complexa $X(\omega)$ tal que:

$$
X(\omega)=\frac{1}{N} \sum_{t=0}^{N-1} x(t) e^{-i \omega \frac{2 \pi t}{N}}
$$

Além disso, é possível otimizar o calculo da DFT, com a chamada FFT, porém, este método só pode ser aplicado para conjunto de dados com numero de potência de 2 . 

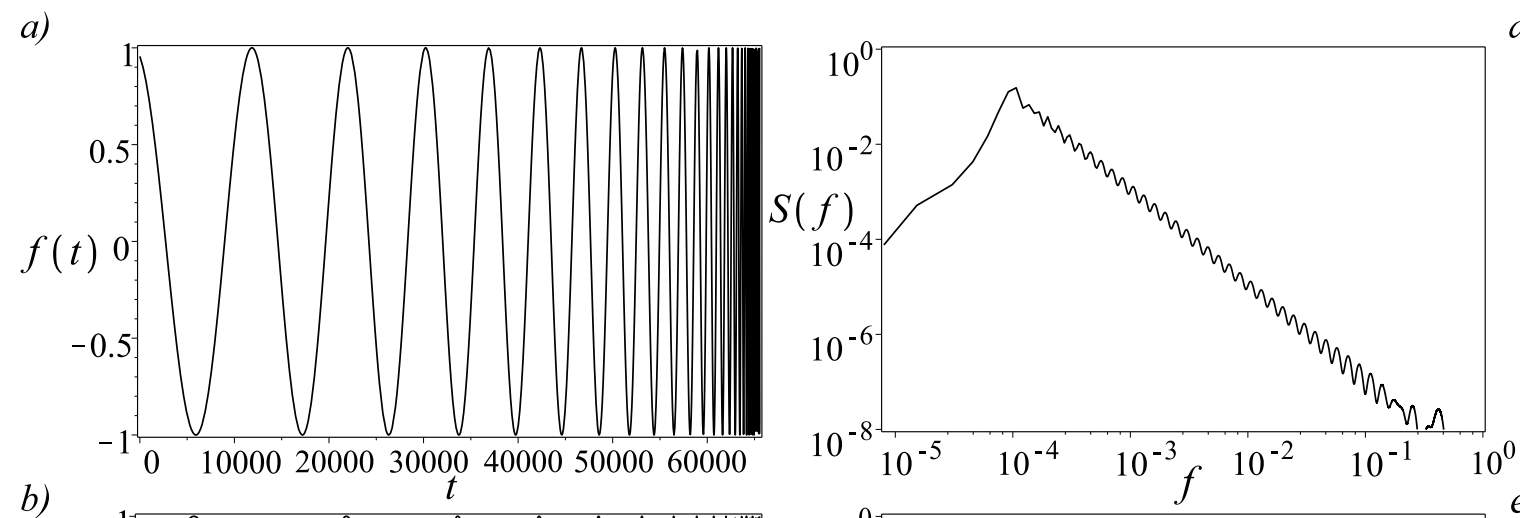

d)
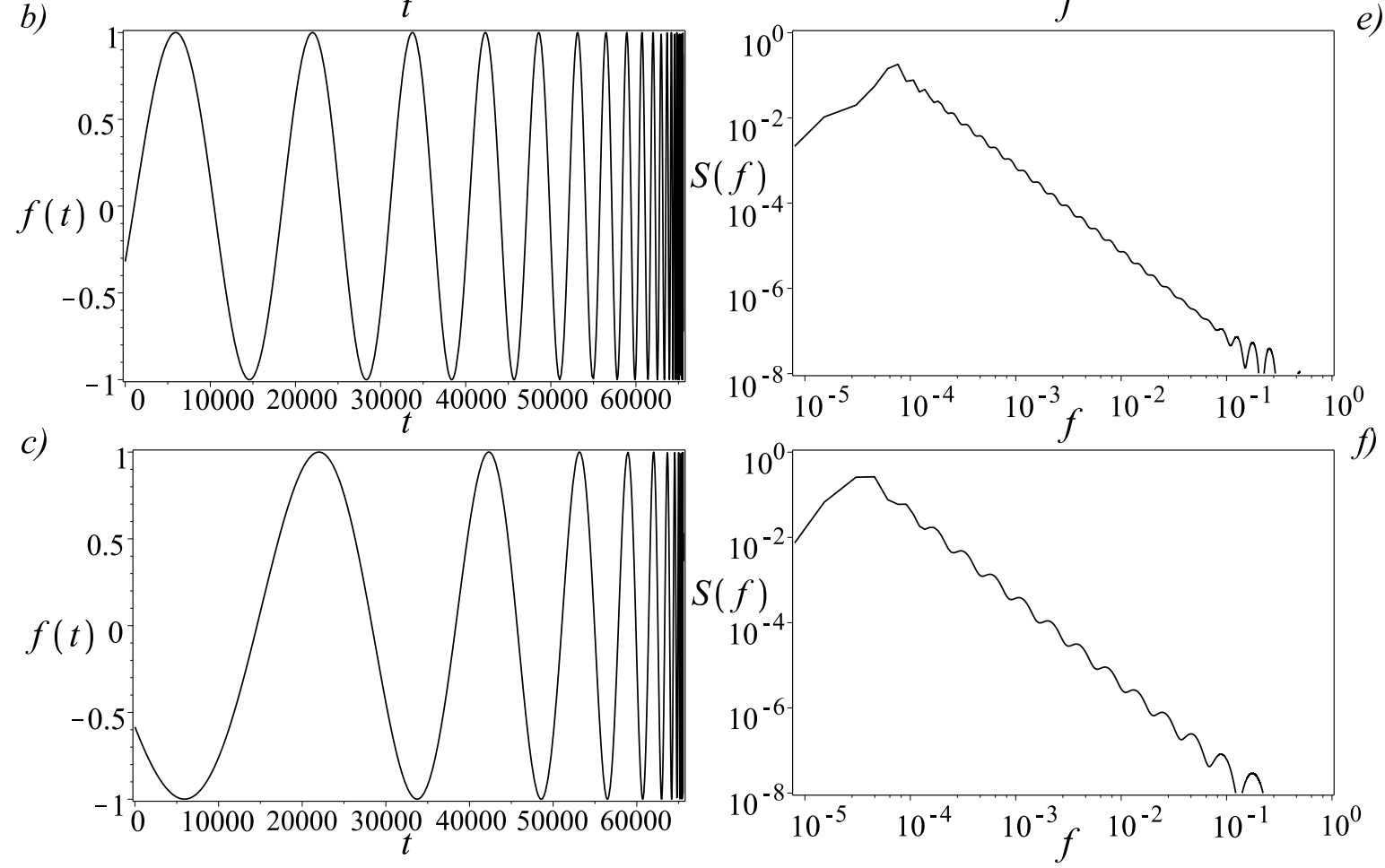

Figura 6.3: Mais exemplos de sinais log-periódicos $f(t)=\cos \left(\omega \ln \left(t_{c}-t\right)\right)$ mostrados para $t=$ $1,2,3 \ldots 2^{16}$ com $t_{c}=2^{16}+1$ e $\omega=30$ (a), $\omega=20$ (b), $\omega=10$ (c), juntamente com os seus espectros de potência $S(f)$ correspondente (d, e, f).

\subsubsection{Periodograma de Lomb-Scargle}

O periodograma de Lomb-Scargle (PLS) ou Lomb-Scargle Fourier Transform (LSFT) é uma técnica de análise espectral, desenvolvida por Lomb (1976) [35] e modificado por Scargle (1982) [35]. Diferente do espectro da Transformada Rápida de Fourier (FFT), o periodograma de Lomb-Scargle pode ser aplicado a series temporais não espacializadas 
no tempo, sendo também uma técnica de analise por mínimos quadrados.

Ele fornece uma boa aproximação para o espectro obtido com ajuste por mínimos quadrados aos dados e traçando a redução na soma dos resíduos contra a frequência.

Este método de mínimos quadrados ou espectro, proporciona a melhor medida provenientes das diferentes frequências para a variância global de dados e pode ser considerada como a extensão natural de métodos de Fourier para dados não-uniformes.

Definição 6.2.4 (Periodograma de Lomb-Scargle) Para uma serie temporal $X\left(t_{n}\right)$, onde $n=1,2, \ldots, N$, o periodograma de Lomb-Scargle $P_{x}\left(\omega_{i}\right)$, considerando $X_{z}\left(t_{n}\right)=$ $\frac{X\left(t_{n}\right)-\mu}{\sigma}=\frac{X\left(t_{n}\right)-\frac{1}{N} \sum_{n=1}^{N} X\left(t_{n}\right)}{\frac{1}{N-1} \sum_{n=1}^{N}\left(X\left(t_{n}\right)-\frac{1}{N} \sum_{n=1}^{N} X\left(t_{n}\right)\right)} e^{\prime}$

$$
P_{x}\left(\omega_{i}\right)=\frac{1}{2}\left\{\frac{\left[\sum_{n=1}^{N} X_{z}\left(t_{n}\right) \cos \left(\omega_{i}\left(t_{n}-\varepsilon\right)\right)\right]^{2}}{\sum_{n=1}^{N} \cos ^{2}\left(\omega_{i}\left(t_{n}-\varepsilon\right)\right)}+\frac{\left[\sum_{n=1}^{N} X_{z}\left(t_{n}\right) \sin \left(\omega_{i}\left(t_{n}-\varepsilon\right)\right)\right]^{2}}{\sum_{n=1}^{N} \sin ^{2}\left(\omega_{i}\left(t_{n}-\varepsilon\right)\right)}\right\}
$$

sendo $\omega_{i}=2 \pi f_{i}$ e $f_{i}>0, i=1,2, \ldots, N$. Onde o valor de $\varepsilon$ (dependente de $\omega_{i}$ ) é definido como:

$$
\tan \left(2 \omega_{i} \varepsilon\right)=\frac{\sum_{n=1}^{N} \sin \left(2 \omega_{i} t_{n}\right)}{\sum_{n=1}^{N} \cos \left(2 \omega_{i} t_{n}\right)}
$$

Segundo Scargle [35], a estimativa espectral $P_{x}(\omega)=\frac{1}{N}\left|\sum_{n=1}^{N} X_{n} e^{-i \omega n}\right|^{2}$ obtida a partir do periodograma modificado (6.15) possuí a mesma distribuição exponencial tanto para dados igualmente espaçados quanto para dados não espaçados. $O$ valor de $\varepsilon$ na equação (6.15) torna o periodograma invariante sobre um deslocamento constante nos tempos amostrados, isso equivale ao ajuste mínimos quadrados de uma função de senos e cossenos da forma $h(t)=\sin (\omega t)+\cos (\omega t)$ [35], a minimização resulta segundo [35], em $\sum_{n=1}^{N} \cos \left(\omega_{i}\left(t_{n}-\varepsilon\right)\right) \sin \left(\omega_{i}\left(t_{n}-\varepsilon\right)\right)=0$, isso equivale a equação (6.16).

O periodograma de Lomb-Scargle não só avalia a ordem dos dados de entrada, mas os instantes de tempo em que foram coletados, fazendo correções estatísticas justamente para analise de series temporais não especializada no tempo. Decompondo dados numéricos em somas de seno e cosseno. 

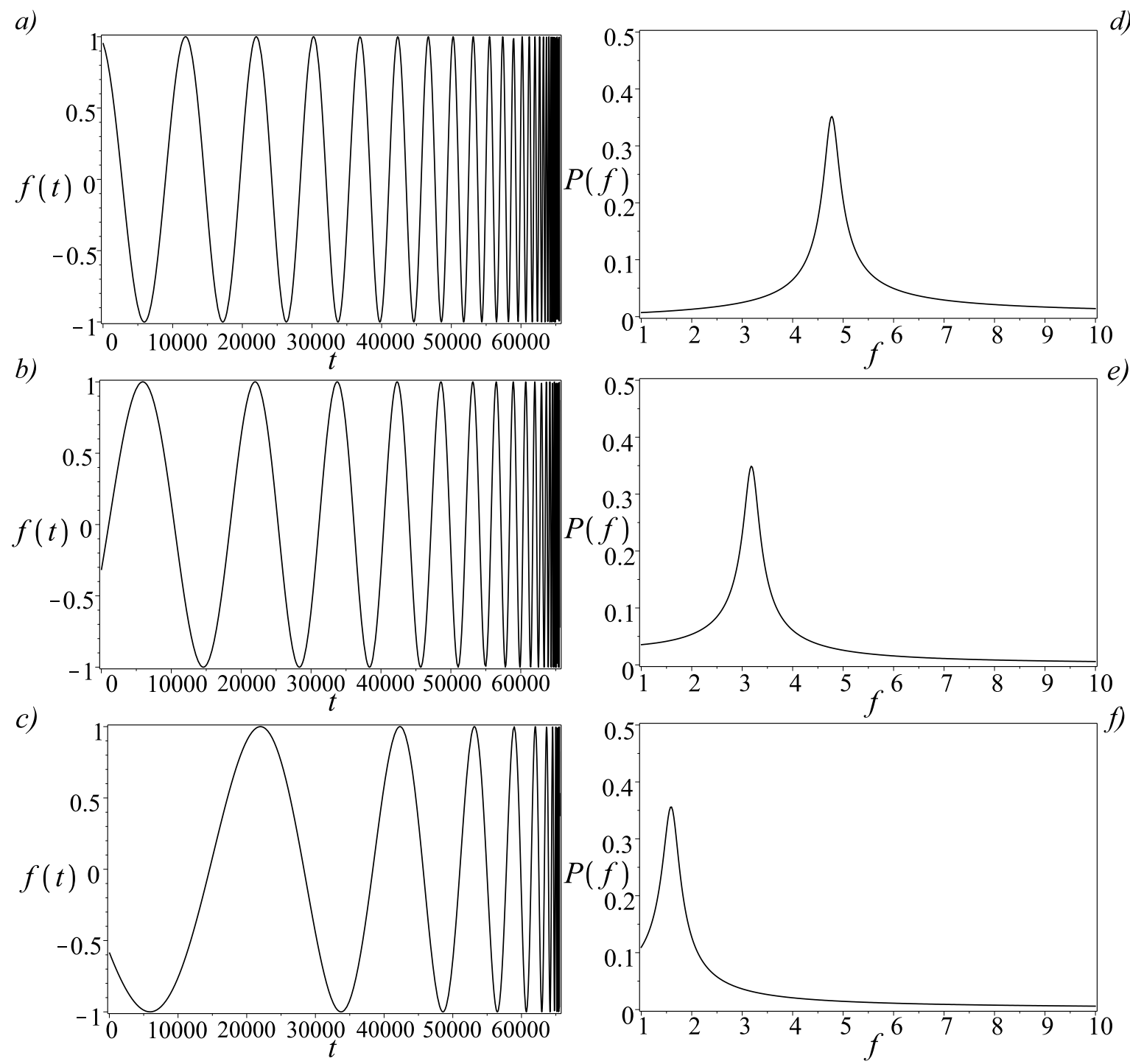

Figura 6.4: Exemplos de sinais log-periódicos $f(t)=\cos \left(\omega \ln \left(t_{c}-t\right)\right)$ mostrados para $t=1,2,3 \ldots 2^{16}$, fazendo a substituição $\tau \equiv \ln \left(t_{c}-t\right)$, com $t_{c}=2^{16}+1$ e $\omega=30$ (a), $\omega=20$ (b), $\omega=10$ (c), juntamente com os seus periodogramas de Lomb-Scargle $P(f)$ correspondente (d, e, f). Fonte: elaborado pelo autor.

\subsubsection{Transformada de Wavelet}

O espectro no domínio da frequência de um sinal, obtido com a transformada de Fourier FT mostra a informação do sinal completo. Entretanto, haveria a dificuldade de analisar o sinal em determinados intervalos de tempo $\Delta t$, isso poderia ser contornado com a aplicação de varias FT nos diferentes intervalos de tempo utilizando o periodograma de 
Lomb-Scargle (PLS) por exemplo, porem é necessário o ajuste desse intervalo para cada tipo de sinal, o que não é prático em algumas situações. Nesse aspecto, a transformada de Wavelet WT pode contornar esse problema, desde que satisfaça algumas condições. Nesse tipo de transformada, o sinal não é analisado no domínio das frequências, mas no domínio das escalas.

Para que uma determinada função $\psi(t)$ seja considerada uma wavelet, ela deve satisfazer duas características:

Definição 6.2.5 (Condições para wavelet) Um sinal $\psi(t)$ é definido como uma wavelet que satisfaz às condições:

1. A área total sob a curva da função é 0 , ou seja $\int_{-\infty}^{\infty} \psi(t) d t=0$;

2. A energia da função é finita, ou seja $\int_{-\infty}^{\infty}|\psi(t)|^{2} d t \quad<L \quad L \in \mathbb{N}$.

As funções $\psi(t)$ pertencem ao conjunto das funções quadrado integráveis. Essas condições diferencia a wavelet da analise de Fourier, devido ao fato que a analise de Fourier utiliza funções seno e cosseno que são periódicas e infinitas. Dessa a forma a transformação de wavelet é caracterizada como um operador local no domínio do tempo.

Definição 6.2.6 (Transformada de Wavelet contínua) Sendo $x(t)$ um sinal constituído por valores discretos e igualmente espaçados no tempo, sua Transformada Discreta de Fourier é definida como a distribuição complexa $X(\omega)$ tal que:

$$
W(a, b)=\int_{-\infty}^{\infty} f(t) \frac{1}{\sqrt{|a|}} \psi^{*}\left(\frac{t-b}{a}\right) d t
$$

A transformada de wavelet é uma ferramenta amplamente utilizada para obter informações da variação em certas bandas de frequências ou detectar estruturas locais presentes em dados [35], a transformada contínua de wavelet $W(a, b)$ de um sinal $f(t)$

$$
W(a, b)=\int_{-\infty}^{\infty} f(t) \frac{1}{\sqrt{|a|}} \psi^{*}\left(\frac{t-b}{a}\right) d t
$$

onde $\psi^{*}(t)$ é o conjugado da função wavelet $\psi(t)$ escolhida, $a$ e $b$ são valores de escala. Basicamente a transformada de wavelet decompõem um sinal em varias funções wavelet $\psi(t)$ ao longo de $t$, para cada $t$ haverá os valores $a$ e $b$, no qual a mudança de escala 


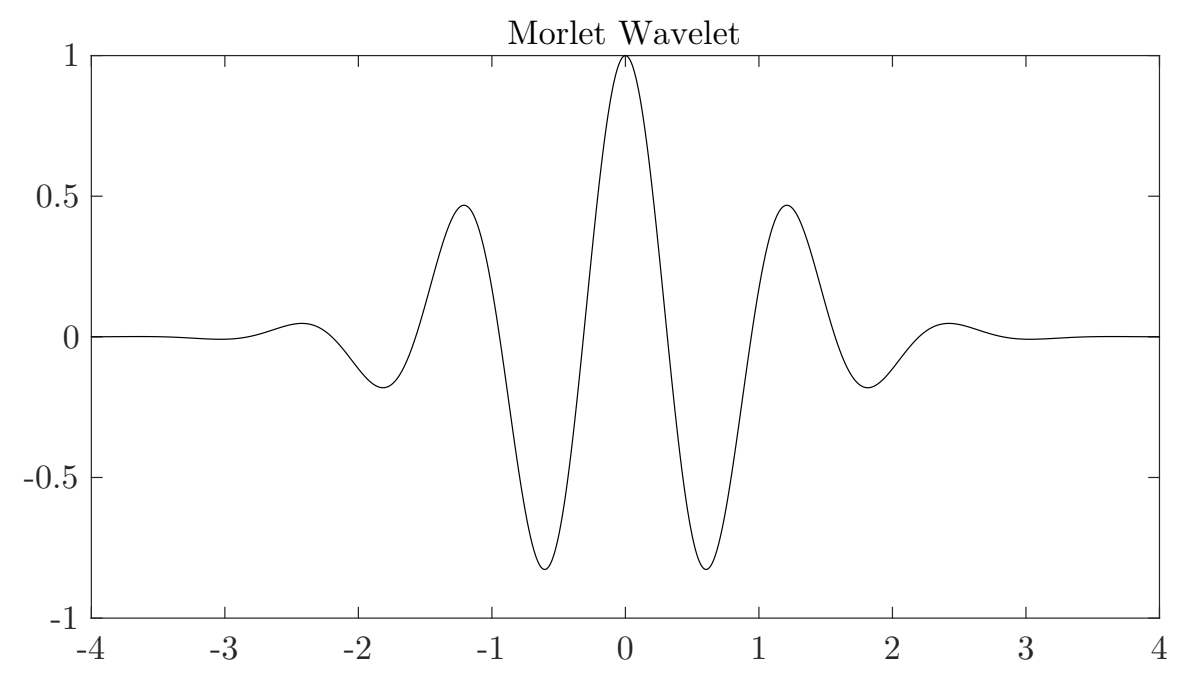

Figura 6.5: Wavelet Molet.

$\psi\left(\frac{t-b}{a}\right)$ que melhor se correlaciona com o sinal em $t$. Como a função wavelet $\psi(t)$ já é definida, a transformada de wavelet analisa o sinal no domínio das escalas $(a, b)$, gerando um escalograma.

Diferente da transformada de Fourier que decompõem o sinal em termos de cossenoides e senoides, analisando o sinal no domínio da frequência, gerando um espectro. Além disso, com a transformada de Fourier é possível analisar a variação de frequência ao longo do tempo, fixando um de intervalo $\Delta t$ (janela), vendo a frequência em cada janela. Entretanto a transformada de wavelet também fornece a frequência ao longo do tempo conhecendo $\psi\left(\frac{t-b}{a}\right)$. A vantagem da transformada de wavelet é que não é necessário fixar uma janela $\Delta t$ para determinar a frequência do sinal ao longo do tempo. Dentre as funções de wavelet disponíveis, utilizamos a função a Molet: $\psi(l)=\left(e^{-i l}-\frac{1}{\sqrt{e}}\right)^{-\frac{1}{2} l^{2}}[19]$, para analisar os sinais de tensão. 

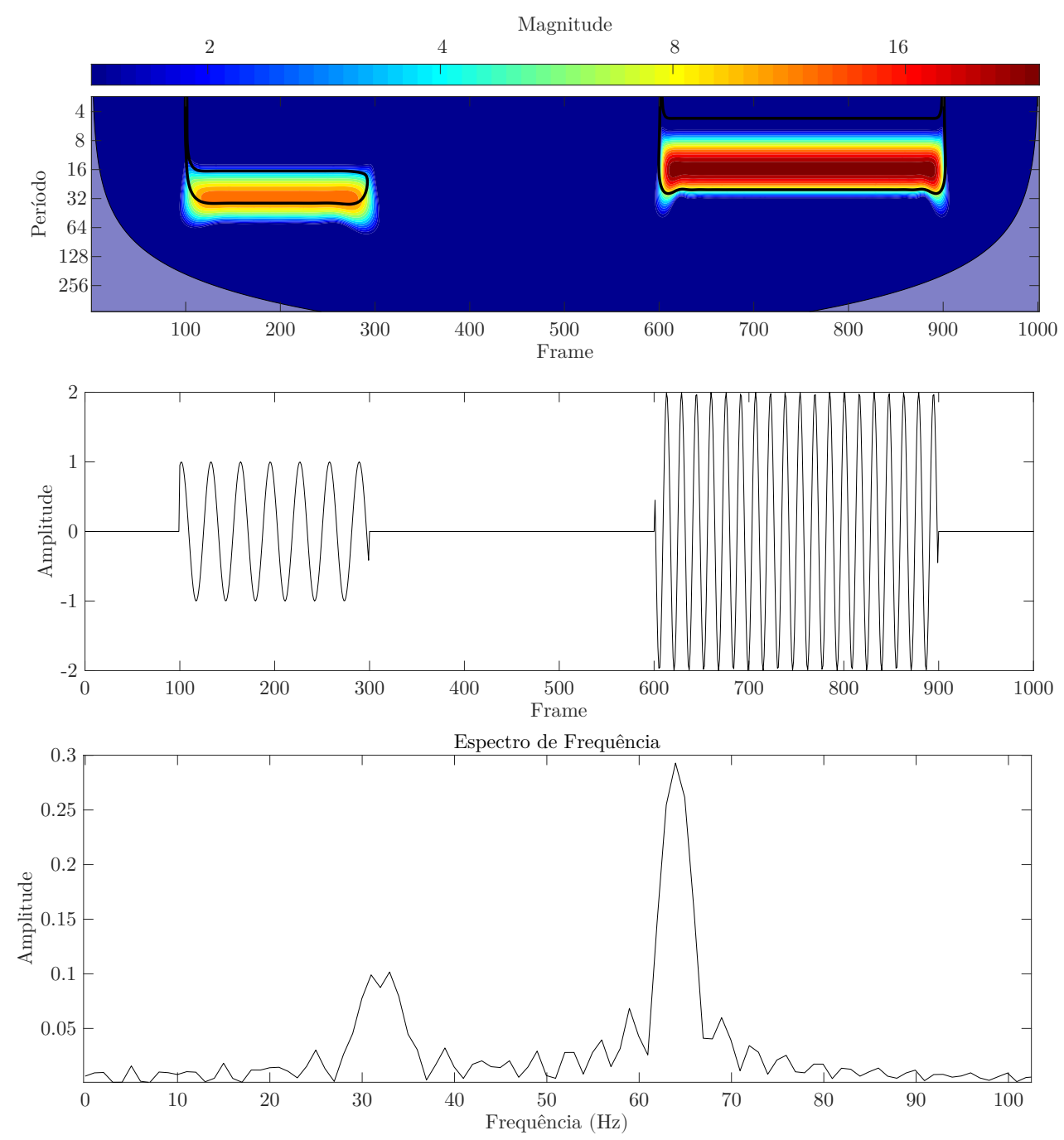

Figura 6.6: Transformada de Wavelet (em cima) e o Periodograma de Lomb (em baixo) aplicados para um sinal que muda a frequência com o tempo. Notamos que a transformada de wavelet mostra as mudanças de frequência no sinal ao longo do tempo, enquanto o periodograma de lomb mostra as os valores frequência do sinal. 


\section{Capítulo 7}

\section{Resultados e Discussões}

Nesse trabalho, mensuramos alguns parâmetros mecânicos de células cardíacas neonatais, aderidas em um substrato elástico bidimensional, utilizando dados coletados de experimentos de TFM, caracterizando o sinal de tensão mecânica proveniente dessas células.

Devemos enfatizar que para o desenvolvimento desse trabalho, houve o processamento das imagens de TFM, previamente coletadas pela equipe de pesquisadores do Laboratório de Micro Reologia LabM를 da USP. Os resultados desse trabalho foram obtidos após o processamento das imagens de TFM, onde extraímos as informações sobre o comportamento mecânico de células cardíacas neonatais.

\subsection{Descrição das Amostras}

As amostras consistem em um grupo de 50 cardiomiócitos neonatais de rato (ver 3.3), coletadas no Instituto do Coração do Hospital das Clínicas INCOR. Após a extração, as células foram cultivadas em uma superfície de poliacrilamida (PAA) recoberta com colágeno e rigidez igual a $9.6 \mathrm{kPa}$. São obtidas as imagens de fluorescência do TFM depois de $24 \mathrm{~h}$, com a maturação das adesões focais e mais $72 \mathrm{~h}$ em cultura para o inicio da contração cíclica das células.

As imagens de fluorescência do TFM da contração de células foram produzidas no Laboratório de Micro Reologia LabM² da USP. A câmera captura imagens a uma taxa de 145 imagens por segundo ou 145 fps. Inicialmente foram obtidas em torno de 2900 imagens de cada cardiomiócito ou 20 s de contração, logo em seguida os cardiomiócitos foram submetidos a uma concentração de $10 \mu \mathrm{M}$ de isoproterenol, servido como um estímulo químico, provocando um aumento da frequência de contração. Posteriormente foram no- 

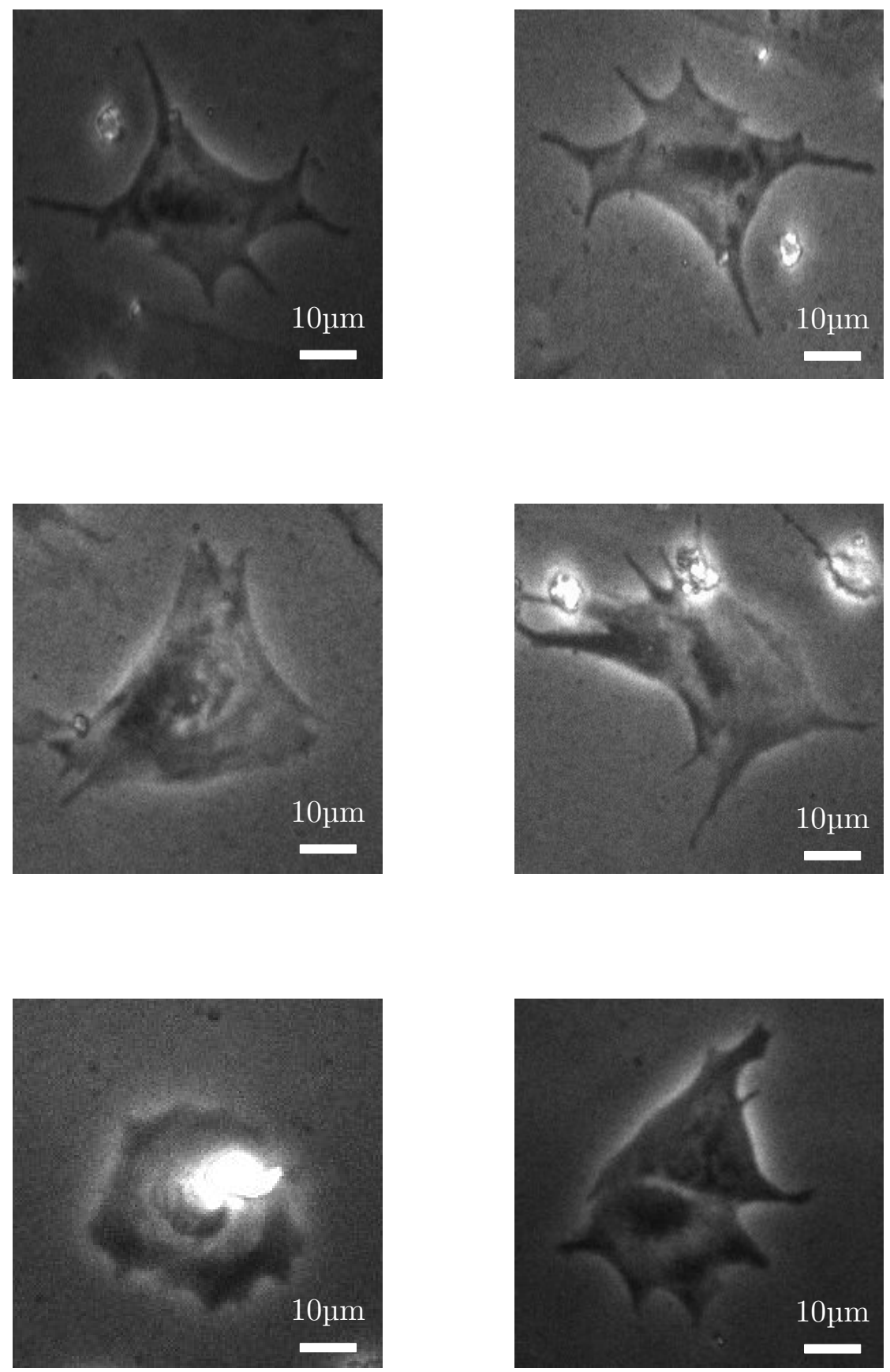

Figura 7.1: Conjunto de imagens de microscopia de contraste de fase de alguns cardiomiócitos neonatais do grupo de amostra, lembrando que a amostra possui 50 cardiomiócitos que foram utilizados para obter os resultados descritos no capítulo.

vamente obtidas 2900 imagens de cada cardiomiócito. A próxima etapa é a aplicação da substância tripsina que remove as células do substrato para obter as imagens do substrato sem quaisquer deformações, justamente para calcular as deformações provocadas pelos cardiomiócitos ao longo do tempo. Ao final do experimento temos dois grupos de 
cardiomiócitos neonatais, os que estavam no estado basal e que foram submetidos ao isoproterenol.

Finalizando a de captura das imagens de TFM dos cardiomiócitos neonatais, temos a etapa de processamento das imagens para o cálculo das tensões aplicadas ao longo do tempo, com auxilio de um software desenvolvido pelo $\mathrm{LabM}^{2}$, calculamos os valores de tensão com base na deformações, verificadas com a movimentação da partículas fluorescentes durante a captura das imagens. No software delimitamos a área das células usando uma imagem de contraste de fase, cada imagem é comparada com imagem após a remoção das células, dessa forma é reconstruído o sinal de tensão ao longo do tempo para cada ponto $(x, y)$ da célula. Com o término do processamento das imagens, temos uma matriz $\sigma(t, x, y)$ que corresponde o valor de tensão para cada instante de tempo $t$ para cada ponto $(x, y)$ da célula. Na Figura 7.2 temos três sinais de contração celular, sobrepostos no mesmo gráfico, que mostra a tensão $\sigma$ em função do tempo $t$, cada sinal corresponde a um ponto $(x, y)$ diferente da célula.

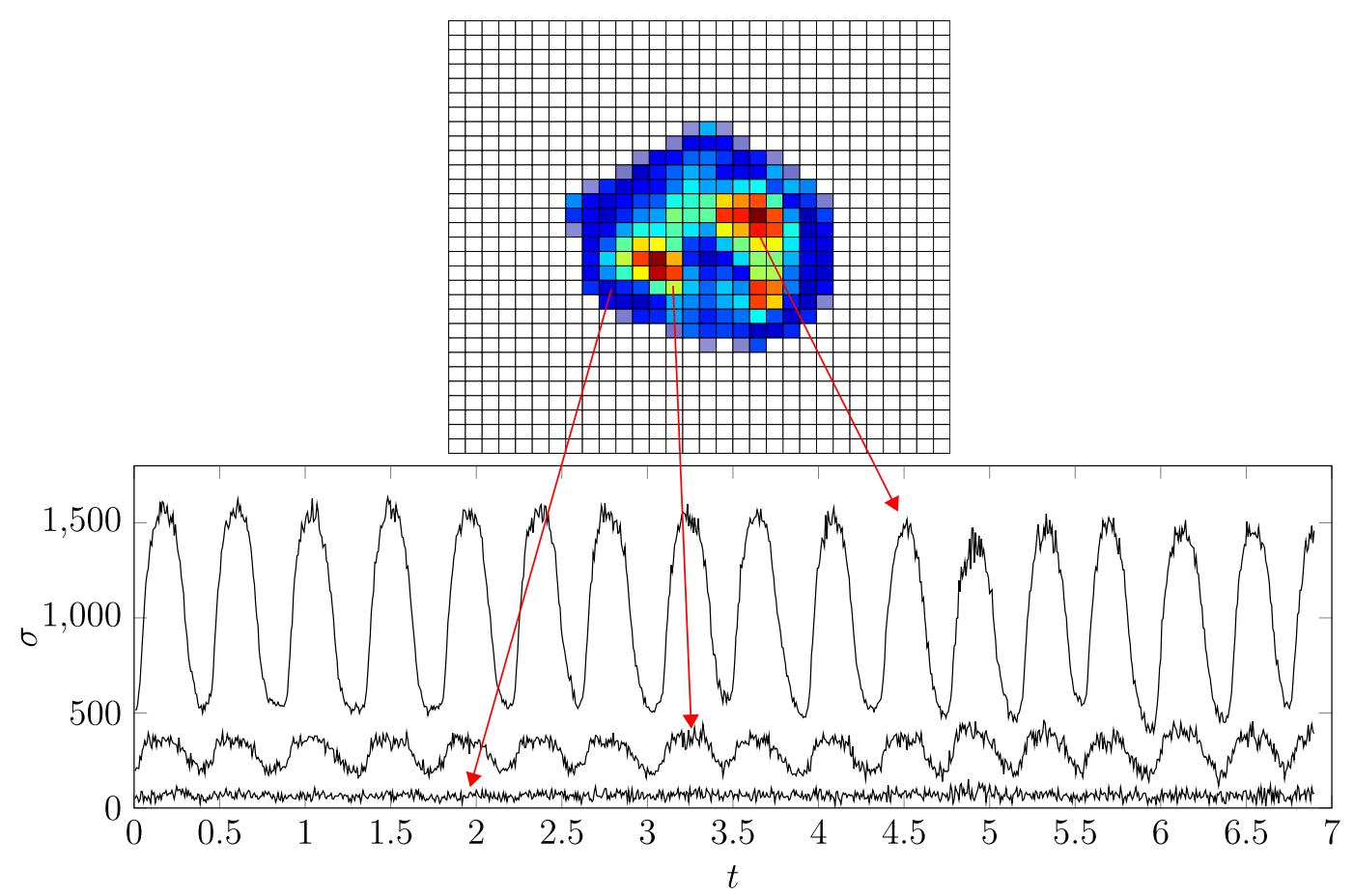

Figura 7.2: Conjunto de sinais de tensão (em pascal Pa) produzido por uma cardiomiócito neonato em três posições diferentes da célula, mostrado para $t=\frac{1}{145}, \frac{2}{145} \ldots \frac{1000}{145} s$, o sinal possui uma frequência $\omega \approx 2.3 \mathrm{hz}$. O valor $\frac{1}{145}$ corresponde ao intervalo entre duas imagens.

Portanto, as amostras são matrizes $\sigma(t, x, y)$ com os valores de tração provenientes aos 50 cardiomiócitos neonatais, onde cada cardiomiócito possui duas matrizes: $\sigma(t, x, y)$, correspondente ao valores de tração no estado basal da célula e $\sigma_{i s o}(t, x, y)$, correspondente 
ao valores de tração com a aplicação do isoproterenol na célula. Utilizando esse grupo de dados realizamos algumas análises sobre a dinâmica de contração cíclica dessas células.

\section{2 Área de Adesão Celular}

A área de adesão celular é a região onde a célula adere no substrato através de forças de actina-miosina e mediadas por integrina, a integrina adere ao colágeno presente no substrato elástico, mimetizando a rigidez do tecido, mas restringindo a célula em uma superfície, o que é distinto em um tecido, onde a célula esta restrita a um volume.

Mensuramos a área de adesão celular fazendo o calculo do número de pixeis que a célula aderida ocupa na imagem de constate de fase, sabendo o número de pixeis, fazemos a conversão de pixel para $\mu \mathrm{m}^{2}$ (usamos o valor $0,22 \mu \mathrm{m}^{2} /$ pixel que é definido pela câmera usada no experimento). Os valores de área obtidos diferem de célula para célula, portanto, verificamos a distribuição de áreas para o grupo de cardiomiócitos.

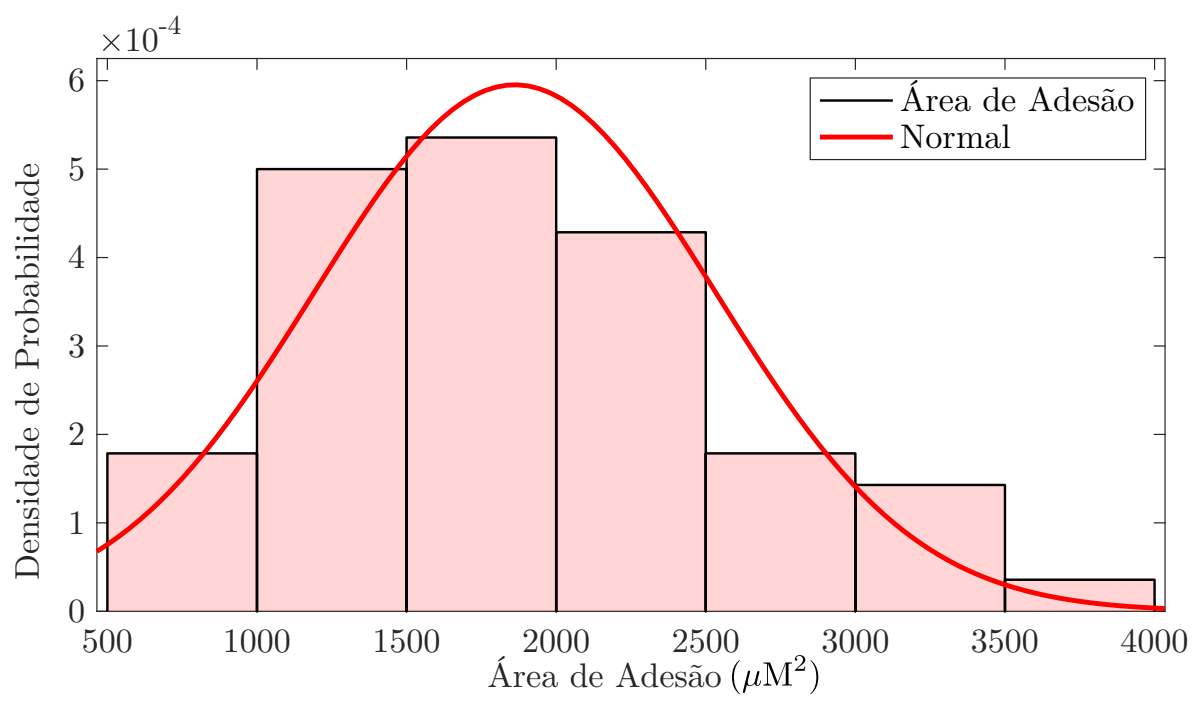

Figura 7.3: Densidade de probabilidade dos valores de área de adesão celular para o grupo de amostras $n=50$, temos seu ajuste normal, onde $\mu=1862 \mu \mathrm{m}^{2}$ e $\mathrm{s}=670.12 \mu \mathrm{m}^{2}$.

Na Figura 7.3 temos a densidade de probabilidade empírica das áreas de 50 células $(n=50)$, para o ajuste da distribuição empírica de área, usamos uma distribuição normal

$$
f(x)=\frac{1}{s \sqrt{2 \pi}} \mathrm{e}^{-\frac{1}{2}\left(\frac{x-\mu}{s}\right)^{2}}
$$

onde $x$ é a área, $\mu$ a média dos valores e $s$ o desvio padrão dos valores de área. 


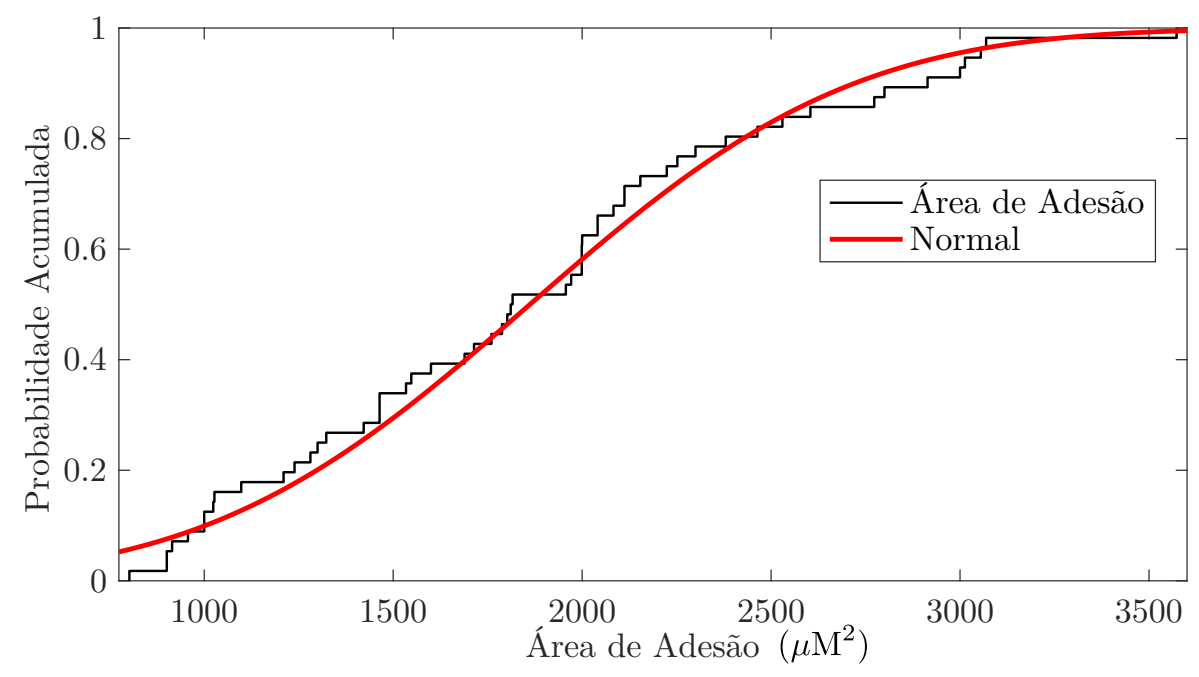

Figura 7.4: Probabilidade acumulada dos valores de área de adesão celular para o grupo de amostras $n=50$, além disso, temos seu respectivo ajuste normal.

Para visualizar o ajuste normal, geramos o gráfico de probabilidade acumulada das distribuições. A Figura 7.4 mostra as probabilidades acumuladas tanto da distribuição de áreas quanto da distribuição normal de ajuste. O ajuste mostra que a distribuição que mais se adequa aos valores de área de adesão celular é a distribuição normal com um valor médio de aproximadamente $1862 \mu \mathrm{m}^{2}$. Uma justificativa para que tenha essa distribuição é a aleatoriedade com que os cardiomiócitos são aderidos ao substrato, além disso a célula dispõe de certa quantidade de energia e volume para aderir mantendo pequenas flutuações de área porém aleatórias e consequentemente se distribuindo como uma distribuição normal.

\subsection{Tensão Média}

O mapa de tensão mostra um movimento oscilatório do valor de tensão ao longo do tempo, para cada posição da área de adesão celular, por esse motivo utilizamos o valor médio para representar a magnitude do valor de tensão por posição. Como exemplo, temos a Figura 7.5 que mostra o mapeamento dos valores médios de tensão em função da posição $\sigma(x, y)$ de alguns cardiomiócitos.

Analisando os mapas de tensão média para o grupo de amostras com $n=50$, verificamos que os valores médios são maiores em determinadas regiões e que estas se distribuem próximas as bordas das células. 

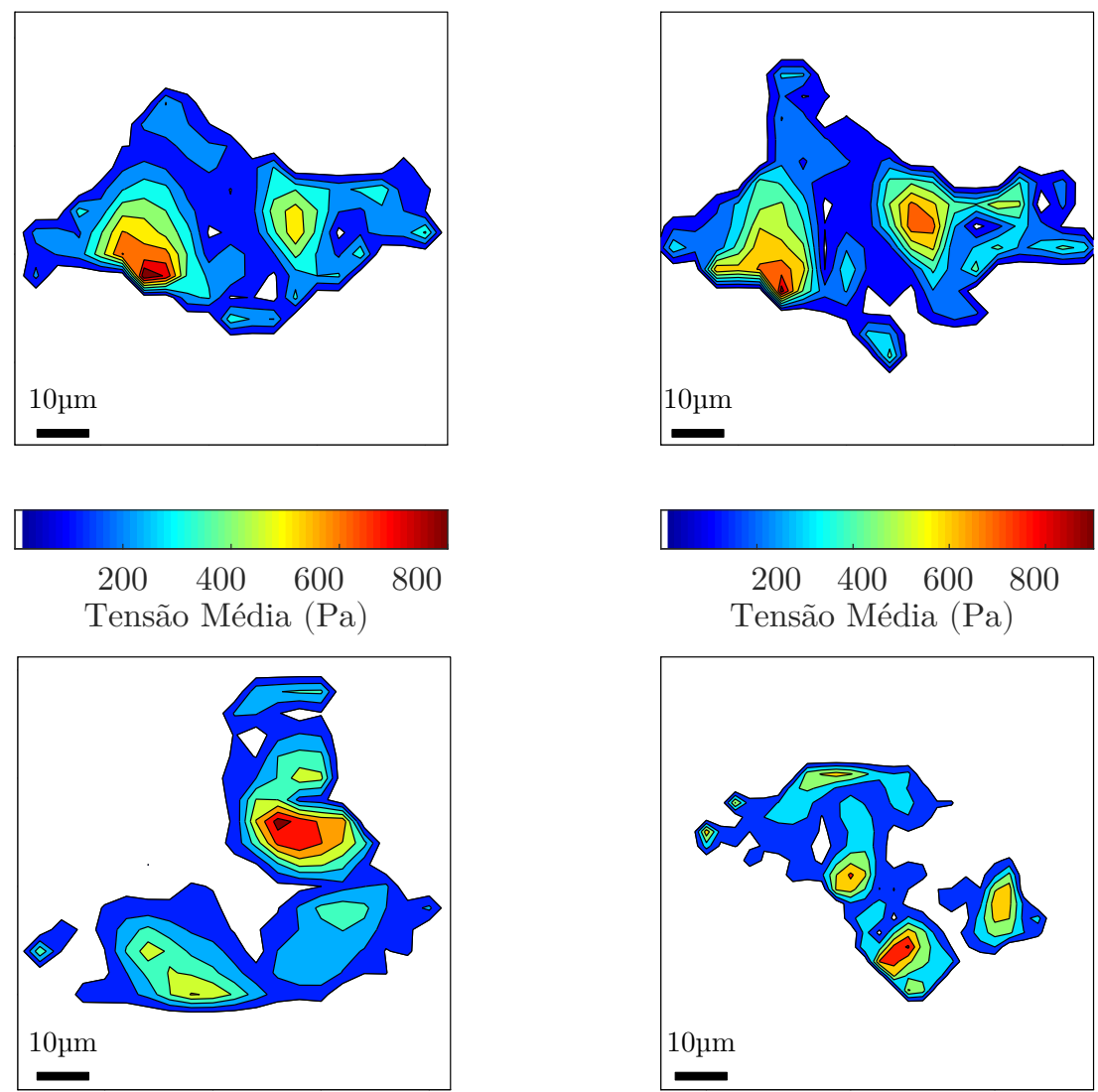

Tensão Média $(\mathrm{Pa})$
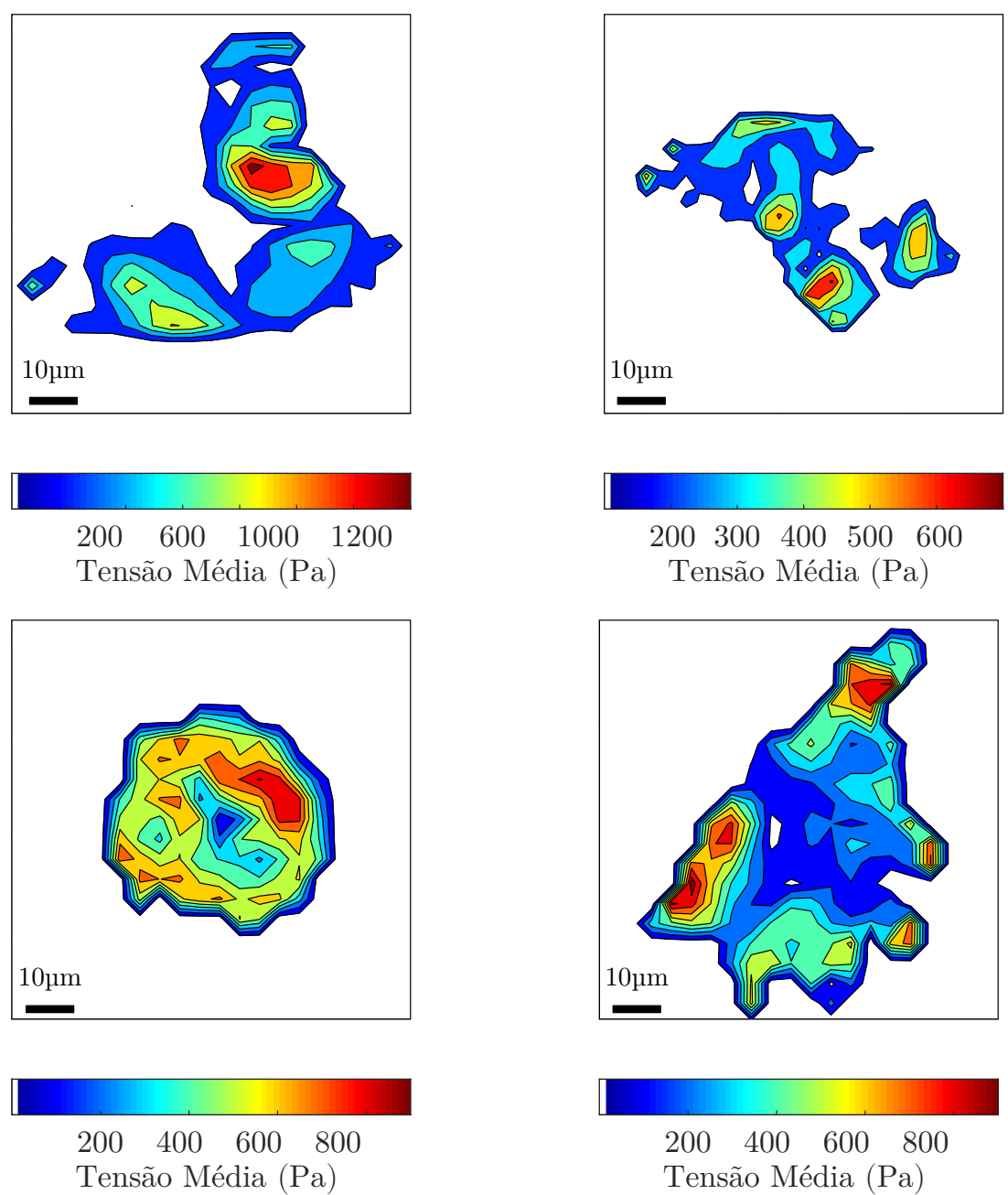

Figura 7.5: Gráficos do mapeamento da tensão media em função da posição, no gráfico temos como exemplo 6 cardiomiócitos neonatais, onde o gradiente de cores indica a intensidade do valor de tensão media. 
Para cada célula, separamos o sinal de $20 \mathrm{~s}$ em quatro sinais de $5 \mathrm{~s}$ e geramos o mapa de tensão média de cada intervalo de tempo, para observar uma possível variação da posição das regiões de alta tensão. O resultado foi uma permanecia dessas regiões entre os intervalos de tempos.

Quanto aos valores de tensão, sua magnitude é acima dos $1000 \mathrm{~Pa}$ nas regiões de alta tensão, esses valores decaem até 200 a 100 Pa no centro da célula. Nesse sentido, o mais provável é que os valores de alta tensão são adesões focais desenvolvidas, enquanto os valores de baixa tensão são adesões focais imaturas ou regiões não aderidas. As regiões de alta tensão se distribuem de forma discreta, apresentando de 2 a 5 regiões próximas as bordas de acordo com as amostras estudadas. A tensão varia de acordo com a posição.

Presumidamente, a célula executa a atividade contrátil de forma discreta e organizada nas bordas, dependente da suas condições iniciais de adesão, visto que não houve alterações significativas da distribuição das tensões na superfície de adesão.

\subsection{Amplitude de Contração}

Um dos parâmetros utilizados no estudo do sinal mecânico dos cardiomiócitos é a amplitude de contração, ela representa a variação entre o maior $\sigma_{M a x}(t)$ e o menor $\sigma_{M i m}(t)$ valor de tensão durante um ciclo de tempo $t$, ou seja:

$$
A=\sigma_{M a x}(t)-\sigma_{M i m}(t)
$$

A amplitude mostra o quanto de força ou energia a célula esta gastando para manter a contração durante o ciclo em específico. Para o estudo dos cardiomiócitos utilizando a amplitude, calculamos os seus valores para cada posição $(x, y)$ da área de adesão celular e mapeamos os seus valores. Como exemplo, temos a Figura 7.6 que mostra o mapeamento dos valores de amplitude em função da posição $A(x, y)$ de alguns cardiomiócitos.

Analisamos os mapas de amplitude para o grupo de amostras com $n=50$, verificamos que os valores de amplitude são maiores na regiões de adesão focal e que estas se distribuem próximas as bordas das células. As regiões de grande amplitude se distribuem de forma discreta, apresentando de 2 a 5 regiões próximas as bordas de acordo com as amostras estudadas. Esse resultado corrobora com o resultado anterior que a célula executa a atividade contrátil de forma discreta e organizada nas bordas. Sendo que o resultado ante- 

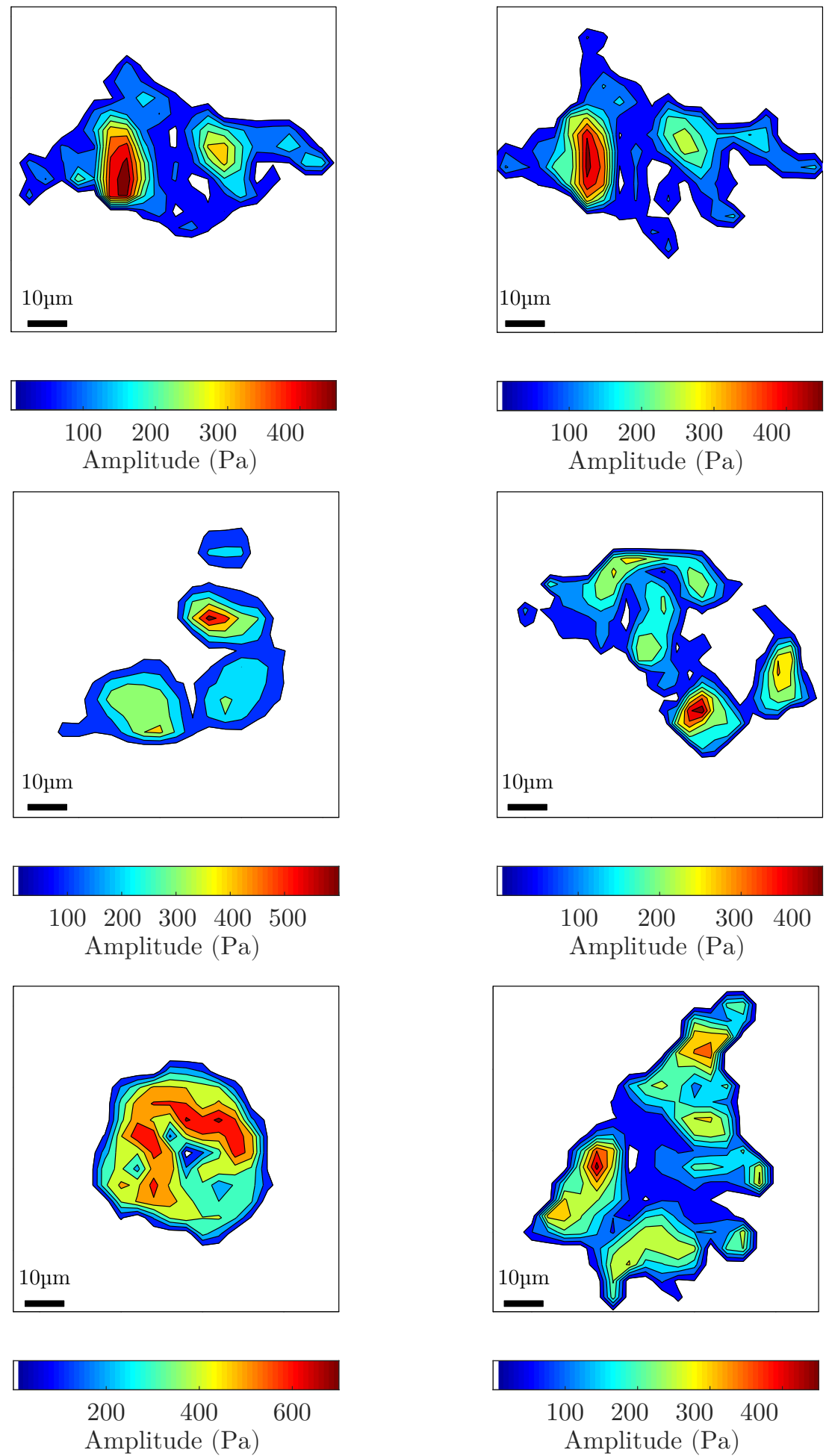

Figura 7.6: Gráficos do mapeamento da amplitude de contração em função da posição, no gráfico temos como exemplo 6 cardiomiócitos neonatais, onde o gradiente de cores indica a intensidade do valor da amplitude de contração. 
rior é uma consequência deste resultado. Mostrando que mecanicamente, o cardiomiócito possui uma atividade contrátil discreta em regiões ao longo da sua borda e que esse é o padrão de adesão em superfícies mimetizadas. Essas superfícies elásticas, que apesar de serem limitadas a vínculos mecânicos em duas dimensões, garante a permanência das adesões focais e da atividade contrátil destas células, com a possibilidade de obter o sinal de output mecânico de contração.

Em resumo, o resultado mostra onde a célula gasta energia para executar especificamente a atividade de contração, esta por sua vez esta distribuída em determinadas regiões, geralmente ao longo da borda devido condições iniciais de adesão.

\subsection{Distribuição das Amplitudes}

A amplitude varia de acordo com a posição $(x, y)$, indicando uma distribuição. Diante dessa observação, uma das abordagens para o estudo das propriedades mecânicas dos cardiomiócitos, é o estudo das distribuições de probabilidade das amplitudes de contração. Nesse aspecto, obtivemos as distribuição de valores de amplitude das células enquanto estavam aderidas ao substrato.

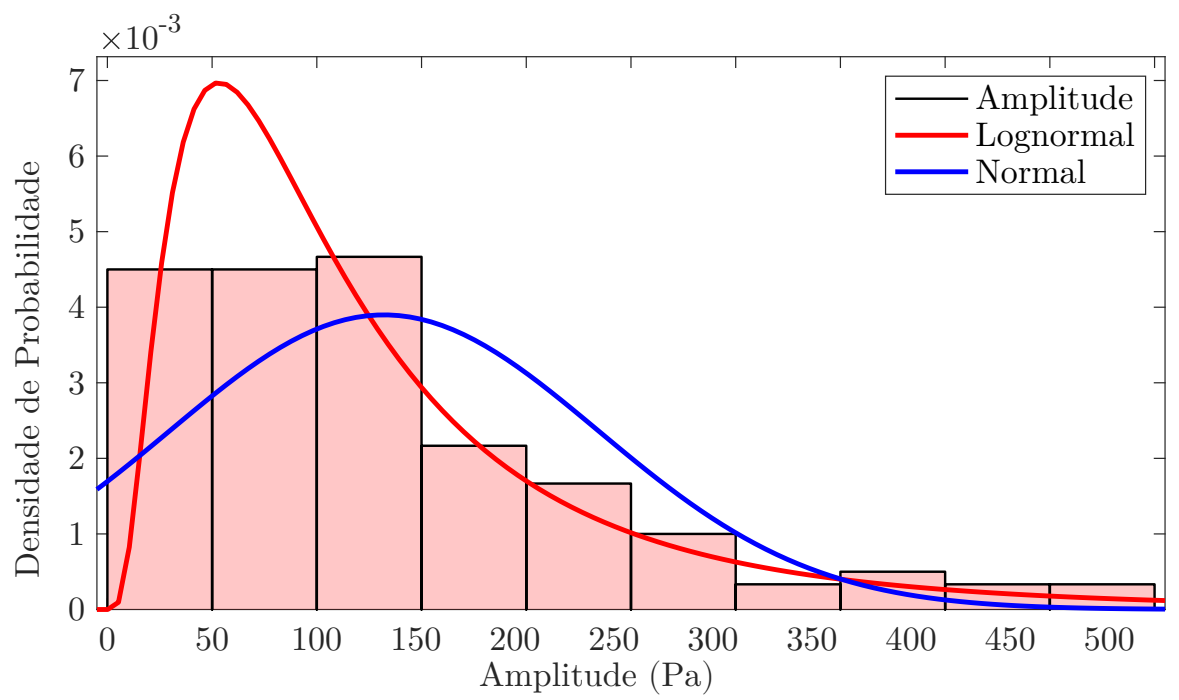

Figura 7.7: Densidade de probabilidade dos valores de amplitude de contração para uma única célula com amplitudes de até $500 \mathrm{~Pa}$, onde temos um ajuste normal sobreposto com um ajuste log-normal.

Analisamos as distribuições de amplitude para o grupo de amostras com $n=50$, cada distribuição correspondente aos valores de amplitude de um único cardiomiócito. Essa distribuição empírica foi comparada com distribuições teóricas conhecidas, dentre essas 


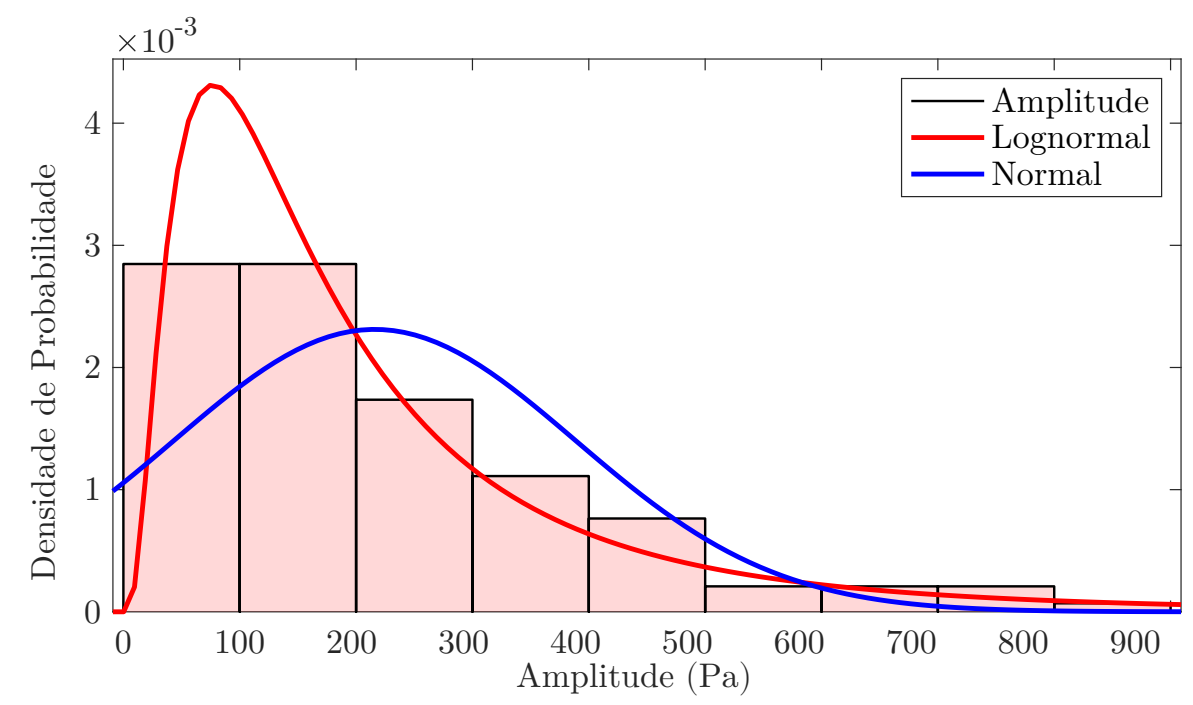

Figura 7.8: Densidade de probabilidade dos valores de amplitude de contração para uma única célula com amplitudes de até $900 \mathrm{~Pa}$, onde temos um ajuste normal sobreposto com um ajuste log-normal.

fizemos o ajuste dos dados. Nas Figuras 7.7 e 7.8, temos a distribuições empíricas das amplitudes de duas células do grupo de amostras. Para o ajuste das distribuições, foi utilizado a distribuição log-normal, sendo esta a que melhor se ajustou as amostras.

$$
f(x ; \mu, s)=\frac{1}{x s \sqrt{2 \pi}} \exp \left[-\frac{(\ln (x)-\mu)^{2}}{2 s^{2}}\right]
$$

Para visualizar o ajuste log-normal, geramos o gráfico de probabilidade acumulada das distribuições. As Figuras 7.7 e 7.8, mostra as probabilidades acumuladas tanto da distribuição das amplitudes quanto da distribuição log-normal de ajuste.

O ajuste mostra que a distribuição que mais se adequa aos valores de amplitude de contração é a distribuição log-normal com um valor médio de aproximadamente 350 Pa. Uma justificativa para que tenha essa distribuição é a aleatoriedade com que os uma grande parte das amplitudes dos cardiomiócitos se distribuem, entretanto existe uma pequena parte significativa que gera assimetria a direita, característica da distribuição log-normal, além disso a célula dispõe de certa quantidade de energia e volume para aderir, mantendo pequenas flutuações de área, porém aleatórias e consequentemente se distribuindo como uma distribuição log-normal.

Eles indicam que existe variabilidade na distribuição das trações, entretanto são distribuições especificas. A maior parte dos valores de $\bar{\sigma}(x, y)$ calculados encontra-se abaixo dos $400 \mathrm{~Pa}$, enquanto uma pequena parte correspondem aos valores acima dos $1000 \mathrm{~Pa}$. 


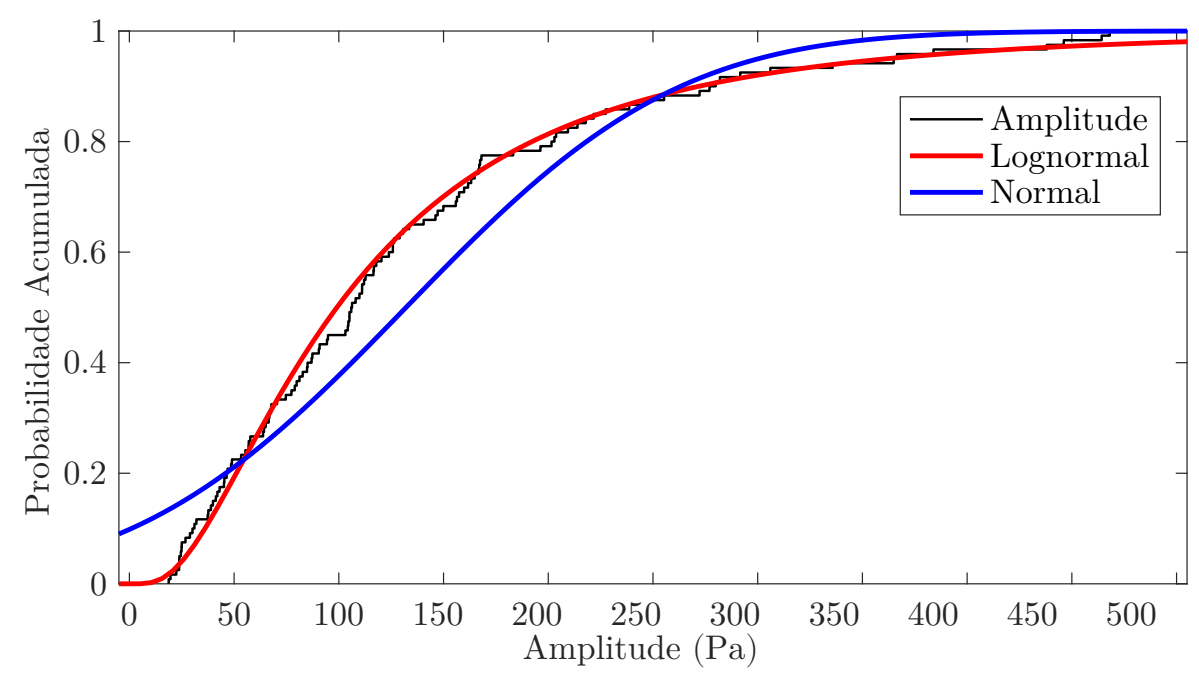

Figura 7.9: Probabilidade acumulada dos valores de amplitude de contração para uma única célula com amplitudes de até $500 \mathrm{~Pa}$, onde temos um ajuste normal sobreposto com um ajuste log-normal.

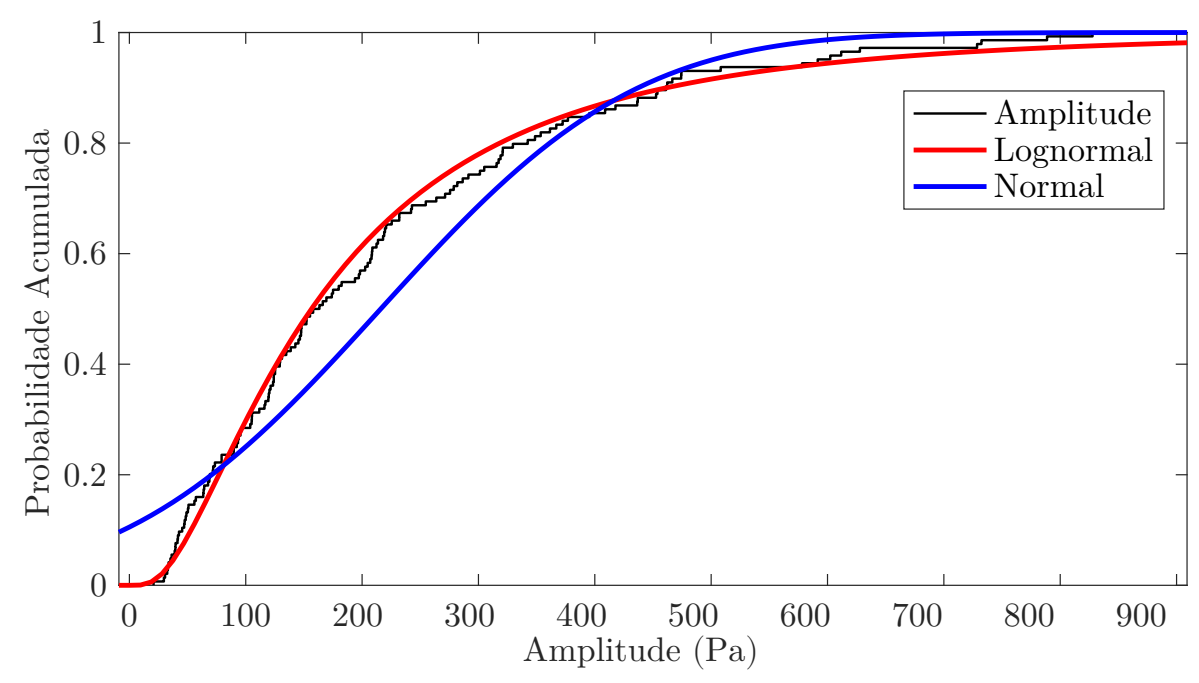

Figura 7.10: Probabilidade acumulada dos valores de amplitude de contração para uma única célula com amplitudes de até $900 \mathrm{~Pa}$, onde temos um ajuste normal sobreposto com um ajuste log-normal.

Isso significa que durante a contração cíclica das células, em boa parte da área de adesão celular, as tensões aplicadas não são significativas enquanto em uma região especifica ocorre tensão efetivas de resposta da célula a rigidez do substrato. 


\subsection{Grau de Correlação}

O grau de correlação como descrito no capítulo 5, mostra o quanto um sinal de determinada posição e semelhante com os demais, fazendo uma analogia com o numero de ligações de determinado nó, onde o critério para a conectividade é o coeficiente de correlação. No caso dos cardiomiócitos, as regiões de maior grau de correlação são as que possuem maior atividade contrátil, não necessariamente as regiões que possuem maiores valores de tensão. Entretanto, considerando o fato de que o sinal de contração é gerado pelas regiões de adesão focal, a correlação nessas posições em especifico serão maiores.

Para quantificar o grau de correlação em cada ponto $(x, y)$, vamos usar o coeficiente de correlação $C_{\rho}(x, y)$ (ver capítulo 5 ), onde o limiar de correlação agora é $\rho \geq 0.99$. Se $C_{\rho}(x, y)=60 \%$, significa por exemplo, que a contração nesse ponto esta fortemente correlacionada com $60 \%$ da área total de adesão celular. Alem disso, foi utilizado um critério para decidir quais posições $(x, y)$ serão analisadas. Se o valor ser $\bar{\sigma}(x, y) \geq 50 \mathrm{~Pa}$, o valor de $C_{\rho}(x, y)$ é contabilizado no mapa, se o valor for $\bar{\sigma}(x, y)<50 \mathrm{~Pa}, C_{\rho}(x, y)=0$. O critério é usado para diferenciar a área de adesão celular com atividade contrátil e agilizar o calculo numérico. Essa regra é utilizada poprque nem toda posição possui atividade contrátil, e portanto, não possuindo quaisquer correlação com as outras regiões. Como exemplo, temos a Figura 7.11 que mostra o mapeamento dos valores de correlação em função da posição $\sigma(x, y)$ de alguns cardiomiócitos.

Analisados os mapas de correlação para o grupo de amostras com $n=50$, verificamos que os seus valores são maiores na regiões de adesão focal e que estas se distribuem próximas as bordas das células. As regiões de grande correlação também se distribuem de forma discreta, apresentando de 2 a 5 regiões próximas as bordas de acordo com as amostras estudadas.

O resultado mostra que as regiões com alta correlação coincide com as regiões de maior atividade contrátil. Além disso, temos o fato de que todos os sinais mecânicos produzidos pela célula possuem a mesma frequência, mas alterando a amplitude do sinal com a posição, dessa maneira podemos presumir que a célula possui duas regiões distintas do ponto de vista mecânico. 

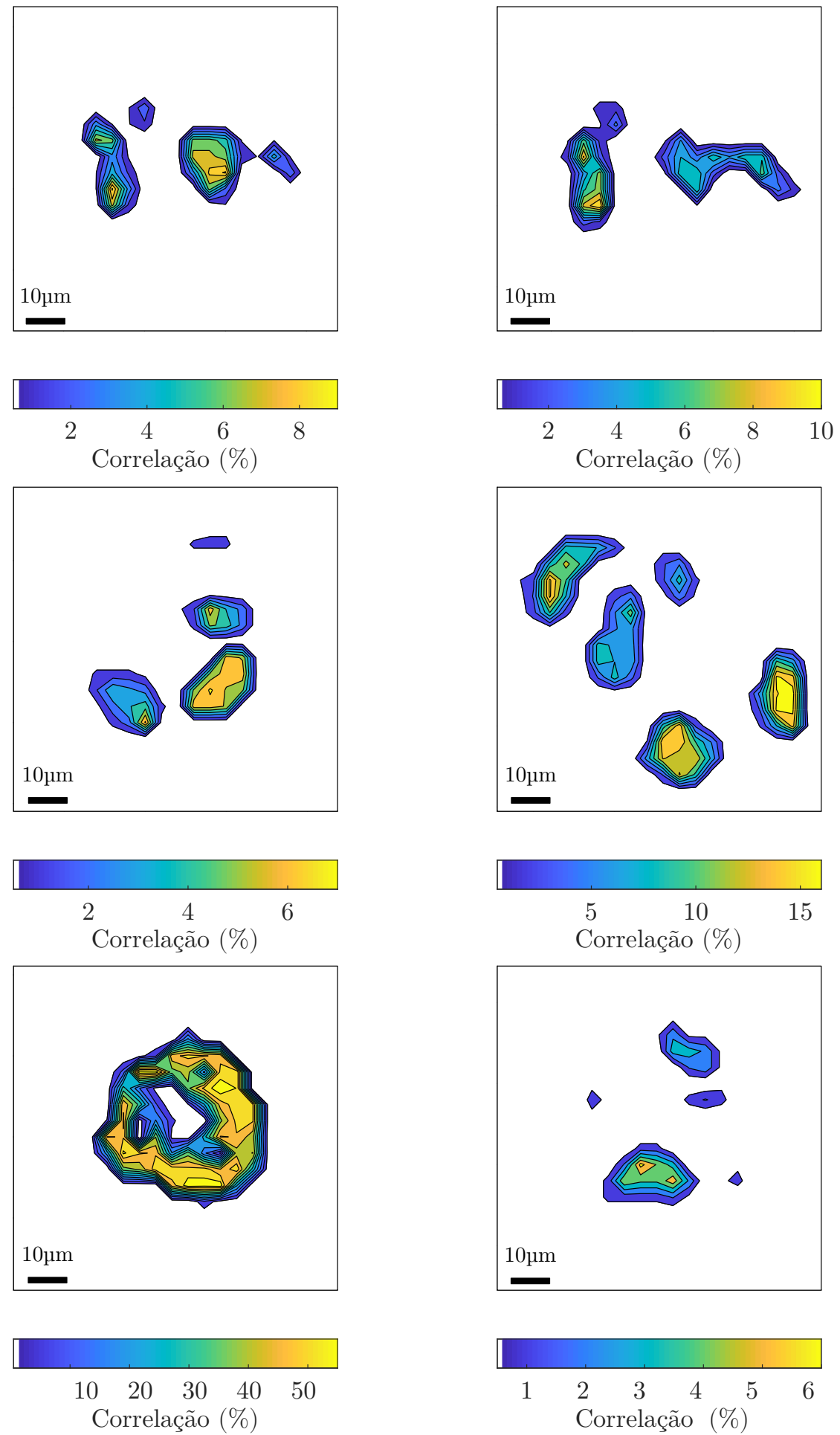

Figura 7.11: Gráficos do mapeamento do grau de correlação em função da posição, no gráfico temos como exemplo 6 cardiomiócitos neonatais, onde o gradiente de cores indica a intensidade do valor do grau de correlação. 
A região primeira corresponde a sinais de baixa amplitude e consequentemente baixa correlação, onde as tensões geradas são provenientes de adesões focais imaturas ou efeito de amortecimento das regiões de alta amplitude. A segunda região é provavelmente onde as fibras de tensão estão fixadas e consequentemente existe uma maior atividade contrátil e maior correlação, visto que os sinais mecânicos dessa região também possuem a mesma frequência.

Apesar de serem regiões de maior atividade contrátil, e significativamente importante para a atividade mecânica da célula, elas possuem valores discretos, apresentando em determinados pontos ao longo da borda e em menor quantidade quando comparado com a região de baixa atividade contrátil. Essa característica foi observada em praticamente todas as amostras usadas ao longo do trabalho.

Quanto a magnitude dos valores de correlação $\rho \geq 0.99$, na maioria dos caso encontramos baixas porcentagens de correlação algo em torno de 5\% a 15\%, em poucos caso esses valores são maiores, como o exemplo da Figura 7.11 onde uma das células alcança uma porcentagem de $50 \%$.

Em resumo, o resultado mostra onde a célula gasta energia para executar especificamente a atividade de contração, esta por sua vez esta distribuída em determinadas regiões de forma sincronizada com os demais sinais, geralmente ao longo da borda devido condições iniciais de adesão. E que superfícies mimetizadas produzidas com gel de poliacrilamida conseguem induzir mecanicamente cardiomiócitos neonatais a gerar um sinal output mecânico de contração cíclica de forma discreta e sincronizada nas adesões focais.

\subsection{Orientação das Tensões}

Além da magnitude das tensões aplicadas pelos cardiomiócitos é possível determinar a direção e o sentido destas em cada posição da área de adesão celular. A orientação do vetor de tensão é calculado usando a seguinte expressão: $\tan (\theta)=\frac{\sigma_{y}(t)}{\sigma_{x}(t)}$. Entretanto o valor de $\theta$ pode variar no tempo pelo fato de tanto $\sigma_{y}(t)$ quanto $\sigma_{x}(t)$ serem dependentes do tempo. Diante desta possibilidade, determinamos o campo vetorial das tensões aplicadas pelos cardiomiócitos amostrados.

A Figura 7.13 mostra o campo vetorial durante o máximo valor de tensão de alguns cardiomiócitos. Foi sobreposto curvas de nível, correspondentes aos valores de correlação 
para verificar a relação entre as regiões de alta atividade contráctil e a orientação das principais tensões (tensões de maior magnitude). A Figura 7.13 mostra a mudança do campo vetorial em diferentes instantes tempo do ciclo de contração, comparando os diferentes campos vetoriais.

Como resultado, os vetores de tensão se orientam para dentro do corpo da célula, onde nas principais tensões surgem das regiões de maior atividade contráctil. Verificamos que ao longo do ciclo de contração, os valores de $\theta$ têm pequenas flutuações ( $\Delta \theta \approx \frac{\pi}{18} \mathrm{rad}$ ) nas regiões de maior atividade contráctil ou adesões focais, mas esses os vetores de tensão não mudavam de sentido durante todo o ciclo.

Nesse aspecto, as células possuem uma orientação definida. Além disso, observamos que os vetores de tensão das adesões focais em grande parte, estão alinhas entre se.

Com base nesses resultados, temos a evidencia que após a maturação das adesões durante o processo de adesão da célula ao substrato, os cardiomiócitos mantem uma orientação definida das principais tensões (tensões da adesão focal) ao longo do ciclo contráctil, alterando apenas o valor de magnitude das tensões $\sigma(t)=\sqrt{\sigma_{x}(t)^{2}+\sigma_{y}(t)^{2}}$.

A Figura 7.13 mostra um desenho esquemático desta dinâmica durante o ciclo, em cada posição no ciclo (A, B, C) temos uma configuração diferente dos campo de tensão, entretanto a orientação das principais tensões não alterou de maneira significativa durante o ciclo, as tensões de baixa magnitude possuem uma alternação da orientação expressiva e até uma mudança no sentido.

Uma Justificativa para esse resultado é que nas adesões focais existe uma atividade contráctil unidirecional promovida pela fibras de tensão, elas contraem para dentro da área celular. Nas tensões de baixa magnitude temos a predominância de ruído o que provoca uma mudança aleatória na sua orientação.

Os resultados apresentados até agora possuem como característica parâmetros mecânicos dependente da posição $(x, y)$. Quanto as orientações nas regiões de alta amplitude, evidenciamos um comportamento multipolar, caracterizando uma anisotropia do campo de tensão dessas células. 

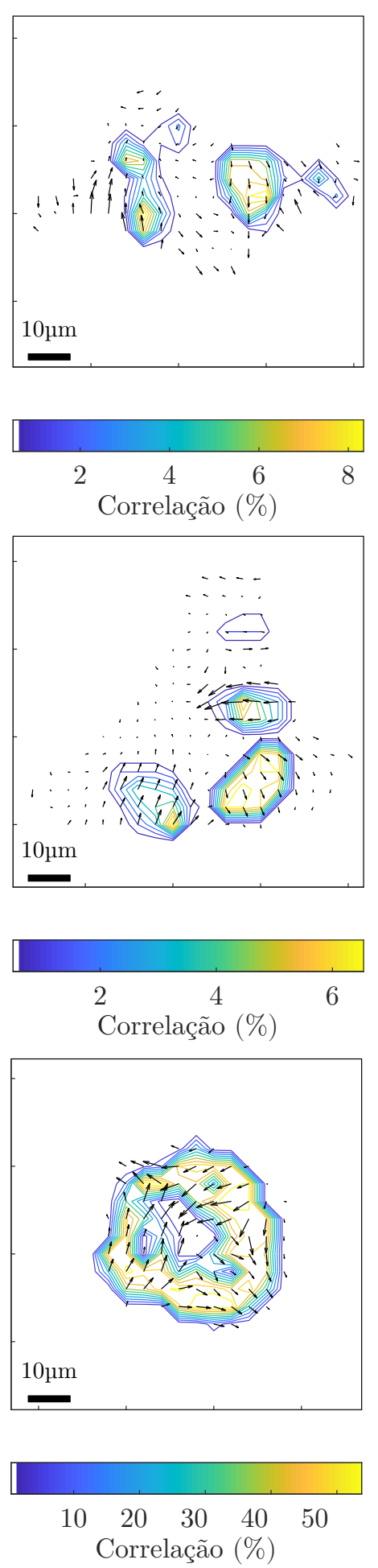
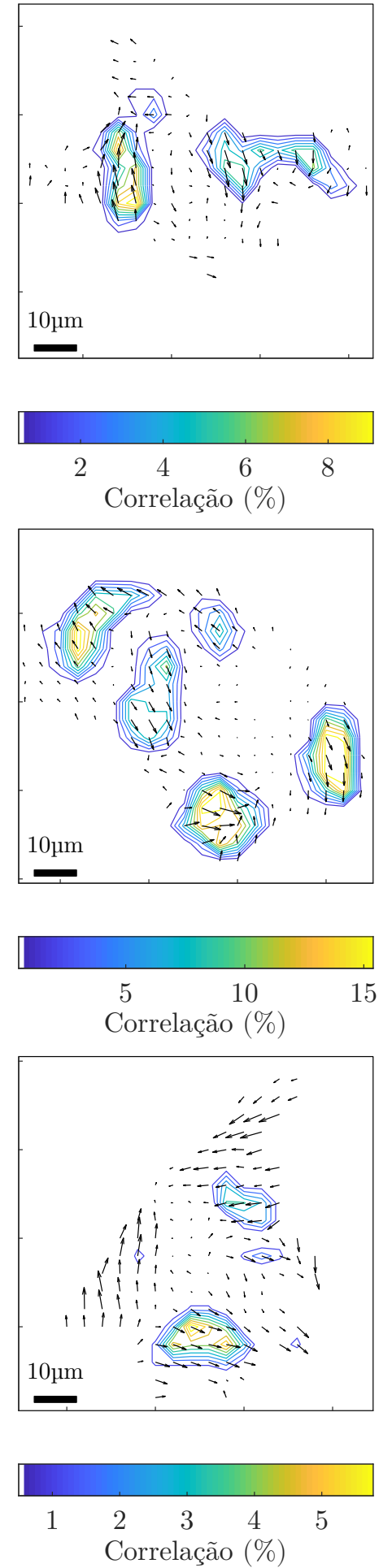

Figura 7.12: Gráficos do campo de tensão sobreposto com as curvas de nível de correlação, no gráfico temos como exemplo 6 cardiomiócitos neonatais, onde o gradiente de cores das curvas indica a intensidade do valor do grau de correlação. 

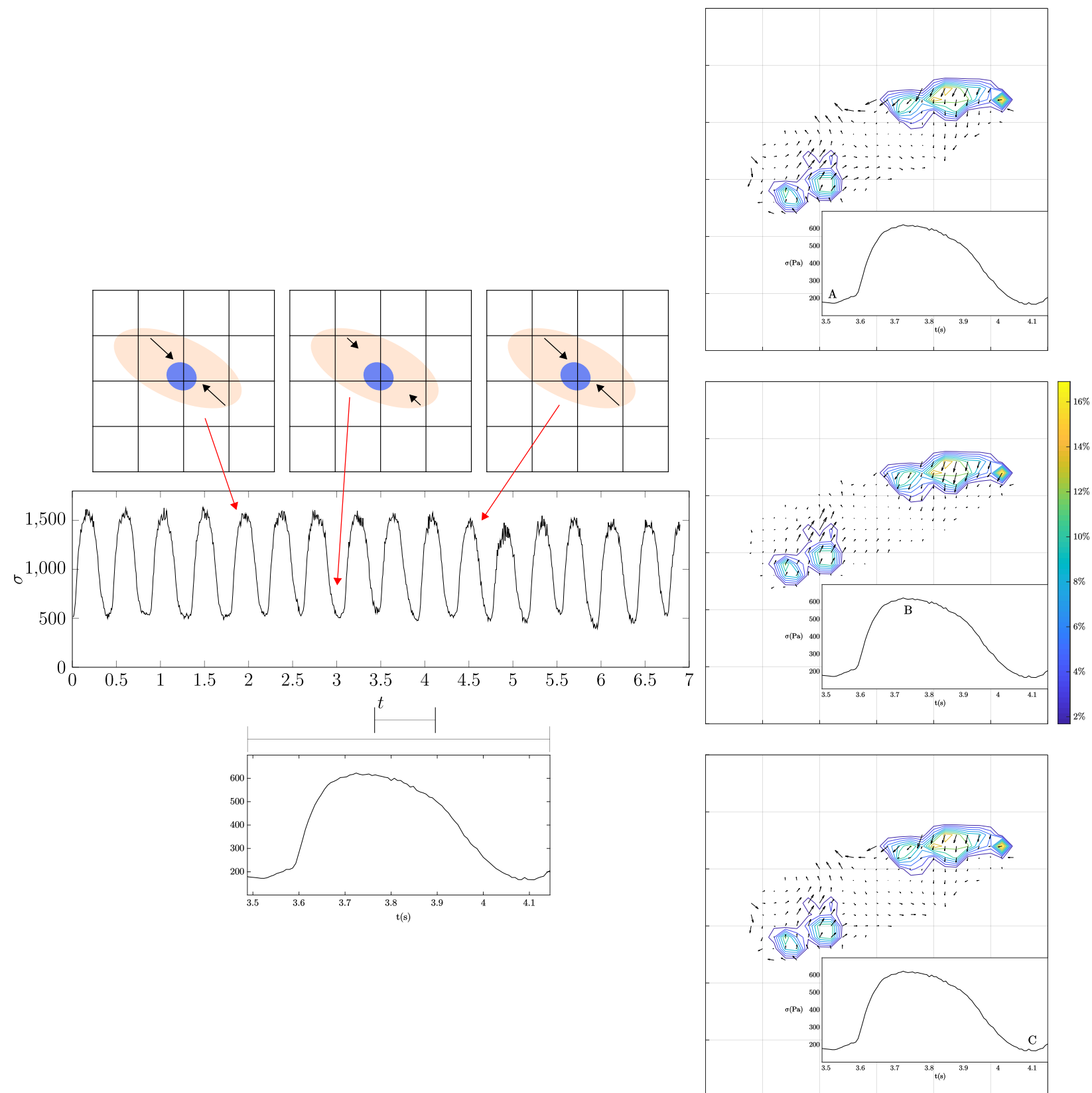

Figura 7.13: Gráficos do campo de tensão sobreposto com as curvas de nível de correlação para varias etapas do ciclo, no gráfico temos como exemplo um único cardiomiócito neonatal, onde o gradiente de cores das curvas indica a intensidade do valor do grau de correlação. 


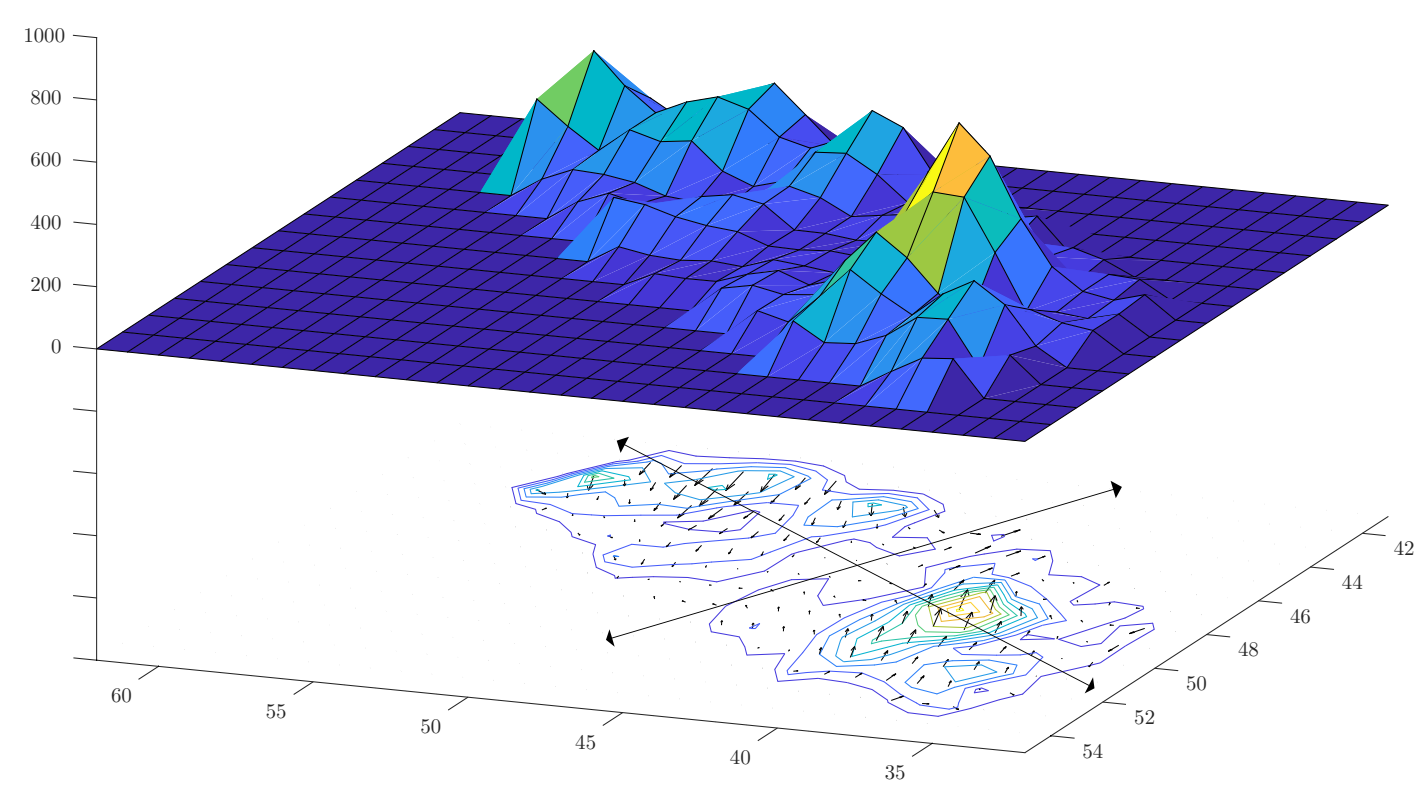

Figura 7.14: Gráfico da tensão média em conjunto com as curvas de nível de correlação, a tensão média esta no eixo z do gráfico enquanto no plano xy temos a posição, este gráfico esta em conjunto com as curvas de nível de correlação e orientação das tensões aplicadas. 


\subsection{Análise dos Sinais de Contração Cíclica}

Uma das abordagens utilizadas para o estudo da mecânica dos cardiomiócitos, foi a análise dos sinais de resposta mecânica dos cardiomiócitos, quando estes estavam aderidos em uma superfície mimetizada. Basicamente foi obtido o sinal de tensão em função do tempo do grupo de amostras descrito anteriormente, usando a Microscopia de Força e Tração TFM. O valor de tensão em função do tempo $\sigma(t)$ é calculado da seguinte forma:

$$
\sigma(t)=\sigma_{x, y}(t)=\sqrt{\sigma_{x}(t)^{2}+\sigma_{y}(t)^{2}}
$$

onde $\sigma_{x}(t)$ e $\sigma_{y}(t)$ são as componentes da tensão aplicadas no substrato, o sinal corresponde a contração cíclica da célula ao longo do tempo.

A Figura 7.15 mostra um desses sinais gerados, onde o valor de tensão $\sigma(t)$ é dependente do tempo $t$, destacamos a forma do ciclo ampliada nesta Figura.
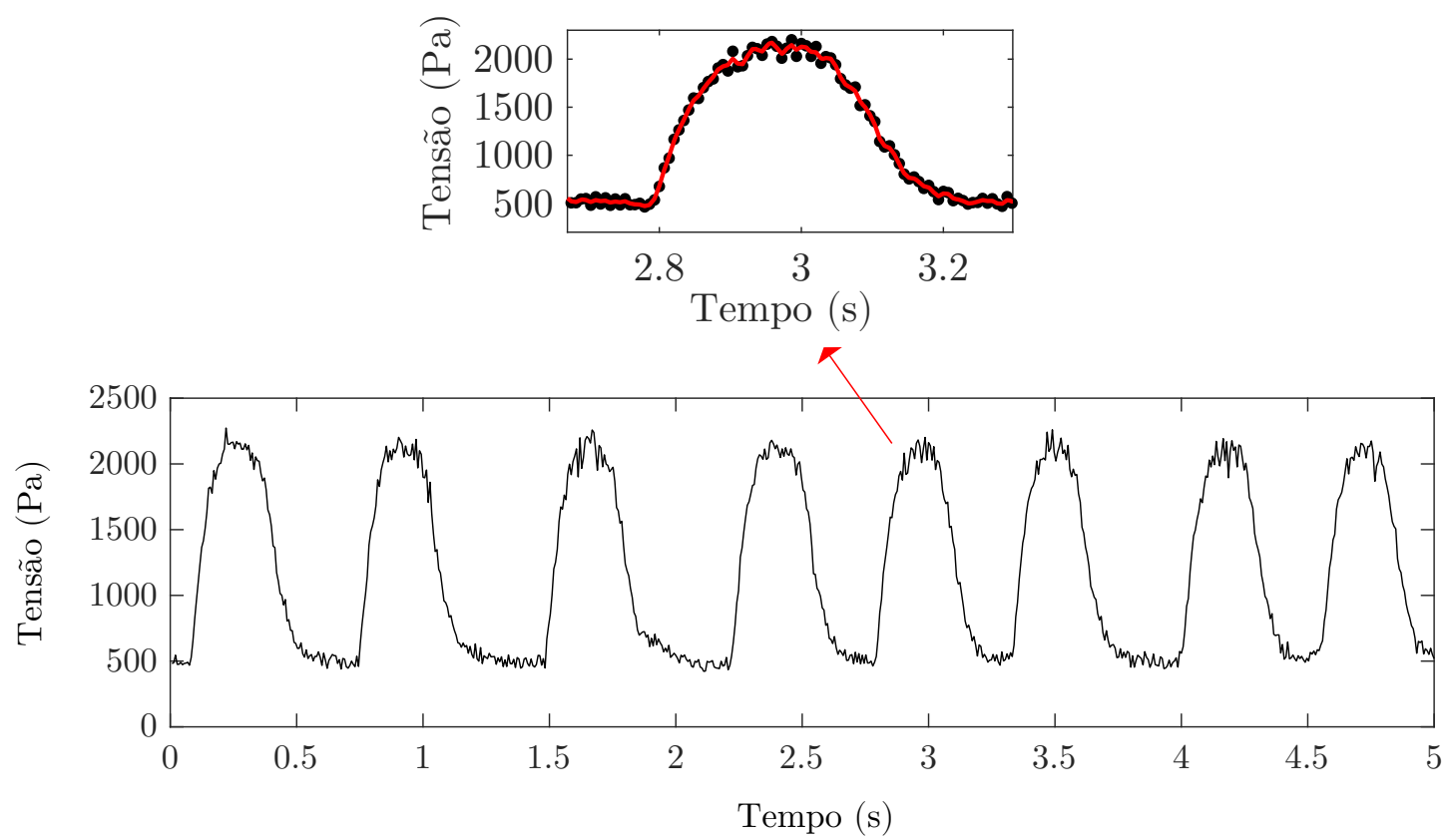

Figura 7.15: Gráfico do sinal de tensão ao longo do tempo de um cardiomiócito, mostrando a variação da tensão em um intervalo de 5 segundo a frequência do sinal foi estimada em 1,03 hz. Destacamos uma parte do sinal para mostrar a sua forma.

Inicialmente fizemos uma análise espectral do sinal de tensão dos cardiomiócitos em estado basal e com estímulo químico, utilizando a transformada de wavelet em conjunto com o periodograma de lomb. A transformada de wavelet é usada para detectar possíveis alterações no sinal ao longo do tempo, dessa forma podemos observar como o sinal de 
tensão se comporta ao longo do tempo, caso houve quaisquer alteração no sinal, seja ela na forma, frequência ou amplitude do ciclo.

Os escalogramas de wavelet dos sinais de tensão (utilizando a função de molet), mostraram que não houve alterações na forma do ciclo, frequência efetiva e nem amplitude de contração no cardiomiócitos do grupo de amostras como podemos observar em dois exemplos das Figuras 7.16 e 7.17 .

Por esse motivo se torna valido a aplicação do periodograma de lomb mesmo com possíveis flutuações no tempo de contração, sendo que a frequência e a forma do sinal permanecem a mesmas.
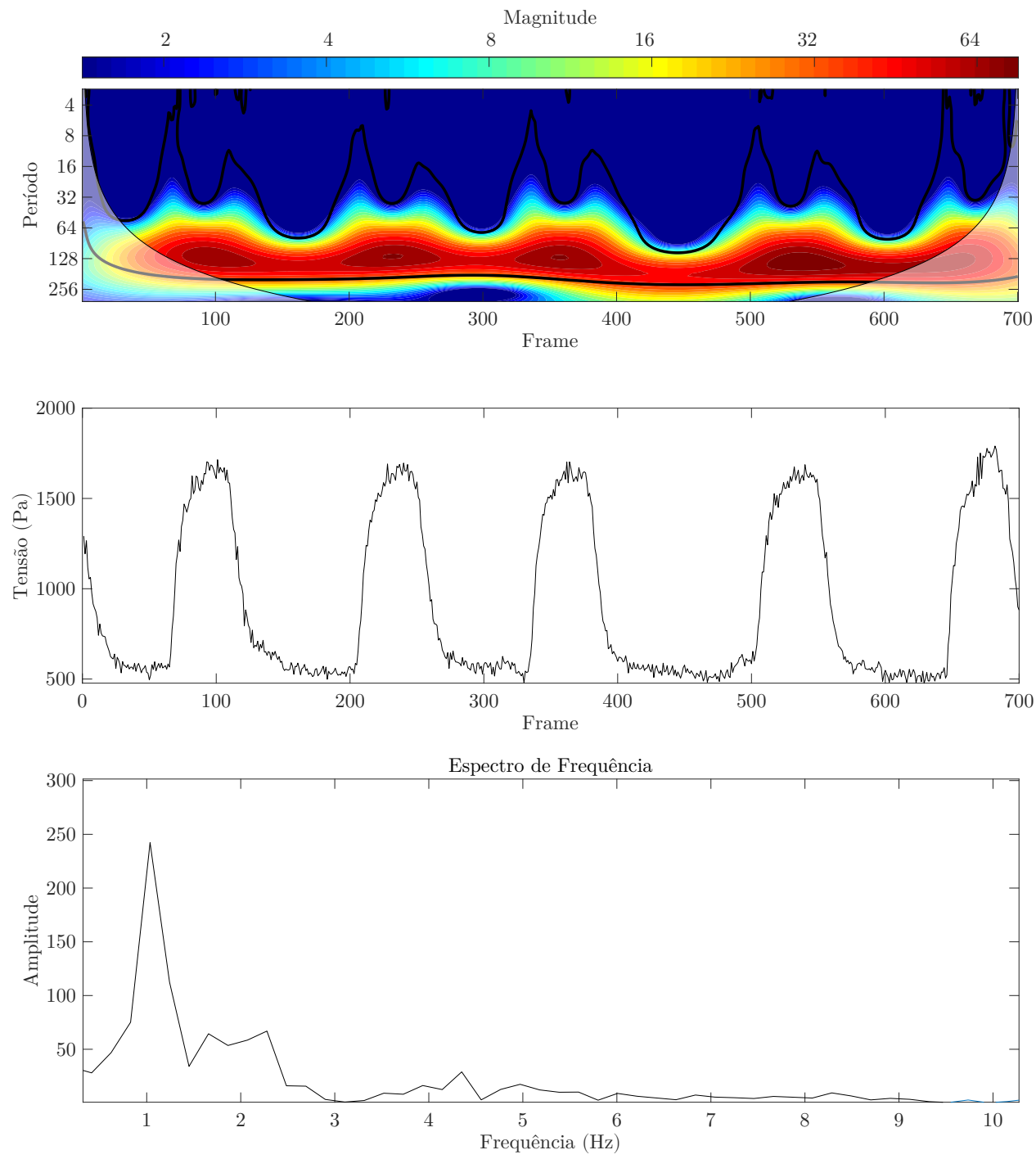

Figura 7.16: Transformada de Wavelet (em cima) e Periodograma de Lomb (em baixo) aplicados em conjunto em um sinal de tensão (no centro) de um cardiomiócito no estado basal, sendo possível determinar a sua alternação na forma e frequência ao longo do tempo, no caso a frequência foi estimada em $1,03 \mathrm{~Hz}$. 
Figuras 7.16 e 7.17 mostram dois exemplos da analise de sinais de tensão, onde foi obtido a transformada de wavelet em conjunto com o periodograma de lomb de dois sinais de tensão com frequências distintas. O sinal da Figura 7.16 possui uma frequência de 1,03 hz, o sinal da Figura 7.16 possui uma frequência de 2,48 hz, ambos verificados pelo periodograma e pela transformada de wavelet sendo que neste caso é a frequência dividido por 145, que corresponde ou fps (frames por segundo) da câmera durante o experimento. Foram calculados todos os valores de frequência do grupo de amostras $n=50$ no estado basal e com estímulo, cujo resultado será explanado posteriormente.
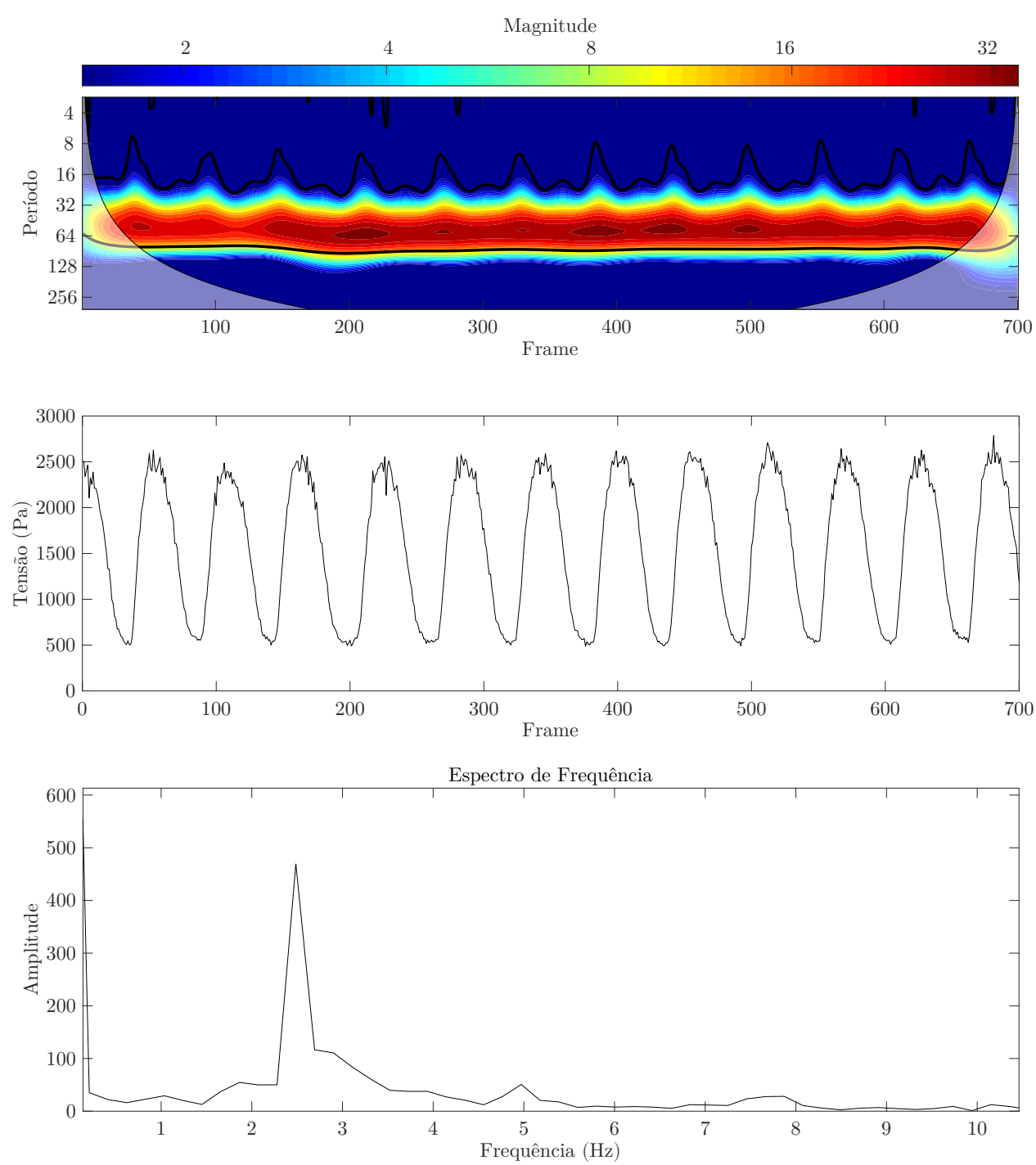

Figura 7.17: Transformada de Wavelet (em cima) e Periodograma de Lomb (em baixo) aplicados em conjunto em um sinal de tensão (no centro) de um cardiomiócito no estado basal, sendo possível determinar a sua alternação na forma e frequência ao longo do tempo, no caso a frequência foi estimada em $2,48 \mathrm{~Hz}$ 
O fato do sinal de tensão manter a sua forma, além de ter uma amplitude constante ao longo do tempo é uma evidência importante para a validação de cardiomiócitos neonatais isolados como possíveis modelos in vitro do tecido ou órgão cardíaco, visto que essas células possuem um comportamento definido (possibilitando a caracterização) e uma amplitude constate sendo que apesar de ter uma frequência característica, esta pode variar de acordo com o estímulo.

Esse resultado mostra que a resposta mecânica dos cardiomiócitos ao microambiente celular onde eles foram cultivados é bem definida, pois mantêm a sua forma de oscilação ao longo do tempo. Esta forma de oscilação caracteriza a resposta mecânica dessas células ao microambiente celular mimetizado.

Tendo em vista que o sinal mecânico possui uma estabilidade ao longo do tempo, fizemos o estudo destes sinais quanto a tensão e a variação de tensão do grupo de amostra, verificado para diferentes valores de frequência apresentados pelos cardiomiócitos. A resolução do sinal é de 145 imagens por segundo ou 145 fps, isso significa que o tempo entre um frame a outro é de aproximadamente $7 \mathrm{~ms}$, essa alta resolução é importante para estudamos a forma do sinal.

A Figura 7.18 mostra um conjunto de sinais correspondente a quatro células distintas do grupo de amostra, os sinais possuem frequências diferentes. O valor de tensão em função do tempo $\sigma(t)$, além disso os sinais da Figura 7.18 são gerados pelas regiões de maior atividade contrátil, notamos que com o aumento da frequência existe uma diminuição do tempo de relaxamento $\Delta \sigma(t)=0$ e que os sinais possuem um comportamento oscilatório, entretanto essa oscilação não é harmônica. A forma do ciclo permanece a mesma e todo o período de contração. 

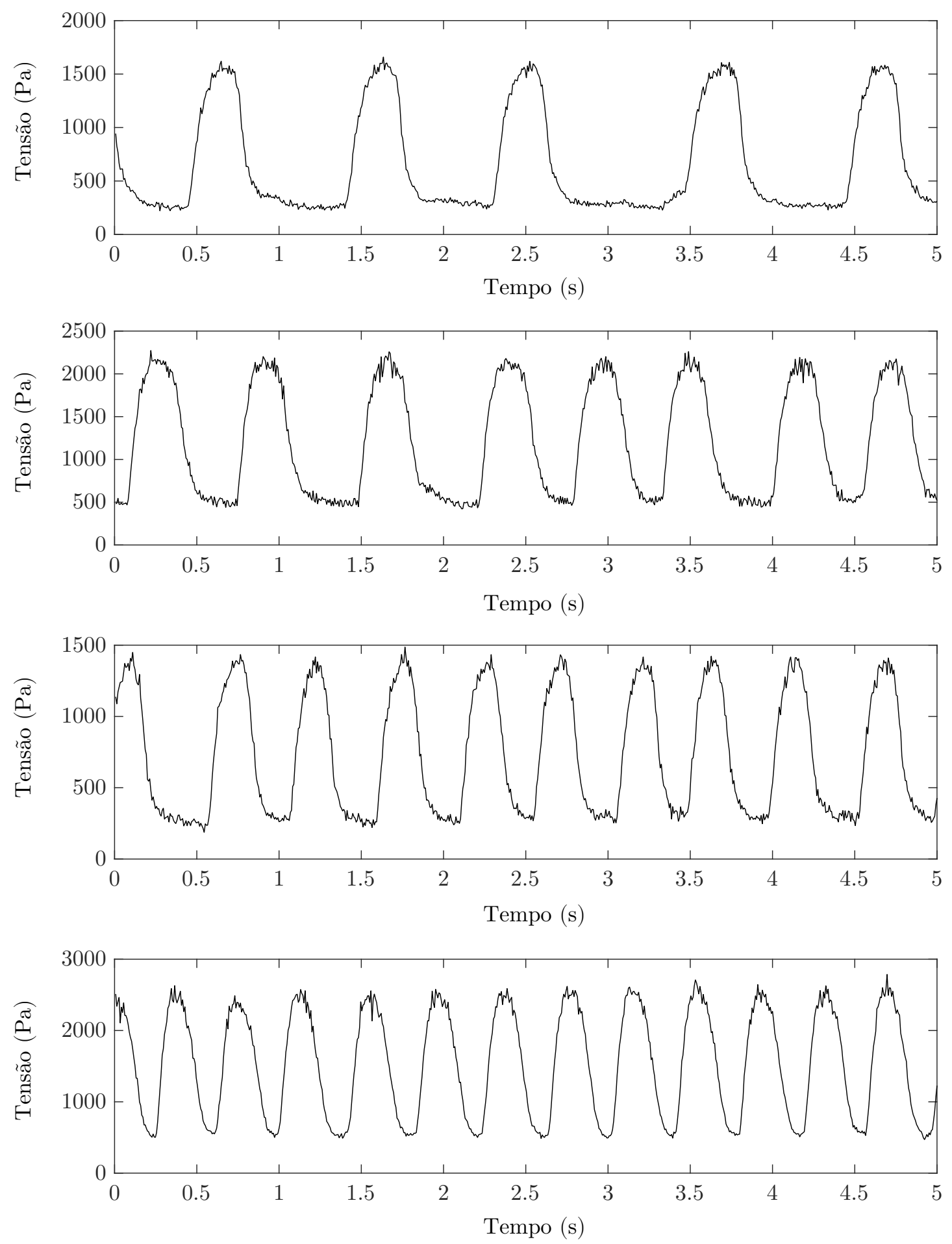

Figura 7.18: Conjunto de sinais de tensão $\sigma(t)$ para diferentes frequências de células em estado basal, estes sinais foram obtidos da regiões de alta atividade contrátil destas células. Do sinal de cima para o sinal de baixo temos as respectivas frequências de contração: $f_{1}=1,03 \mathrm{~Hz}, f_{2}=1,65 \mathrm{~Hz}, f_{3}=2,07 \mathrm{~Hz}$ e $f_{4}=2,48 \mathrm{~Hz}$. 
Obtendo o sinal de tensão em função do tempo, foi calculado o sinal de velocidade de contração $\frac{d \sigma(t)}{d t} \approx \frac{\Delta \sigma(t)}{\Delta t}$ em função do tempo. A Figura 7.19 mostra um conjunto de velocidade de contração dos sinais correspondente a quatro células distintas do grupo de amostra. O valor de velocidade de contração em função do tempo é usado o seguinte calculo numérico:

$$
\frac{d \sigma(t)}{d t} \approx \frac{\Delta \sigma(t)}{\Delta t}=\frac{\sigma\left(t_{i}\right)-\sigma\left(t_{i-1}\right)}{t_{i}-t_{i-1}}
$$

onde $\Delta t=t_{i}-t_{i-1}=7 \mathrm{~ms}$ é o tempo entre dois frames.

O sinal de velocidade de contração é bem definido para diferentes frequências de contração das células, apresentando varias etapas no sinal (mudanças na velocidade), correspondente a contração e relaxamento das células. 

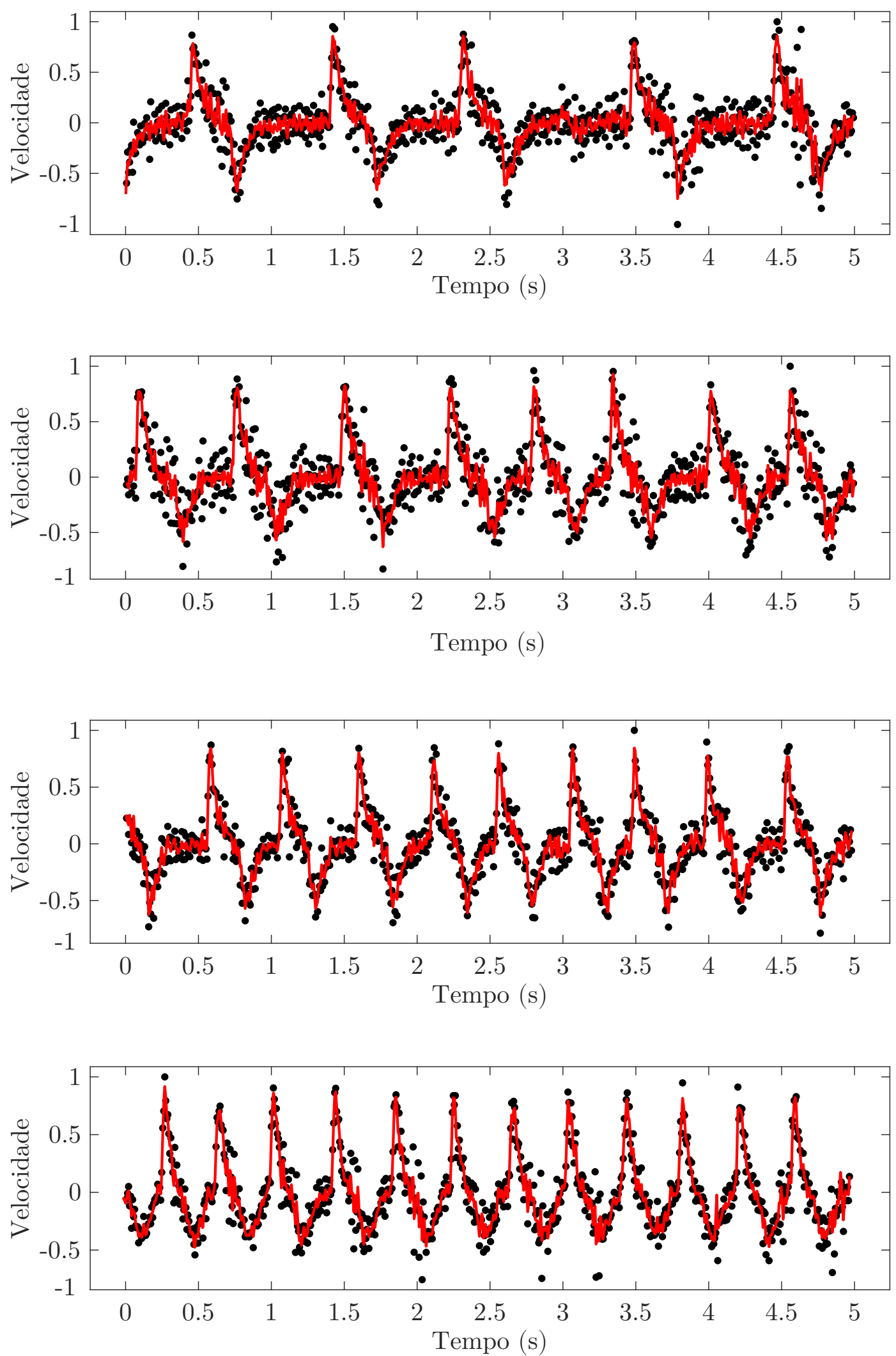

Figura 7.19: Conjunto de sinais de variação de tensão $\frac{\Delta \sigma(t)}{\Delta t}$ para diferentes frequências de células em estado basal, estes sinais foram obtidos da regiões de alta atividade contrátil destas células. Do sinal de cima para o sinal de baixo temos as respectivas frequências de contração: $f_{1}=1,03 \mathrm{~Hz}, f_{2}=1,65 \mathrm{~Hz}$, $f_{3}=2,07 \mathrm{~Hz}$ e $f_{4}=2,48 \mathrm{~Hz}$. 
Se observamos detalhadamente o sinal de velocidade da contração, notamos que este e composto por regiões (I, II, III, IV, V, VI e VII) que formam ciclo de velocidade. O sinal começa em uma suposta região de relaxamento I onde $\frac{\Delta \sigma(t)}{\Delta t}=0$, a região II ocorre um aumento abrupto da velocidade, em III temos uma redução abrupta acompanhado da região IV que corresponde a uma redução amortecida até 0 . Em V temos novamente uma redução abrupta acompanhado da região VI que corresponde a uma aumento abrupto, por ultimo temos a região aumento amortecido VII, fechando o ciclo.

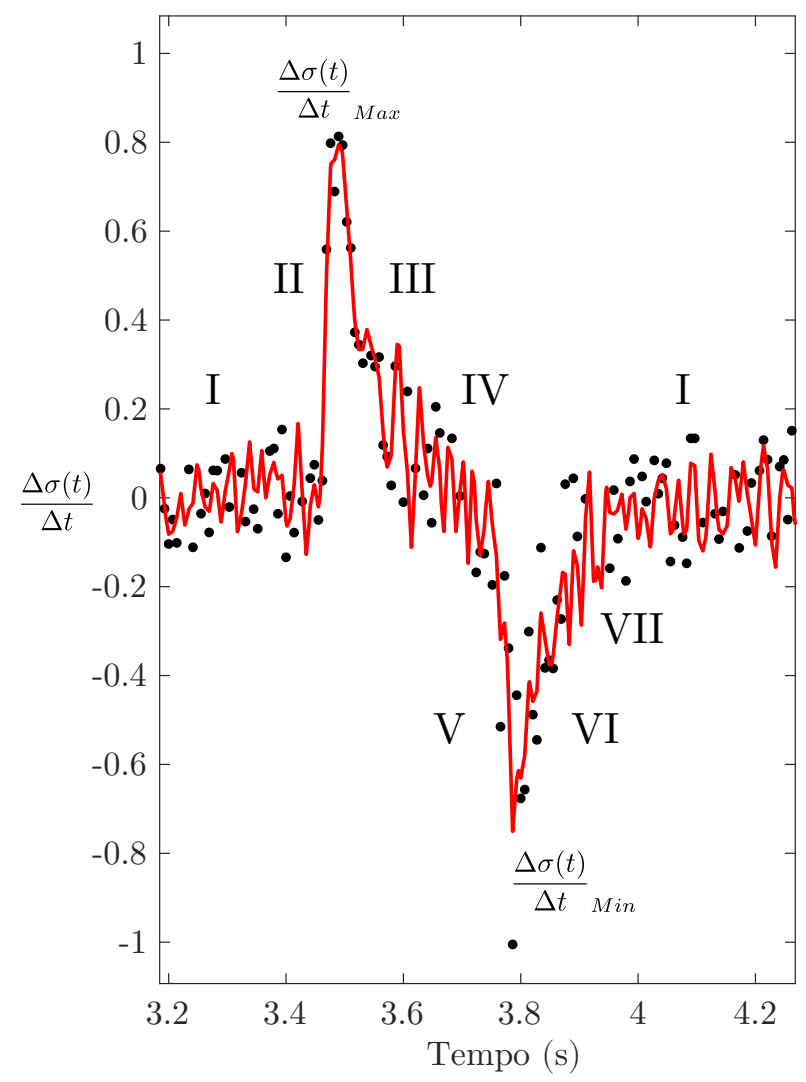

Figura 7.20: Ampliação da forma do sinal de variação de tensão $\frac{\Delta \sigma(t)}{\Delta t}$, neste gráfico podemos perceber que a variação da tensão muda conforme a sua posição no ciclo, sendo positivo na contração e negativo no relaxamento. Neste gráfico separamos em sete regiões (I, II, III, IV, V, VI), conforme a taxa de variação de tensão, o sinal é de uma célula em estado basal com frequência de 1,03 Hz.

Dessa forma, as regiões caracterizam cada etapa do ciclo contráctil, onde a região I é a zona de latência, as regiões II, III e IV caracterizam a contração e gasto de energia da célula e as regiões V, VI e VII caracterizam o relaxamento e recuperação de energia da célula e retorno para a zona de latência I. 


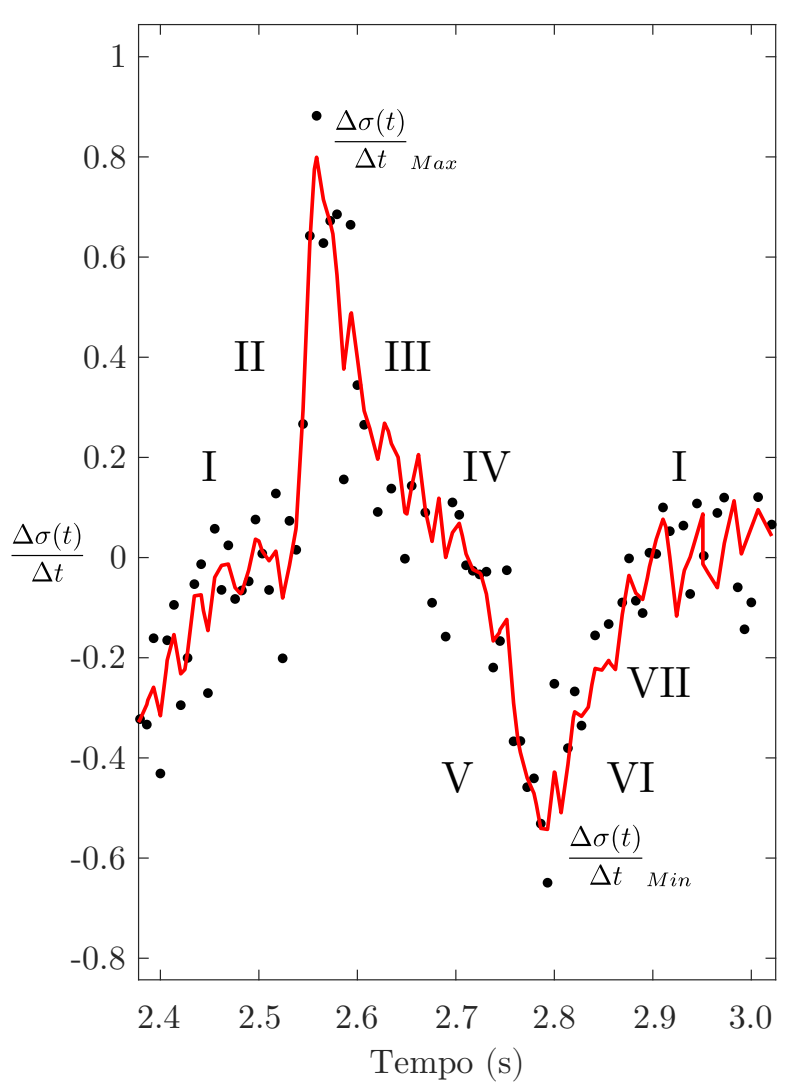

Figura 7.21: Ampliação da forma do sinal de variação de tensão $\frac{\Delta \sigma(t)}{\Delta t}$, neste gráfico podemos perceber que a variação da tensão muda conforme a sua posição no ciclo, sendo positivo na contração e negativo no relaxamento. Neste gráfico as regiões III-IV e VI-VII possuem praticamente a mesma inclinação, o sinal é de uma célula em estado basal com frequência de 2,48 Hz.

Agora, se observamos detalhadamente o sinal de velocidade da contração para altas frequências, notamos algumas diferenças nas regiões, primeiro existe uma redução da região de latência I, as regiões III e IV começam apresentar praticamente a mesma inclinação, isso ocorre também com as regiões VI e VII que também começam apresentar a mesma inclinação.

Essas observações evidenciam que o sinal de tensão e o sinal de variação de tensão, possuem uma mudança na forma de oscilar de acordo com a frequência de contração, caracterizando o estado de contração. Para baixas frequências temos, uma oscilação que tende para uma oscilação amortecida, enquanto para altas frequências temos, uma oscilação tendendo para uma oscilação harmônica. 
Um estudo feito em paralelo com a análise de sinais de tensão em estado basal, foi o estudo dos sinais de tensão com um estímulo químico. O estímulo é realizado com a aplicação de uma substancia chamada isoproterenol

O isoproterenol é uma substância que aumenta a frequência cardíaca, recomendado para o tratamento de bradicardia (frequência cardíaca baixa). Atuando nos receptores $\beta 1$ e $\beta 2$ da célula cardíaca, a tabela 7.1 mostra as informações químicas do isoproterenol e a Figura 7.22 mostra a sua estrutura molecular.

Tabela 7.1: Tabela com as informações químicas do Isoproterenol

\begin{tabular}{cc}
\hline \hline Nome IUPAC & (RS)-4-[1-hydroxy-2-(isopropylamino)ethyl]benzene-1,2-diol \\
\hline \hline Fórmula Molecular & $\mathrm{C}_{11} \mathrm{H}_{17} \mathrm{NO}_{3}$ \\
Massa Molar & $211,258 \mathrm{~g} / \mathrm{mol}$ \\
Meia-Vida & $2 \mathrm{~min}$ \\
\hline \hline
\end{tabular}

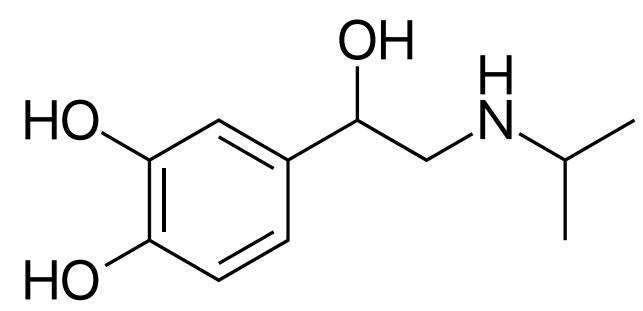

Figura 7.22: Estrutura molecular do Isoproterenol.

Em nossos experimentos de TFM, o isoproterenol foi utilizado em uma concentração de $10 \mu \mathrm{M}$, diluído no meio de cultura celular. Nesse trabalho constatamos o aumento efetivo de frequência com aplicação do isoproterenol em nível celular.

A Figura 7.23 mostra o que acontece com o sinal de tensão antes e após a aplicação do isoproterenol, inicialmente percebemos um aumento da frequência de contração, o sinal antes tinha uma frequência de $1,03 \mathrm{~Hz}$ e depois da aplicação do isoproterenol, a frequência aumentou para 2,27 Hz. Entretanto esta variação depende de célula para célula, especificamente da frequência basal (será explicado mais adiante), mas em todos os casos houve um aumento da frequência de contração

Um outro aspecto relevante é que praticamente não houve uma variação perceptível da amplitude de contração. Sugerindo que a aplicação do isoproterenol não cause um aumento da força celular, mas um aumento da potência celular, visto que um aumento da frequência indica um maior gasto energético ao longo do tempo. 

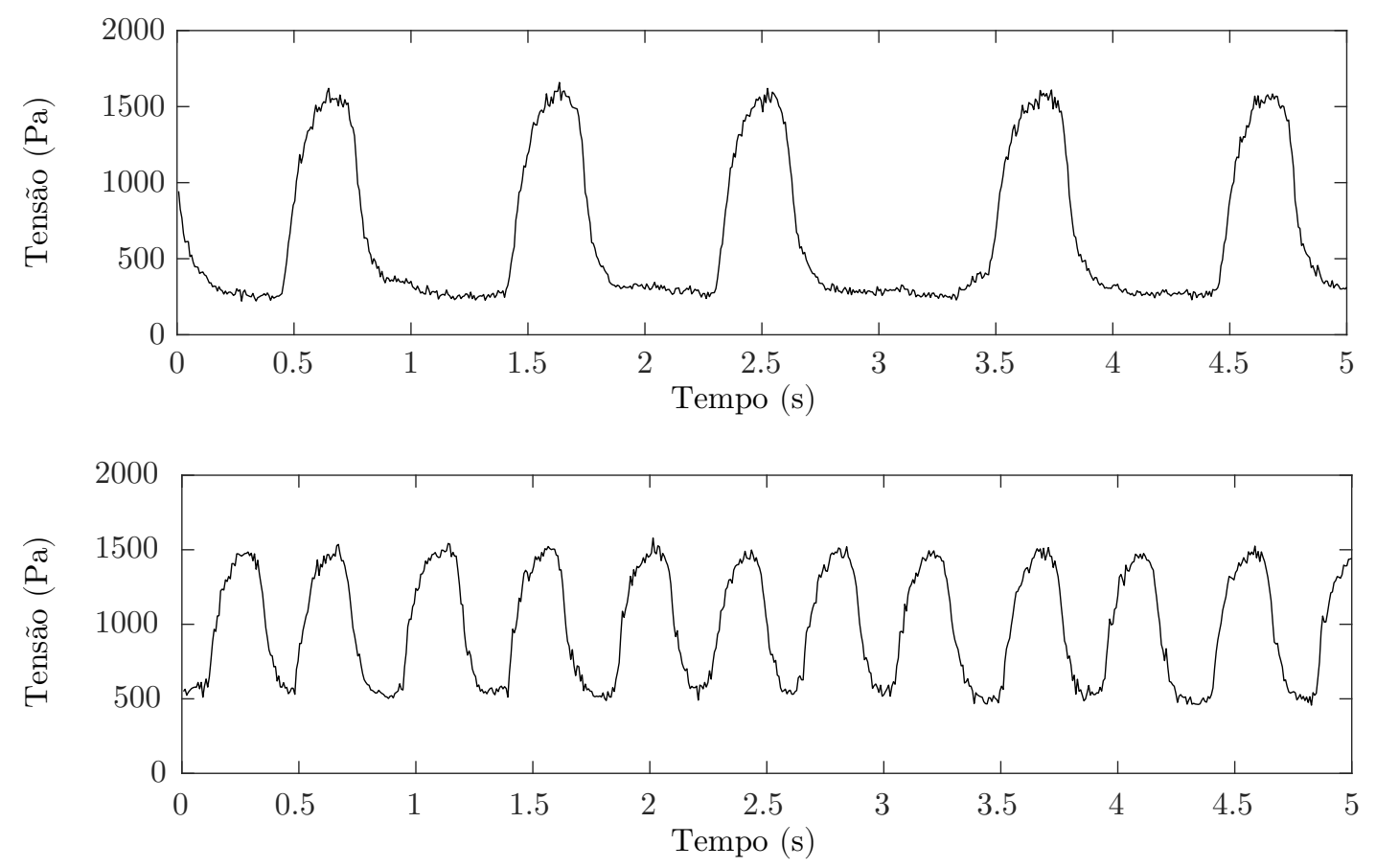

Figura 7.23: Alteração da frequência do sinal de tensão com aplicação do isoproterenol, temos dois sinais de tensão do mesmo cardiomiócito, o de cima esta em estado basal com frequência de $f_{\text {bas }}=1,03$ $\mathrm{Hz}$, enquanto o de baixo teve a sua frequência alterada para $f_{i s o}=2,27 \mathrm{~Hz}$ com isoproterenol.

Na Figura 7.24 mostra o que acontece com o sinal de variação de tensão antes e após a aplicação do isoproterenol, o sinal tinha uma frequência de 1,03 Hz e depois da aplicação do isoproterenol, a frequência aumentou para 2,27 Hz. Quando comparamos a variação do sinal com isoproterenol, notamos que as alterações no sinal são as mesmas entre sinais com frequências diferentes em estado basal, visto que tanto o sinal de tensão quanto o sinal de variação de tensão são os mesmos dos sinais de alta frequência encontrados nos cardiomiócitos em estado basal.

Esse resultado traz uma informação importante sobre o funcionamento do cardiomiócito, sendo que para a concentração de isoproterenol de $10 \mu \mathrm{M}$ os efeitos químicos não provocam alterações na forma do sinal, isso significa que apesar dessa substancia alterar a frequência de contração, esta não provoca a mudança da função contráctil.

Em resumo, não é possível distiguir entre um sinal de um cardiomiócito em estado basal e outro estimulado com isoproterenol, por exemplo, tanto o sinal com isoproterenol da Figura 7.23 quanto o sinal em estado basal da Figura 7.18 são semelhantes. Além disso, a célula mantem a sua atividade contráctil caracterizada pelo sinal de tensão, mostrado na Figura 7.18 e pelo sinal de variação de tensão, mostrado na Figura 7.19. 
Entretanto é possível mensurar a variação de frequência com a aplicação do isoproterenol. Cada célula tem uma variação de frequência, escrita da seguinte forma: $\Delta f=f_{\text {iso }}-f_{\text {bas }}$, onde $f_{\text {bas }}$ é a frequência basal e $f_{\text {iso }}$ é a frequência com aplicação de isoproterenol.
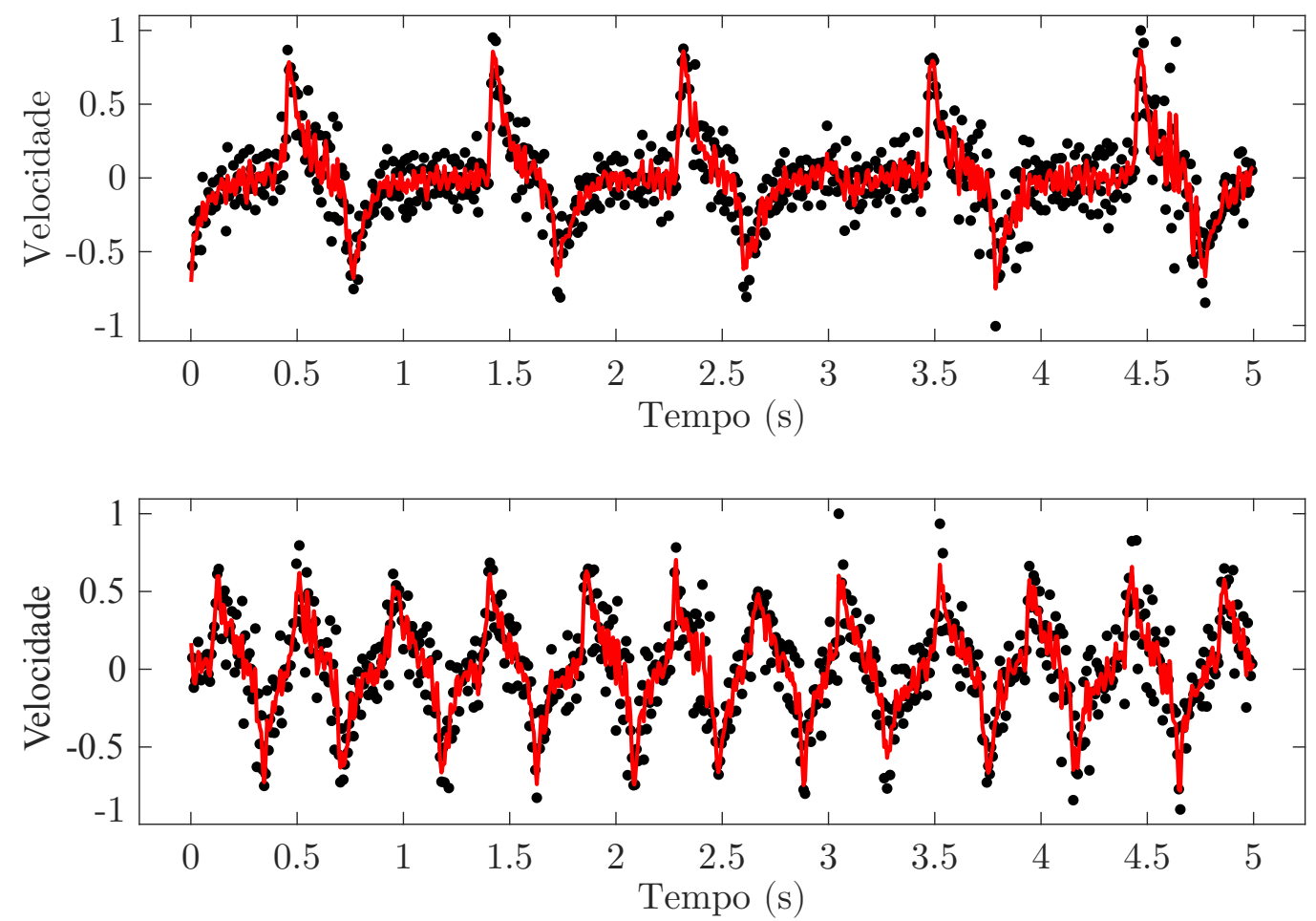

Figura 7.24: Alteração da frequência do sinal de variação tensão com aplicação do isoproterenol, temos dois sinais de tensão do mesmo cardiomiócito, o de cima esta em estado basal com frequência de $f_{\text {bas }}=$ $1,03 \mathrm{~Hz}$, enquanto o de baixo teve a sua frequência alterada para $f_{i s o}=2,27 \mathrm{~Hz}$ com isoproterenol.

A variação de frequência entre estado basal e isoproterenol não é constante, muda de célula para célula. Frente a esse resultado, decidimos estudar tanto a distribuição de frequências no estado basal quanto as correlações entre elas.

\subsection{Frequência de Contração Basal e Estimulada}

Em nossos resultados, verificamos que os cardiomiócitos possuem frequências de $1 \mathrm{~Hz}$ até $3 \mathrm{~Hz}$, essa variabilidade ocorre em grupos de células sobre as mesmas condições de cultura, a única diferença são as suas condições iniciais de adesão ao substrato. Onde apresentam áreas de adesão diferentes, isso motivou a estudar essa variabilidade tanto com as células em estado basal quanto com células com isoproterenol, das quais forma discutidas anteriormente. 
Analisamos as distribuições de frequência basal e com isoproterenol do grupo de amostras com $n=50$ (basal) e $n=30$ (isoproterenol). Essas distribuições foram comparada com distribuições teóricas conhecidas, dentre essas fizemos o ajuste dos dados.

Na Figura 7.25, temos as distribuições empíricas de frequência de um grupo de amostras em estado basal e de frequências de um grupo de amostras com isoproterenol. Para o ajuste das distribuições, foi utilizado a distribuição normal que melhor se ajustou as amostras. As duas distribuições de frequência foram sobrepostas onde o valor medio de frequência basal é $2 \mathrm{~Hz}$ e o valor medio de frequência com isoproterenol é $2,8 \mathrm{~Hz}$, além disso, temos uma região de sobreposição das duas distribuições. Note que essa região começa depois da frequência $2 \mathrm{~Hz}$, indicando que para valores acima de $2 \mathrm{~Hz}$, não teríamos como diferenciar entre o estado basal e o estado estimulando com base na frequência, visto que nessa região é preenchida por ambas as distribuições.

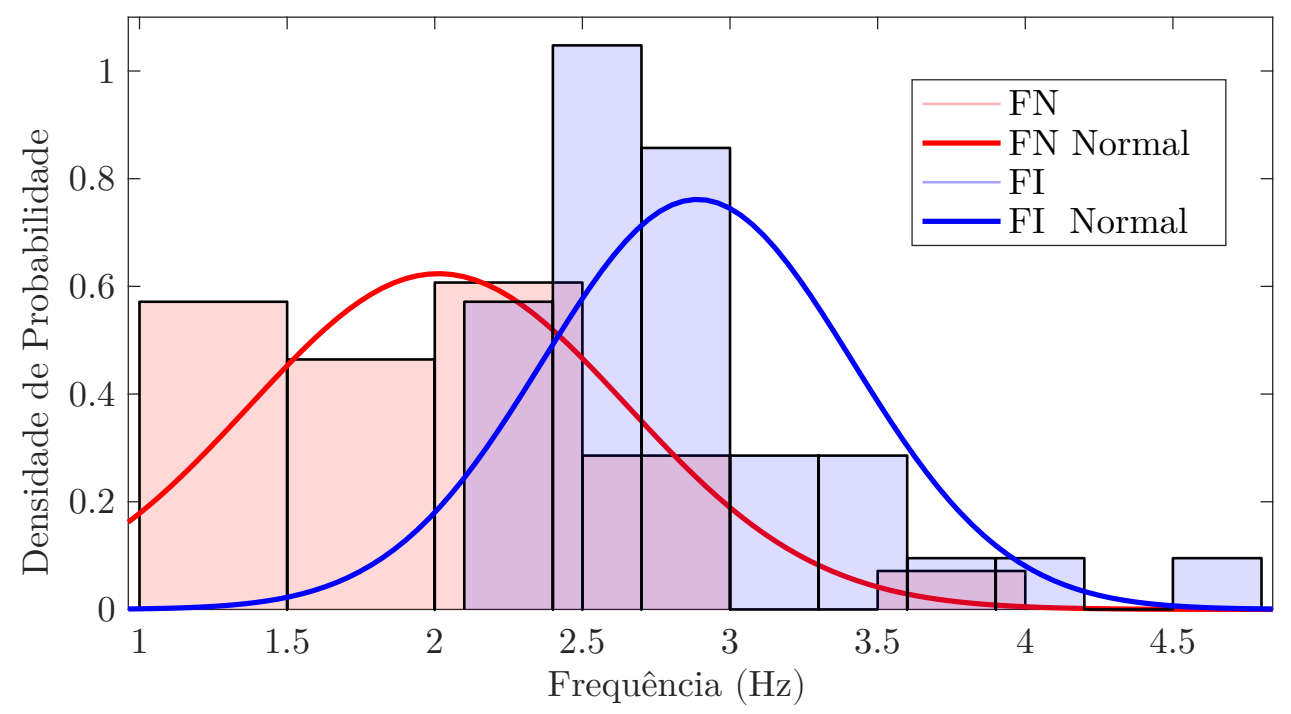

Figura 7.25: Gráfico de densidade de probabilidade dos valores de frequência, as distribuições de frequência basal FN e frequência estimulada FI foram colocados de forma sobreposta no mesmo gráfico, para verificar as suas diferenças. Além disso, temos seus respectivos ajustes normais.

Para visualizar o ajuste normal, geramos o gráfico de probabilidade acumulada das distribuições. A Figura 7.26, mostra as probabilidades acumuladas tanto da distribuição das frequências quanto da distribuição normal de ajuste, os valores de frequência estimuladas com isoproterenol estão acima dos $2 \mathrm{~Hz}$, e que só a distribuição de frequência basal apresenta valores de frequência abaixo de $2 \mathrm{~Hz}$. Além disso, na medida que valores de frequência aumentam, a distância entre as curvas diminui. 


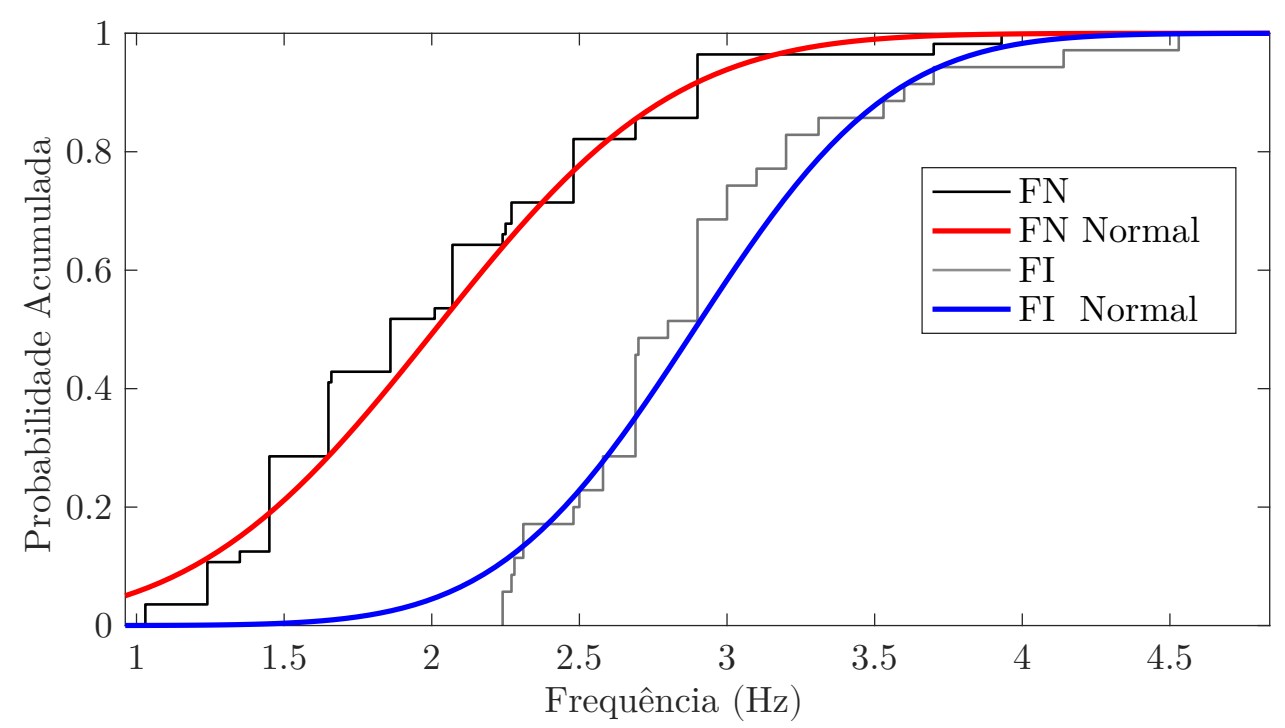

Figura 7.26: Gráfico de densidade de probabilidade acumulada dos valores de frequência, as distribuições de frequência basal FN e frequência estimulada FI foram colocados de forma sobreposta no mesmo gráfico, para verificar as suas diferenças. Além disso, temos seus respectivos ajustes normais.

Os gráficos mostram que quando essas células contraem ciclicamente em microambiente mimetizado sem quaisquer restrição de área de adesão, estas possuem uma distribuição de frequências normal ou Gaussiana. Isso também é valido para a distribuição de frequências estimuladas com isoproterenol.

Uma justificativa para que tenha essa distribuição é a aleatoriedade com que os cardiomiócitos são aderidos ao substrato, mantendo pequenas flutuações aleatórias frequência e consequentemente se distribuindo como uma distribuição normal.

Agora, vamos correlacionar os valores de frequência basal e frequência com isoproterenol com a área de adesão celular. Os dados utilizados para essa análise estão na Tabela 7.2 , onde temos os valores de frequência basal e frequência com isoproterenol de vários cardiomiócitos, com as suas respectivas áreas de adesão. 
Tabela 7.2: A tabela mostra um conjunto de parâmetros mecânicos de um grupo de 30 cardiomiócitos neonatais do tipo WT, para cada amostra temos os seguintes parâmetros: frequência basal $f_{\text {bas }}$, frequência com isoproterenol $f_{\text {iso }}$ e área de adesão celular.

\begin{tabular}{|c|c|c|c|}
\hline \multirow{2}{*}{ Amostra } & \multicolumn{3}{|c|}{ Variável } \\
\hline & $f_{b a s}(\mathrm{~Hz})$ & $f_{i s o}(\mathrm{~Hz})$ & Área $\left(\mu \mathrm{M}^{2}\right)$ \\
\hline $\bar{~} 1$ & $\overline{1,66}$ & 2,90 & 901 \\
\hline 2 & 1,45 & 2,69 & 1788 \\
\hline 3 & 2,07 & 3,00 & 2041 \\
\hline 4 & 1,65 & 2,80 & 2914 \\
\hline 5 & 1,35 & 2,28 & 3055 \\
\hline 6 & 1,45 & 2,31 & 1999 \\
\hline 7 & 1,45 & 2,32 & 1800 \\
\hline 8 & 2,90 & 3,70 & 2041 \\
\hline 9 & 2,90 & 3,60 & 2380 \\
\hline 10 & 1,65 & 3,20 & 1024 \\
\hline 11 & 1,45 & 2,70 & 1999 \\
\hline 12 & 2,07 & 2,69 & 1422 \\
\hline 13 & 1,65 & 3,31 & 2773 \\
\hline 14 & 2,27 & 2,69 & 2604 \\
\hline 15 & 2,90 & 3,53 & 2464 \\
\hline 16 & 1,03 & 2,27 & 1534 \\
\hline 17 & 2,48 & 2,58 & 3013 \\
\hline 18 & 1,65 & 2,90 & 1210 \\
\hline 19 & 1,45 & 3,10 & 901 \\
\hline 20 & 1,86 & 3,00 & 1098 \\
\hline 21 & 1,24 & 2,24 & 802 \\
\hline 22 & 2,25 & 2,69 & 3000 \\
\hline 23 & 1,45 & 2,90 & 1802 \\
\hline 24 & 1,45 & 2,69 & 1281 \\
\hline 25 & 1,24 & 2,69 & 1239 \\
\hline 26 & 2,07 & 2,48 & 1000 \\
\hline 27 & 2,07 & 2,50 & 1000 \\
\hline 28 & 2,69 & 2,90 & 2083 \\
\hline 29 & 2,9 & 3,2 & 2083 \\
\hline 30 & 1,24 & 2,9 & 1714 \\
\hline
\end{tabular}

A Figura 7.27 mostra um gráfico de frequência basal em função da área de adesão celular. Como resultado imediato, notamos que esses valores não possuem quaisquer correlação. Isso não significa que a frequência não dependa da área de adesão celular, apenas que nesse tipo medida não foi encontrado uma tendência entre esses valores.

Na Figura 7.28 repetimos o mesmo procedimento da Figura 7.27, mas agora temos um gráfico de frequência estimulada em função da área de adesão celular. Como resultado 


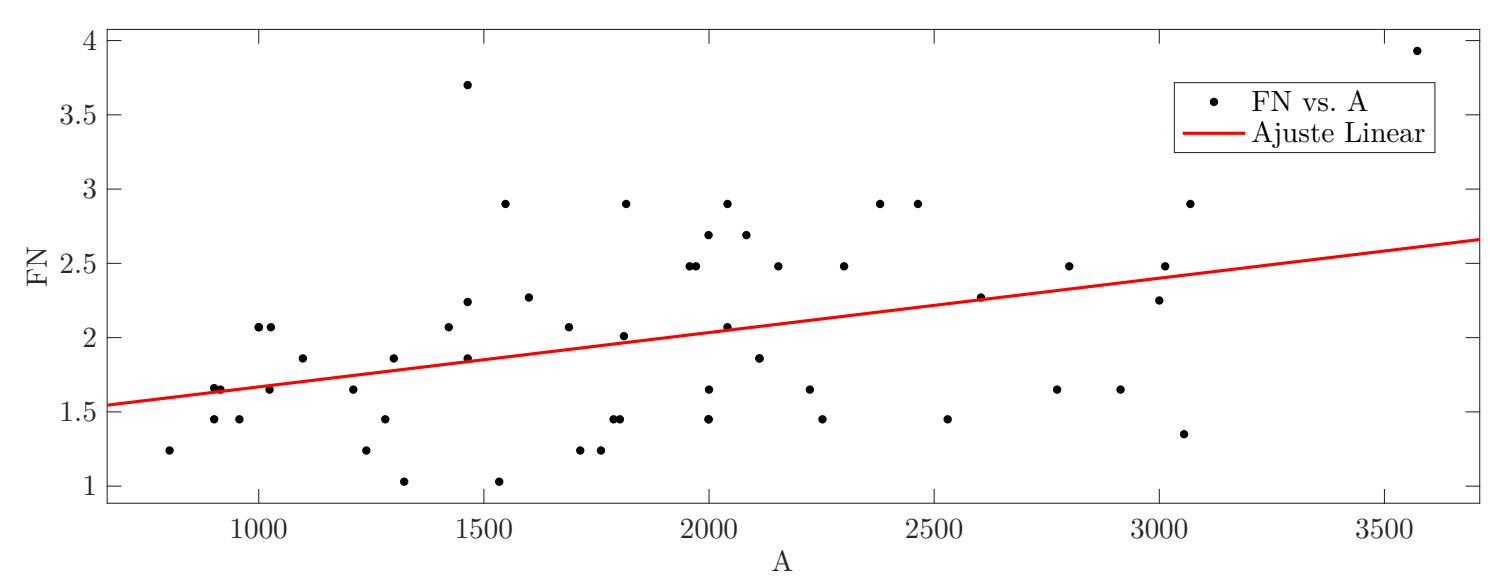

Figura 7.27: Gráfico com os valores de frequência basal FN em função da área de adesão celular A, nesse gráfico temos um ajuste linear $F R(A)=0,0003 A+1,328$, onde $R^{2}=0,15$.

imediato, novamente que esses valores não possuem quaisquer correlação.

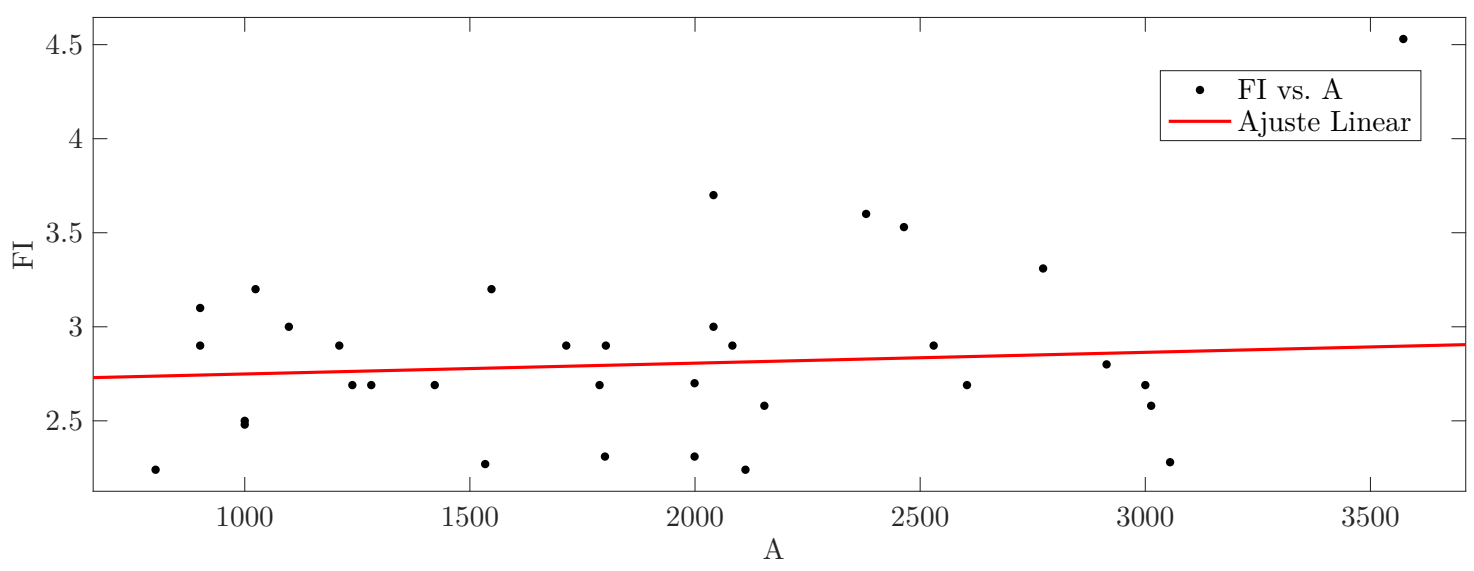

Figura 7.28: Gráfico com os valores de frequência com isoproterenol FI em função da área de adesão celular A, nesse gráfico temos um ajuste linear $F I(A)=0,0002 A+2,389$, onde $R^{2}=0,14$.

Esse resultado mostra que a frequência basal e frequência com isoproterenol não podem ser correlacionados com a área da célula aderida a um substrato mimetizado. Entretanto, apesar de desconhecemos as causas que modulam frequência basal, podemos verificar o quanto esta frequência interfere em um estímulo, visto que a variação de frequência não é constante para uma mesma dosagem de isoproterenol.

O fato da variação de frequência não ser constante para uma mesma dosagem de isoproterenol nos leva a fazer uma análise da relação entre a frequência basal e o acréscimo de frequência com a aplicação de isoproterenol, esse acréscimo percentual pode ser escrito 
da seguinte forma:

$$
\begin{aligned}
P=\frac{\Delta f}{f_{\text {bas }}}=\frac{f_{\text {iso }}-f_{\text {bas }}}{f_{\text {bas }}} & =\frac{f_{\text {iso }}}{f_{\text {bas }}}-1 \\
P & =\frac{f_{\text {iso }}}{f_{\text {bas }}}-1
\end{aligned}
$$

onde $\mathrm{P}$ é o percentual de acréscimo, $f_{\text {bas }}$ é a frequência basal e $f_{i s o}$ é a frequência com aplicação de isoproterenol.

A Figura 7.29 mostra os valores de percentual de acréscimo $P=\frac{f_{i s o}}{f_{\text {bas }}}-1$ em função dos valores de frequência basal $f_{\text {bas }}$. Para gerar o gráfico utilizamos uma amostragem igual a $n=30$, que corresponde ao número de cardiomiócitos do grupo de amostras que foram possíveis obter os valores de frequência basal e frequência com isoproterenol.

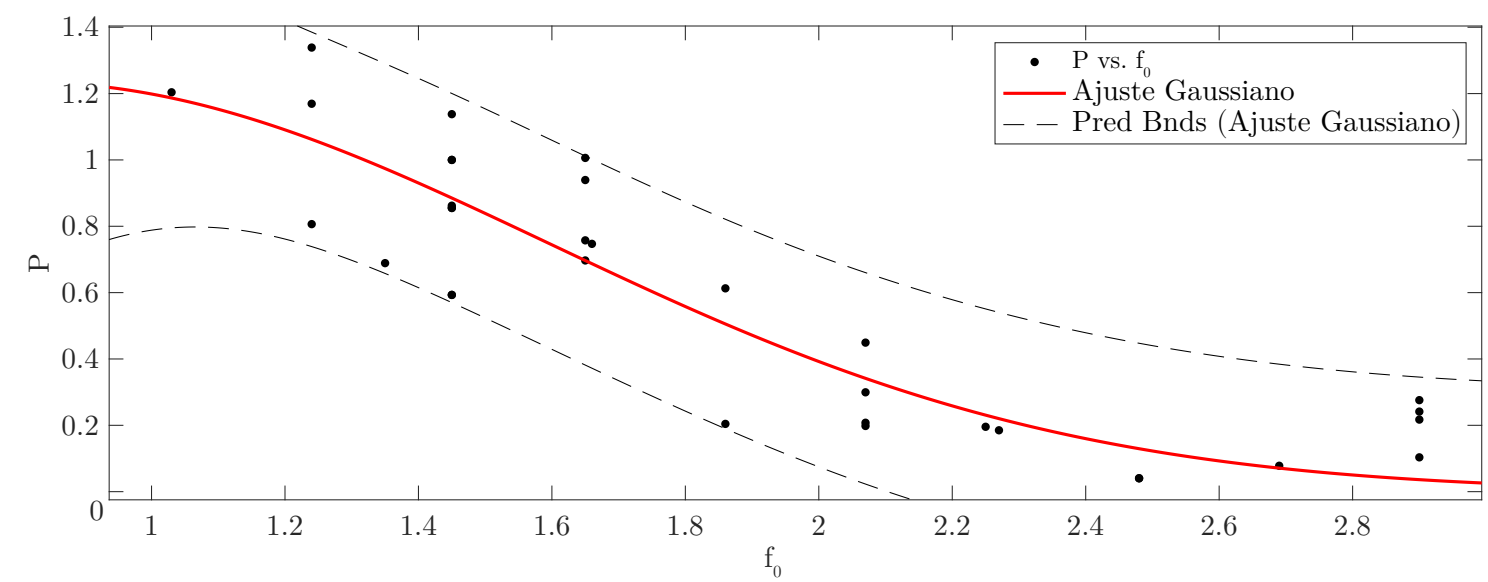

Figura 7.29: Gráfico do valor de percentual de acréscimo de frequência $\mathrm{P}=\frac{f_{\text {iso }}}{f_{\text {bas }}}-1$ em função da frequência basal FN, nesse gráfico temos um ajuste gaussiano $P(F N)=1,2 \mathrm{e}^{\left(\frac{0,8-F N}{1,1}\right)}$, onde $R^{2}=0,8$.

O resultado mostra que percentual de acréscimo decai com o aumento da frequência basal, na Figura 7.29 utilizamos uma função gaussiana para o ajuste dos dados, apresentando o menor erro dentre os tipos de ajustes conhecidos, isso não significa que o valor de P se comporta como uma função gaussiana, mas que para a quantidade de dados amostrados, esta função é a que melhor se ajusta aos dados. O fato importante desse resultado é o decaimento de $\mathrm{P}$ em função da frequência basal.

Na Figura 7.30 temos um mapeamento dos valores de P em função da frequência basal e da área de adesão, as regiões com os maiores valores de P são aquelas onde a frequência basal e baixa o que corrobora com os resultado anterior.

A evidência do decaimento de P em função da frequência basal, mostra por premissa, 
que o cardiomiócito possui uma frequência limite superior. O isoproterenol atua nos receptores $\beta 1$ e $\beta 2$ da célula cardíaca, alterando a frequência cardíaca. A existência de uma frequência limite superior é um indicativo que nessas condições, a célula estaria acima da sua capacidade contráctil, e que esta por sua vez possui um mecanismo que module a frequência para valores regulares de frequência durante o estímulo químico.

Por esse motivo o acréscimo de frequência é variável para uma mesma dosagem de isoproterenol, provavelmente existem outros parâmetros envolvidos, um deles é a frequência basal da célula, mostrado nesse trabalho como um resultado do uso das propriedades mecânicas para elucida fenômenos fisiológicos da célula cardíaca.

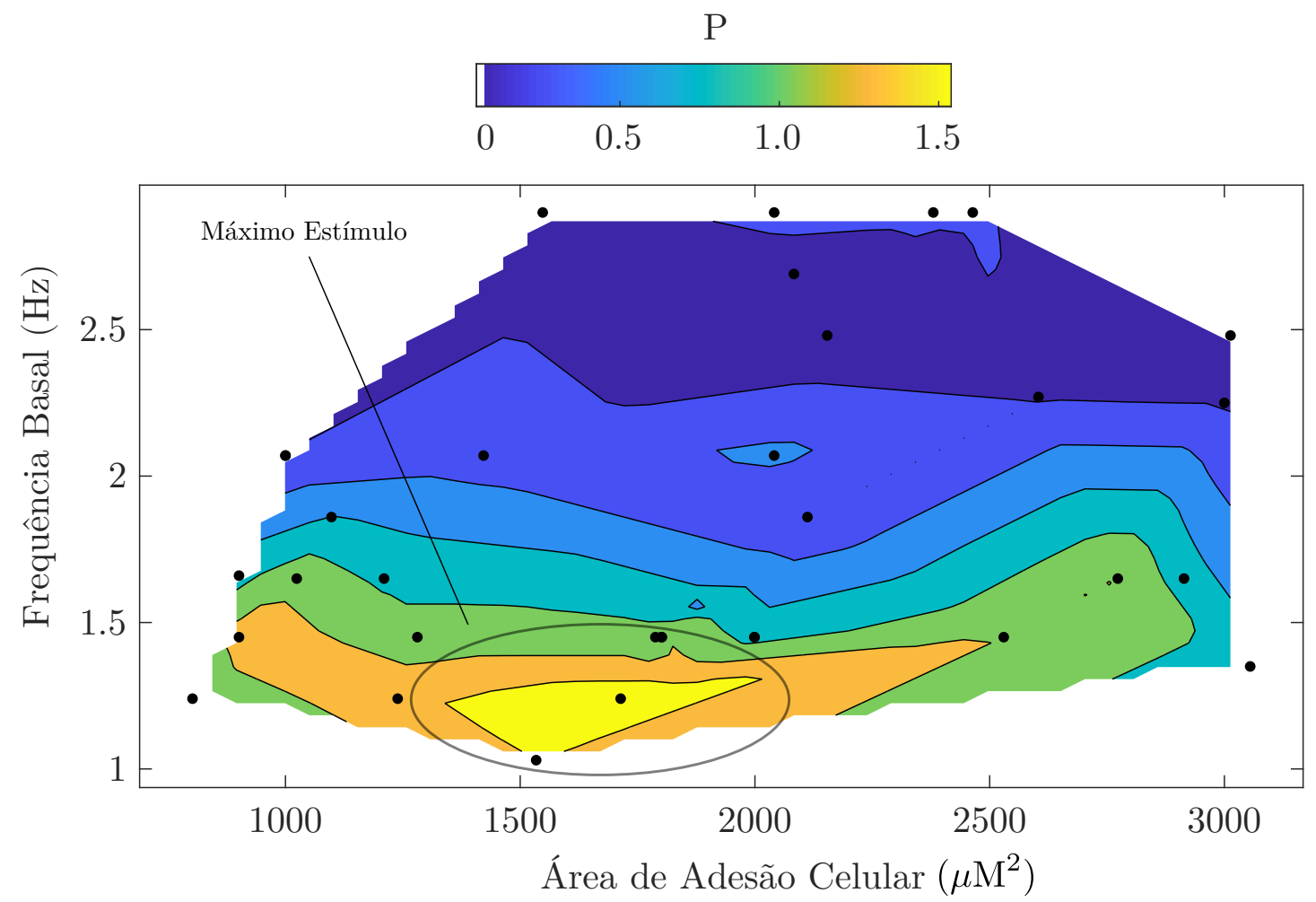

Figura 7.30: Gráfico do mapeamento do percentual de acréscimo de frequência $\mathrm{P}$ em função da frequência basal e da área de adesão celular, nesse gráfico podemos identificar uma região de máximo estimo, o valor de $\mathrm{P}$ é maior. 


\subsection{Modelo de Oscilador para a Contração Cíclica}

Com a geração dos gráficos de tensão e o de variação de tensão, tentamos elucida o comportamento dinâmico do cardiomiócito, associando este a um modelo de oscilador conhecido.

Os cardiomiócitos estudados apresentam uma curva característica de velocidade, ela não tem a forma da curva de velocidade do movimento harmônico (altas frequências), entretanto, estas curvas se assemelham com a curva de velocidade de uma oscilação nãolinear, especificamente o oscilador de Van Der Pol

$$
\frac{d^{2} \sigma(t)}{d t^{2}}-\mu\left(1-\sigma^{2}(t)\right) \frac{d \sigma(t)}{d t}+\sigma(t)=0
$$

Apesar do oscilador de Van Der Pol não ter uma solução analítica, este pode ser solucionado numericamente, a Figura 7.31 mostra a solução numérica do oscilador.

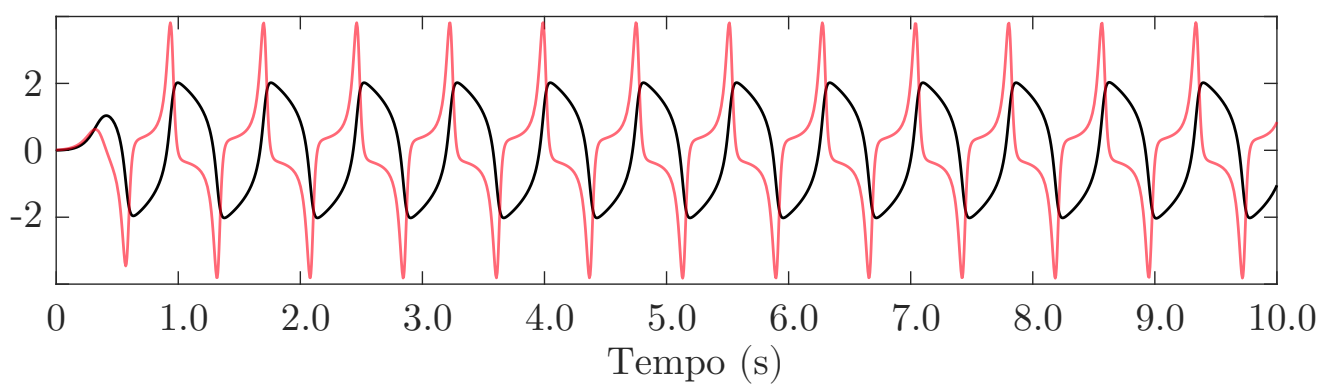

Figura 7.31: Gráfico da solução do oscilador de Van Der Pol para $\mu=3$, no gráfico temos a solução $\sigma(t)$ (curva em preto) e a sua derivada $\frac{d \sigma(t)}{d t}$ (curva em vermelho).

Entretanto, observando os gráficos da Figuras 7.18 e 7.19, notamos que o sinal de tensão e variação de tensão comparado com a solução do modelo esta invertido. Na Figura 7.32, geramos as soluções do oscilador de Van Der Pol invertidas no tempo fazendo a seguinte transformação $t=t_{f}-t$ onde $t_{f}$ é o ultimo instante de tempo. Com isso, as soluções das Figura 7.32 ficam invertidas.

Cada uma das soluções da Figura 7.32 apresentam um valor de $\mu$. Do sinal de cima para o sinal de baixo temos os respectivos valores de $\mu: \mu_{1}=1, \mu_{2}=2, \mu_{3}=3$ e $\mu_{4}=4$. Uma propriedade do oscilador de Van der Pol é que quando o valor de $\mu$ aumenta, a frequência de oscilação diminui, como é mostrado na Figura 7.33.

Se a dinâmica contráctil do cardiomiócito for descrita como um oscilador de Van Der Pol, mesmo que invertido, essa propriedade estaria presente. Para verificar esse fato 

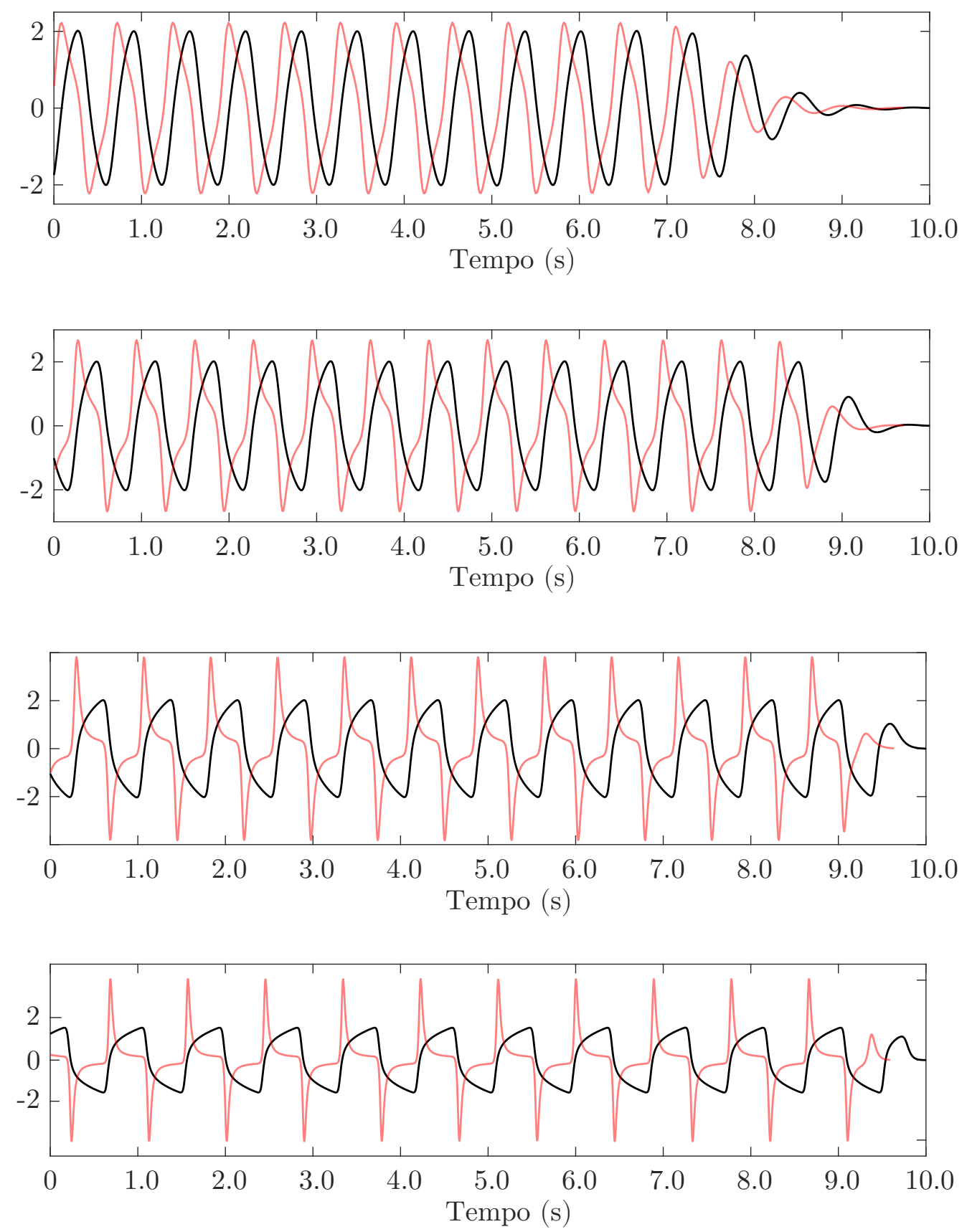

Figura 7.32: Conjunto de soluções $\sigma(t)$ do oscilador de Van Der Pol inverso para diferentes valores de $\mu$, no gráfico temos a solução $\sigma(t)$ (curva em preto) e a sua derivada $\frac{d \sigma(t)}{d t}$ (curva em vermelho), do sinal de cima para o sinal de baixo temos os respectivos valores de $\mu$ : $\mu_{1}=1, \mu_{2}=2, \mu_{3}=3$ e $\mu_{4}=4$.

podemos gerar o retrato de fase do sinal de tensão e verificar o que acontece quando a frequência da célula aumenta.

Nessa próxima análise, usamos os dados de contração e velocidade para gerar os retratos de fase empíricos da contração cíclica. Comparando a duas situações distintas, quando eles estavam no estado basal e quando eles foram submetidos ao isoproterenol. 


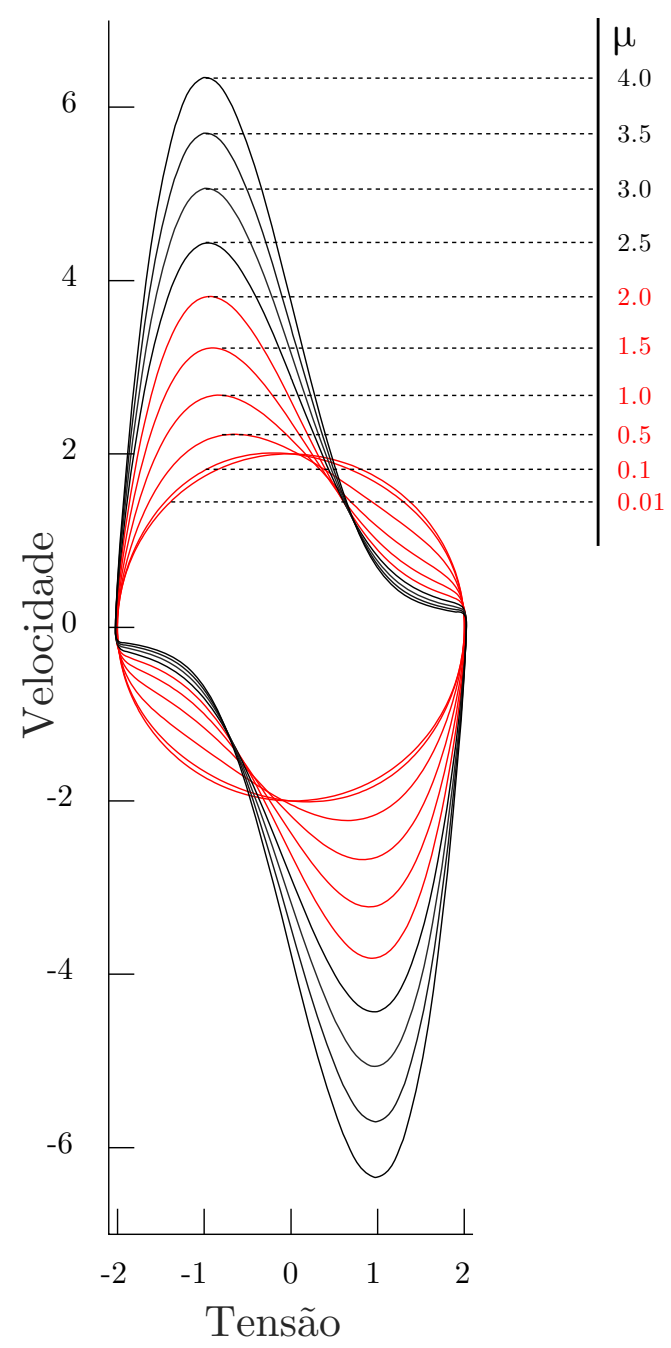

Figura 7.33: Evolução do ciclo limite no plano de fase do oscilador inverso de Van Der Pol em função de $\mu$. O ciclo limite começa como um círculo e, com variação de $\mu$, fica cada vez mais nítido. Um exemplo de um oscilador de relaxamento.

O retrato de fase representa as curvas das soluções de um sistema dinâmico no plano $\left(y, \frac{d y}{d x}\right)$, este plano é chamado de espaço de fase. A geometria e trajetória das curvas revela informações sobre a existência de atratores, repulsores e ciclos limites.

Utilizamos os valores de contração $\sigma(t)$ e velocidade de contração $\frac{\Delta \sigma(t)}{\Delta t}$ para gerar os retratos de fase da dinâmica contráctil das células. Comparamos os retratos de fase com o aumento da frequência entre células em estado basal e para um aumento de frequência com isoproterenol, o resultado é demostrado nas Figuras 7.34 e 7.35.

Observando as Figuras 7.34, temos dois retratos de fase, o da esquerda é o retrato de fase de um sinal de tensão com frequência de 1,03 Hz, enquanto da direita, temos o retrato de um sinal de tensão com frequência $2,48 \mathrm{~Hz}$. Os retratos de fase gerados formam curvas fechadas, essas trajetórias caracterizam o ciclo limite, que aparece em ambos os 

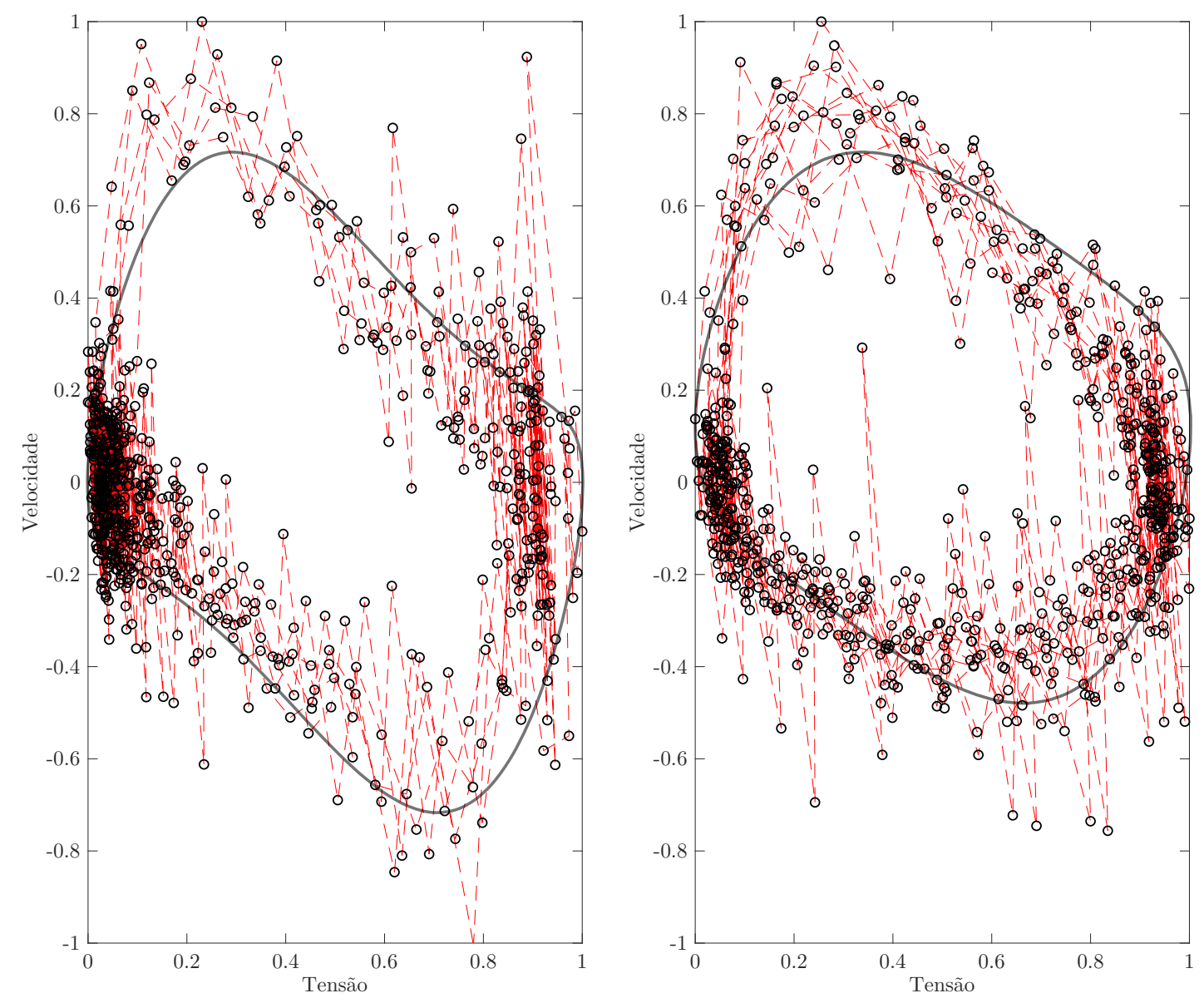

Figura 7.34: Retrato de fase empírico de dos sinais de tensão de frequências basais diferentes, no retrato de fase da esquerda temos um sinal com frequência de $1.03 \mathrm{~Hz}$, ajustamos uma solução do oscilador de Van Der Pol inverso (curva cinza) com $\mu=1,5$, o retrato de fase da direita temos um sinal com frequência de 2,48 Hz, ajustamos uma solução do oscilador de Van Der Pol inverso (curva cinza) com $\mu=0,5$.

gráficos da Figura 7.34 .

Ajustamos essas trajetórias as curvas das soluções de Van Der Pol, no retrato de fase a esquerda, utilizamos uma solução com $\mu=1,5$ e no retrato de fase a direita, utilizamos uma solução com $\mu=0,5$. Isso esta de acordo com o previsto pelo modelo de Van Der Pol, sendo que pelo fato do gráfico da esquerda possuir uma frequência menor do que o gráfico da direita, o seu valor de $\mu$ deve ser maior do o gráfico da direita.

Observando as Figuras 7.35, temos dois retratos de fase, o da esquerda é o retrato de fase de um sinal de tensão com frequência de 1,03 Hz, enquanto da direita, temos o retrato do mesmo sinal de tensão estimulado com isoproterenol, com uma frequência 2,27 Hz. Os retratos de fase gerados formam curvas fechadas, essas trajetórias caracterizam o ciclo limite, que aparece em ambos os gráficos da Figura 7.35. 

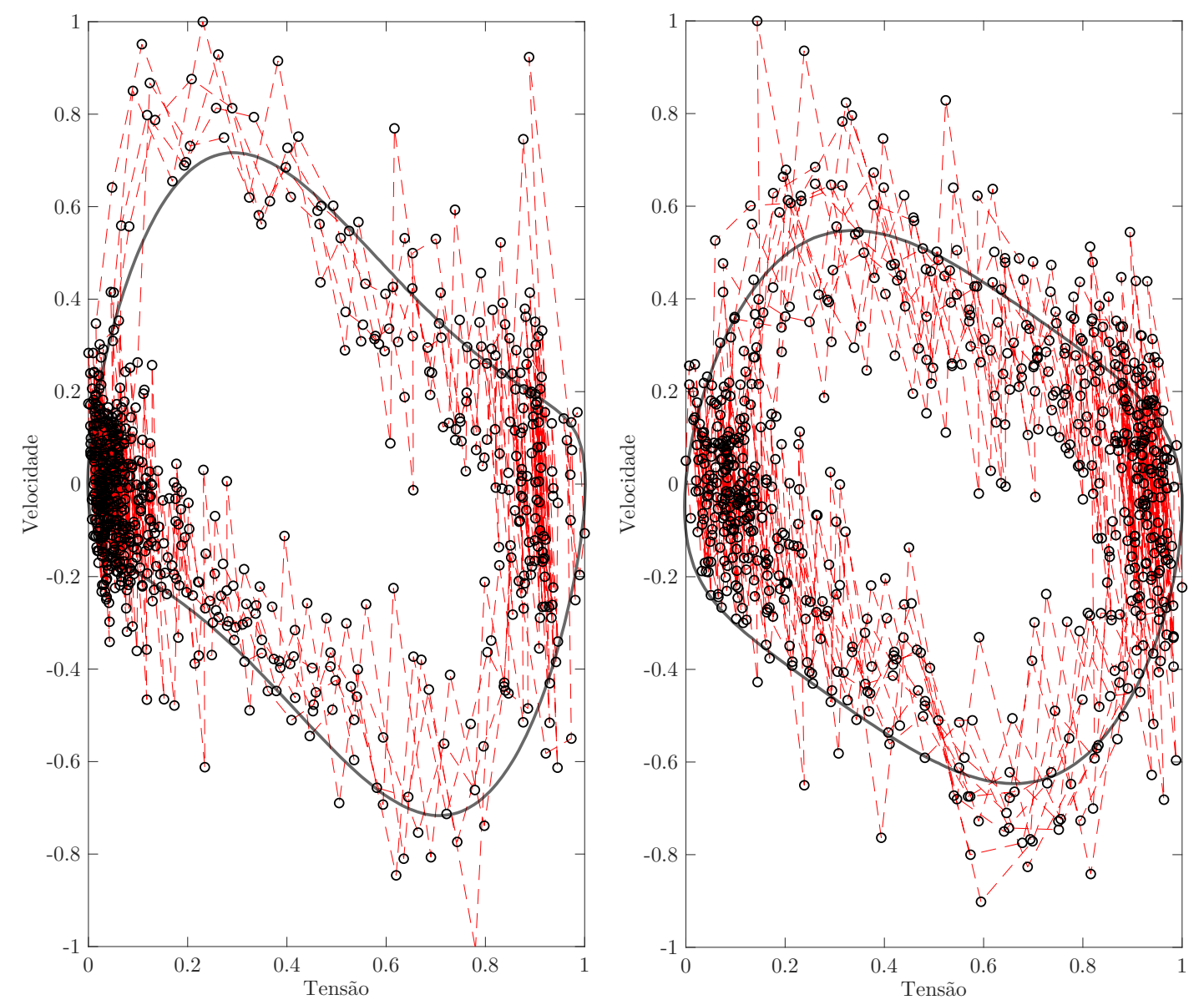

Figura 7.35: Retrato de fase empírico do mesmo sinal de tensão com frequência basal e frequência com isoproterenol, no retrato de fase da esquerda temos o sinal com frequência basal de $1.03 \mathrm{~Hz}$, ajustamos uma solução do oscilador de Van Der Pol inverso (curva cinza) com $\mu=1,5$, o retrato de fase da direita temos o mesmo sinal com aplicação de isoproterenol, onde a frequência é $2,27 \mathrm{~Hz}$, ajustamos uma solução do oscilador de Van Der Pol inverso (curva cinza) com $\mu=0,5$.

O resultado mostra que o sinal de tensão se comportou como um oscilador não-linear, especificamente o oscilador de Van Der Pol invertido nos dois casos, tanto entre frequências no estado basal quanto pelo comparativo entre frequência basal e frequência com isoproterenol. Onde a análise do retrato de fase nos mostra uma evidência desse fato.

O fato do cardiomiócito se comportar mecanicamente como um oscilador de Van Der Pol é importante, porque mostra que uma célula cardíaca aderida em um microambiente mimetizado, restrito a uma superfície bidimensional exerce funções mecânicas semelhantes ao órgão de origem. Isso porque o oscilador de Van Der Pol é do tipo oscilador de relaxamento, isso significa que esse tipo de oscilador vai manter uma amplitude de oscilação relativamente constante ao passo que o período de oscilação pode facilmente ser alterado. Isso tem relação com o comportamento do coração, sendo que para manter um 
fluxo sanguíneo regular é necessário ter uma amplitude de oscilação mecânica constante, entretanto a frequência de batimento cardíaco deve ser facilmente alterado dependendo a situação. Agora o fato do cardiomiócito se comportar especificamente como um oscilador de Van Der Pol invertido esta relacionado com o fato da célula ter uma contração abrupta seguida de um relaxamento amortecido que muitas vezes ocorre em várias etapas. 


\section{Capítulo 8}

\section{Conclusões}

Ao longo desse trabalho, estudamos as propriedades mecânicas da contração cíclica, executada por células cardíacas isoladas, aderidas em superfície mimetizada. Estudamos de forma bidimensional, através dos mapas de tensão, mapas amplitude, mapas de correlação e orientação das tensões aplicadas ao substrato. Estudamos de forma unidimensional, através do sinal de tensão ao longo do tempo.

Inicialmente, relatamos que a área de adesão celular se distribui de forma aleatória, especificamente uma distribuição normal, concluindo que os cardiomiócitos quando aderidos possuem flutuações de área de adesão condicionadas a uma distribuição normal. Através da análise bidimensional das trações celulares aplicadas ao substrato, concluímos que as tensões de maior magnitude são discretas e aplicadas próximo as bordas das células. Onde, em uma grande parte da área de adesão celular, as tensões aplicadas não são significativas, enquanto em uma região especifica ocorre tensões efetivas de maior magnitude, promovida pelas fibras de tensão, evidenciando uma atividade contráctil discreta ao longo da área de adesão.

O resultado encontrado com os mapas de amplitude de contração, corrobora com o resultado anterior, mostrando que essas regiões possuem altas amplitudes e consequentemente, um maior gasto energético. Além disso, temos os mapas de correlação, que indicam que as regiões de maior atividade contráctil possuem alta correlação. Mostrando que superfícies mimetizadas com gel de poliacrilamida conseguem induzir mecanicamente cardiomiócitos neonatais, a gerar um sinal de output mecânico de contração cíclica. Apresentando um comportamento multipolar de zonas de atividade contráctil sem restrições geométricas subcelulares, mas com restrição dimensional (adesão bidimensional) e dinâmica (coeficiente de Poisson próximo de 0,5). 
Um dado interessante obtido sobre os valores de amplitude, é que as células cardíacas estudadas possuem uma distribuição log-normal quanto as valores de amplitude distribuídos pela área de adesão celular.

Quanto aos mapas de orientação, concluímos que os cardiomiócitos possuem uma anisotropia quanto a orientação das tensões, sendo direcionadas para o centro da célula, promovida pelos seus multipolos de atividade contráctil. Entretanto o número de polos é variado devido as condições iniciais de adesão do cardiomiócito, não havendo a possibilidade de modulação da quantidade de polos (regiões de maior atividade contráctil).

O estudo do sinal de contração gerado pelas trações aplicadas ao substrato, nos mostra a característica oscilatória dessas células. Concluímos que a resposta mecânica dos cardiomiócitos ao microambiente celular é bem definida, pois mantem a sua forma de oscilação ao longo do tempo. Esta forma de oscilação caracteriza a resposta mecânica dessas células ao microambiente celular mimetizado. Apresentando várias etapas durante a contração e relaxamento e com etapas transitórias entre esse dois estados, essas etapas se alteram com a frequência basal. Mostrando com alta resolução tanto no sinal de tensão $\sigma(t)$ quanto no sinal de variação de tensão $\frac{d \sigma(t)}{d t}$ (ou velocidade de contração), através do método de microscopia de força e tração TFM com alta velocidade de captura, desenvolvido no Laboratório de Micro Reologia LabM² da USP.

Relatamos que a aplicação de isoproterenol em cardiomiócitos neonatais, promove um aumento da frequência de contração em escala celular. Entretanto o estimulo químico não aumenta nem a tensão e nem a amplitude de contração, apenas aumenta a frequência e consequentemente promove um aumento da potência energética da célula cardíaca. Sobre a variação de frequência devido ao isoproterenol, concluímos que a variação percentual de frequência depende da frequência basal da célula cardíaca. Onde a variação percentual decai com o aumento da frequência basal, evidenciando um limite superior de frequência, onde a célula estaria acima da sua capacidade contráctil, e que esta por sua vez possui um mecanismo que modula a frequência para valores regulares.

Uma extensão da análise da variação de frequência com isoproterenol, foi investigar o mapeamento da variação percentual em função da frequência basal e da área de adesão celular. Concluímos que o mapeamento evidencia uma região de máximo estímulo, onde a variação percentual de frequência será maior. O máximo estímulo está em uma região de frequências basais entre 1,0 Hz a 1,5 Hz e áreas de adesão entre $1500 \mu \mathrm{m}^{2}$ a $2000 \mu \mathrm{m}^{2}$, 
nela a variação de até $150 \%$ na frequência da célula.

Quanto a um tipo de modelo oscilatório que se aproxima dos dados reais de contração obtidos nessa Tese, concluímos que cardiomiócitos neonatais isolados aderidos em substratos elásticos mimetizado (rigidez 9,6 kPa), comportam-se in vitro como um oscilador de Van Der Pol invertido onde a frequência do estado contração-relaxamento (desconsiderando o tempo entre o inicio da contração e fim do relaxamento), pode ser modelado com o ajuste do parâmetro amortecimento $\mu$ da equação de Van Der Pol $\frac{d^{2} \sigma(t)}{d t^{2}}-\mu\left(1-\sigma^{2}(t)\right) \frac{d \sigma(t)}{d t}+\sigma(t)=0$.

Essa é uma informação importante, visto que a pulsação do coração também segue o modelo oscilatório de Van Der Pol a diferença esta na inversão do sinal. Onde em ambos os casos a amplitude de oscilação é constante enquanto a frequência de oscilação e facilmente alterada. A inversão do sinal no caso dos cardiomiócitos se deve a um estado de contração (etapa de contração do sinal de tensão) mais abrupto e um estado de relaxamento (etapa de relaxamento de tensão) mais amortecido.

As propriedades mecânicas das amostras demostraram ser bastante robustas e bem definidas, o que corrobora para a sua aplicabilidade como modelo de miocárdio in vitro.

Entre possíveis extensões deste trabalho, destacamos:

1) Estudo das propriedades mecânicas com restrição geométrica utilizando micro padrões na superfície mimetizada (Micropatterns).

2) Aplicações de estímulos elétricos em cardiomiócitos isolados em conjunto com o TFM.

3) Estudo da variação do sinal mecânico característico dos cardiomiócitos devido a aplicação de fármacos.

Esperamos sinceramente que esta tese possa ajudar a todos aqueles interessados nos estudos das propriedades mecânicas de células cardíacas. 


\section{Referências Bibliográficas}

[1] SCHWARZ, Ulrich S.; SAFRAN, Samuel A. Physics of adherent cells. Reviews of Modern Physics, v. 85, n. 3, p. 1327, 2013.

[2] KREIS, Thomas; VALE, Ronald. Guidebook to the cytoskeletal and motor proteins. New York: Oxford, 1993.

[3] ALBERTS, Bruce et al. Molecular biology of the cell Garland. New York, p. 18-19, 1994.

[4] BOAL, David; BOAL, David H. Mechanics of the Cell. Cambridge University Press, 2012.

[5] PELHAM, Robert J.; WANG, Yu-li. Cell locomotion and focal adhesions are regulated by substrate flexibility. Proceedings of the National Academy of Sciences, v. 94, n. 25, p. 13661-13665, 1997.

[6] LO, Chun-Min et al. Cell movement is guided by the rigidity of the substrate. Biophysical journal, v. 79, n. 1, p. 144-152, 2000.

[7] MCBEATH, Rowena et al. Cell shape, cytoskeletal tension, and RhoA regulate stem cell lineage commitment. Developmental cell, v. 6, n. 4, p. 483-495, 2004.

[8] DE, Rumi; ZEMEL, Assaf; SAFRAN, Samuel A. Theoretical concepts and models of cellular mechanosensing. In: Methods in cell biology. Academic Press, 2010. p. $143-175$.

[9] DISCHER, Dennis E.; JANMEY, Paul; WANG, Yu-li. Tissue cells feel and respond to the stiffness of their substrate. Science, v. 310, n. 5751, p. 1139-1143, 2005. 
[10] CALLAGHAN, Neal I. et al. Modeling cardiac complexity: Advancements in myocardial models and analytical techniques for physiological investigation and therapeutic development in vitro. APL bioengineering, v. 3, n. 1, p. 011501, 2019.

[11] TANG, Xin et al. How far cardiac cells can see each other mechanically. Soft Matter, v. 7, n. 13, p. 6151-6158, 2011.

[12] HE, Shijie et al. Some basic questions on mechanosensing in cell - substrate interaction. Journal of the Mechanics and Physics of Solids, v. 70, p. 116-135, 2014.

[13] DEMBO, Micah; WANG, Yu-Li. Stresses at the cell-to-substrate interface during locomotion of fibroblasts. Biophysical Journal, v. 76, n. 4, p. 2307-2316, 1999.

[14] ISKRATSCH, Thomas; WOLFENSON, Haguy; SHEETZ, Michael P. Appreciating force and shape - the rise of mechanotransduction in cell biology. Nature Reviews Molecular Cell Biology, v. 15, n. 12, p. 825, 2014.

[15] SCHWARZ, Ulrich S.; SOINÉ, Jérôme RD. Traction force microscopy on soft elastic substrates: A guide to recent computational advances. Biochimica et Biophysica Acta (BBA)-Molecular Cell Research, v. 1853, n. 11, p. 3095-3104, 2015.

[16] NEU, Corey P.; GENIN, Guy M. (Ed.). Handbook of imaging in biological mechanics. CRC press, 2014.

[17] BUTLER, James P. et al. Traction fields, moments, and strain energy that cells exert on their surroundings. American Journal of Physiology-Cell Physiology, v. 282, n. 3, p. C595-C605, 2002.

[18] STRICKER, Jonathan et al. Spatiotemporal constraints on the force-dependent growth of focal adhesions. Biophysical Journal, v. 100, n. 12, p. 2883-2893, 2011.

[19] LIMA, Paulo Cupertino. Wavelets: teoria, algoritmos e aplicações. Belo Horizonte: Departamento de Matemática - ICEX - UFMG, 2004.

[20] SHILTS, Kent; NAUMANN, Christoph A. Tunable cell-surface mimetics as engineered cell substrates. Biochimica et Biophysica Acta (BBA)-Biomembranes, v. 1860, n. 10, p. 2076-2093, 2018. 
[21] SHILTS, Kent; NAUMANN, Christoph A. Tunable cell-surface mimetics as engineered cell substrates. Biochimica et Biophysica Acta (BBA)-Biomembranes, v. 1860, n. 10, p. 2076-2093, 2018.

[22] MOFRAD, Mohammad RK. Rheology of the cytoskeleton. Annual Review of Fluid Mechanics, v. 41, p. 433-453, 2009.

[23] DOLAN, Eimear B.; VERBRUGGEN, Stefaan W.; ROLFE, Rebecca A. Techniques for studying mechanobiology. In: Mechanobiology in Health and Disease. Academic Press, 2018. p. 1-53.

[24] BRUCE, A. et al. Fundamentos da biologia celular: uma introdução à biologia molecular da célula. Porto Alegre: Artmed, 1999.

[25] MOFRAD, Mohammad RK; KAMM, Roger D. (Ed.). Cytoskeletal mechanics: models and measurements in cell mechanics. Cambridge University Press, 2006.

[26] EHLER, Elisabeth; PERRIARD, Jean-Claude. Cardiomyocyte cytoskeleton and myofibrillogenesis in healthy and diseased heart. Heart failure reviews, v. 5, n. 3, p. 259-269, 2000.

[27] RIBEIRO, Alexandre JS et al. Contractility of single cardiomyocytes differentiated from pluripotent stem cells depends on physiological shape and substrate stiffness. Proceedings of the National Academy of Sciences, v. 112, n. 41, p. 12705$12710,2015$.

[28] JENSEN, Leonardo et al. Integrated molecular, biochemical, and physiological assessment unravels key extraction method mediated influences on rat neonatal cardiomyocytes. Journal of cellular physiology, v. 233, n. 7, p. 5420-5430, 2018.

[29] VIDYASEKAR, Prasanna et al. A simplified protocol for the isolation and culture of cardiomyocytes and progenitor cells from neonatal mouse ventricles. European journal of cell biology, v. 94, n. 10, p. 444-452, 2015.

[30] TIMOSHENKO, S.; GOODIER, J. N. Theory of Elasticity McGraw-Hill Book Company. Inc. New York, 1951. 
[31] ARANTES E OLIVEIRA, E. R. Elementos da teoria da elasticidade. 1999.

[32] OKUMURA, Isamu A. On the generalization of Cerruti's problem in an elastic half-space. Doboku Gakkai Ronbunshu, v. 1995, n. 519, p. 1-10, 1995.

[33] LANDAU, L. D. et al. Theory of elasticity: Vol. 7 of course of theoretical physics. Phys. Today, v. 13, p. 44, 1960.

[34] GARDEL, Margaret L. et al. Traction stress in focal adhesions correlates biphasically with actin retrograde flow speed. J cell Biol, v. 183, n. 6, p. 999-1005, 2008.

[35] MEYER, Yves. Wavelets-algorithms and applications. Wavelets-Algorithms and applications Society for Industrial and Applied Mathematics Translation., 142 p., 1993.

[36] PLOTNIKOV, Sergey V. et al. High-resolution traction force microscopy. In: Methods in cell biology. Academic Press, 2014. p. 367-394.

[37] ARATYN-SCHAUS, Yvonne et al. Preparation of complaint matrices for quantifying cellular contraction. JoVE (Journal of Visualized Experiments), n. 46, p. e2173, 2010.

[38] DELANOË-AYARI, H.; RIEU, J. P.; SANO, M. 4D traction force microscopy reveals asymmetric cortical forces in migrating Dictyostelium cells. Physical Review Letters, v. 105, n. 24, p. 248103, 2010.

[39] MOEENDARBARY, Emad; HARRIS, Andrew R. Cell mechanics: principles, practices, and prospects. Wiley Interdisciplinary Reviews: Systems Biology and Medicine, v. 6, n. 5, p. 371-388, 2014.

[40] GRINSTED, Aslak; MOORE, John C.; JEVREJEVA, Svetlana. Application of the cross wavelet transform and wavelet coherence to geophysical time series. Nonlinear processes in geophysics, v. 11, n. 5/6, p. 561-566, 2004.

[41] IVANOV, Plamen Ch et al. Scaling behaviour of heartbeat intervals obtained by wavelet-based time-series analysis. Nature, v. 383, n. 6598, p. 323, 1996. 
[42] KANCHANAWONG, Pakorn et al. Nanoscale architecture of integrin-based cell adhesions. Nature, v. 468, n. 7323, p. 580, 2010.

[43] BANERJEE, Shiladitya; MARCHETTI, M. Cristina. Controlling cell?matrix traction forces by extracellular geometry. New Journal of Physics, v. 15, n. 3, p. $035015,2013$.

[44] CHARRAS, Guillaume; SAHAI, Erik. Physical influences of the extracellular environment on cell migration. Nature reviews Molecular cell biology, v. 15, n. 12 , p. 813, 2014.

[45] CHAUDHURI, Ovijit et al. Substrate stress relaxation regulates cell spreading. Nature communications, v. 6, p. 6365, 2015.

[46] MOFRAD, M. R.; KAMM, R. D. Introduction, with the biological basis for cell mechanics. Cytoskeletal mechanics: models and measurements, 1st edn. Cambridge University Press, Cambridge, p. 1-17, 2006.

[47] BURSAC, Predrag et al. Cytoskeletal remodelling and slow dynamics in the living cell. Nature materials, v. 4, n. 7, p. 557, 2005.

[48] CALDARELLI, Guido. Scale-free networks: complex webs in nature and technology. Oxford University Press, 2007.

[49] LEWIS, Ted G. Network science: Theory and applications. John Wiley \& Sons, 2011.

[50] DOROGOVtSEV, S. N. Clustering of correlated networks. Physical Review E, v. 69, n. 2, p. 027104, 2004.

[51] FOSTER, David V. et al. Clustering drives assortativity and community structure in ensembles of networks. Physical Review E, v. 84, n. 6, p. 066117, 2011.

[52] BOLLOBÁS, Béla; RIORDAN, Oliver M. Mathematical results on scale-free random graphs. Handbook of graphs and networks: from the genome to the internet, p. 1-34, 2003. 
[53] NEWMAN, Mark EJ; STROGATZ, Steven H.; WATTS, Duncan J. Random graphs with arbitrary degree distributions and their applications. Physical review E, v. 64, n. 2, p. 026118, 2001.

[54] KHALFA, Nadia et al. Heart rate regulation processed through wavelet analysis and change detection: some case studies. Acta biotheoretica, v. 60, n. 1-2, p. 109-129, 2012.

[55] SEVERS, Nicholas J. The cardiac muscle cell. Bioessays, v. 22, n. 2, p. 188-199, 2000.

[56] RAJASINGH, Sheeja et al. Manipulation-free cultures of human iPSC-derived cardiomyocytes offer a novel screening method for cardiotoxicity. Acta Pharmacologica Sinica, v. 39, n. 10, p. 1590, 2018.

[57] COHEN, Ohad; SAFRAN, Samuel A. Theory of frequency response of mechanically driven cardiomyocytes. Scientific reports, v. 8, n. 1, p. 2237, 2018.

[58] NITSAN, Ido et al. Mechanical communication in cardiac cell synchronized beating. Nature Physics, v. 12, n. 5, p. 472, 2016.

[59] ENGLER, Adam J. et al. Embryonic cardiomyocytes beat best on a matrix with heart-like elasticity: scar-like rigidity inhibits beating. Journal of cell science, v. 121, n. 22, p. 3794-3802, 2008.

[60] ATTUEL, Guillaume et al. Multifractal desynchronization of the cardiac excitable cell network during atrial fibrillation. I. Multifractal analysis of clinical data. Frontiers in physiology, v. 8, p. 1139, 2018.

[61] ATTUEL, Guillaume et al. Multifractal desynchronization of the cardiac excitable cell network during atrial fibrillation. II. Modeling. Frontiers in physiology, v. 10, p. 480, 2019.

[62] MAKUCH, Robert W.; FREEMAN JR, Daniel H.; JOHNSON, Mary F. Justification for the lognormal distribution as a model for blood pressure. Journal of chronic diseases, v. 32, n. 3, p. 245-250, 1979. 
[63] TAO, Zhong; TAGARE, Hemant D.; BEATY, James D. Evaluation of four probability distribution models for speckle in clinical cardiac ultrasound images. IEEE transactions on medical imaging, v. 25, n. 11, p. 1483-1491, 2006.

[64] COHEN, Ohad; SAFRAN, Samuel A. Theory of frequency response of mechanically driven cardiomyocytes. Scientific reports, v. 8, n. 1, p. 2237, 2018.

[65] TRUONG, Duy; BAHLS, Christian Rüdiger; VAN RIENEN, Ursula. An efficient 2D implementation of a bio-chemo-mechanical model employing a quadratic representation to study cells on micro-post arrays. Finite Elements in Analysis and Design, v. 146, p. 16-27, 2018.

[66] DEL ÁLAMO, Juan C. et al. Three-dimensional quantification of cellular traction forces and mechanosensing of thin substrata by fourier traction force microscopy. PloS one, v. 8, n. 9, p. e69850, 2013.

[67] HOLENSTEIN, Claude N.; SILVAN, Unai; SNEDEKER, Jess G. High-resolution traction force microscopy on small focal adhesions-improved accuracy through optimal marker distribution and optical flow tracking. Scientific reports, v. 7, p. 41633, 2017.

[68] BASOLI, Francesco et al. Biomechanical characterization at the cell scale: present and prospects. Frontiers in physiology, v. 9, 2018.

[69] BANERJEE, Shiladitya; MARCHETTI, M. Cristina. Contractile stresses in cohesive cell layers on finite-thickness substrates. Physical review letters, v. 109, n. 10, p. 108101, 2012.

[70] GRÖNHOLM, Tiia; ANNILA, Arto. Natural distribution. Mathematical biosciences, v. 210, n. 2, p. 659-667, 2007.

[71] GOULET, Dave. Modeling, simulating, and parameter fitting of biochemical kinetic experiments. SIAM Review, v. 58, n. 2, p. 331-353, 2016.

[72] FRIEDRICH, Benjamin M.; SAFRAN, Samuel A. How cells feel their substrate: spontaneous symmetry breaking of active surface stresses. Soft Matter, v. 8, n. 11, p. 3223-3230, 2012. 
[73] ALI, Olivier et al. Cooperativity between integrin activation and mechanical stress leads to integrin clustering. Biophysical journal, v. 100, n. 11, p. 2595-2604, 2011.

[74] AMBROSI, D. et al. Perspectives on biological growth and remodeling. Journal of the Mechanics and Physics of Solids, v. 59, n. 4, p. 863-883, 2011.

[75] BAKER, Brendon M.; CHEN, Christopher S. Deconstructing the third dimension ? how 3D culture microenvironments alter cellular cues. J Cell Sci, v. 125, n. 13, p. 3015-3024, 2012.

[76] GINOUX, Jean-Marc. Van der Pol's Method: A Simple and Classic Solution. In: History of Nonlinear Oscillations Theory in France (1880-1940). Springer, Cham, 2017. p. 275-289.

[77] DI, Abarbanel Henry et al. Introduction to nonlinear dynamics for physicists. World Scientific, 1993.

[78] FLETCHER, Daniel A.; THERIOT, Julie A. An introduction to cell motility for the physical scientist. Physical Biology, v. 1, n. 1, p. T1, 2004.

[79] BURSAC, Predrag et al. Cytoskeletal remodelling and slow dynamics in the living cell. Nature materials, v. 4, n. 7, p. 557, 2005.

[80] CHOWDHURY, Farhan H. Control of cell fate decisions of embryonic stem cells by mechanical forces. 2011. Tese de Doutorado. University of Illinois at Urbana-Champaign.

[81] BUXBOIM, Amnon; IVANOVSKA, Irena L.; DISCHER, Dennis E. Matrix elasticity, cytoskeletal forces and physics of the nucleus: how deeply do cells ?feel?outside and in?. J Cell Sci, v. 123, n. 3, p. 297-308, 2010.

[82] CALIFANO, Joseph P.; REINHART-KING, Cynthia A. Substrate stiffness and cell area predict cellular traction stresses in single cells and cells in contact. Cellular and molecular bioengineering, v. 3, n. 1, p. 68-75, 2010.

[83] CAMPAS, Otger; MAHADEVAN, L.; JOANNY, Jean-François. Actin network growth under load. Biophysical journal, v. 102, n. 5, p. 1049-1058, 2012. 
[84] CHAN, Clarence E.; ODDE, David J. Traction dynamics of filopodia on compliant substrates. Science, v. 322, n. 5908, p. 1687-1691, 2008.

[85] CROW, Ailey et al. Contractile equilibration of single cells to step changes in extracellular stiffness. Biophysical journal, v. 102, n. 3, p. 443-451, 2012.

[86] DE, Rumi. A general model of focal adhesion orientation dynamics in response to static and cyclic stretch. Communications biology, v. 1, n. 1, p. 81, 2018.

[87] SHARMA, Vivek; ANNILA, Arto. Natural process - Natural selection. Biophysical chemistry, v. 127, n. 1-2, p. 123-128, 2007. 